NBER WORKING PAPER SERIES

\title{
INFORMATION AND THE PERSISTENCE OF THE GENDER WAGE GAP: EARLY EVIDENCE FROM CALIFORNIA'S SALARY HISTORY BAN
}

\author{
Benjamin Hansen \\ Drew McNichols \\ Working Paper 27054 \\ http://www.nber.org/papers/w27054 \\ NATIONAL BUREAU OF ECONOMIC RESEARCH \\ 1050 Massachusetts Avenue \\ Cambridge, MA 02138 \\ April 2020
}

We are grateful to Amanda Agan, Sandra Black, Bo Cowgill, Jon Davis, Jennifer Doleac, Christine Exley, Claudia Goldin, John Horton, Michael Kuhn, Simeon Minard, Muriel Niederle, Emily Nix, Edward Rubin, Joseph Sabia, Heather Sarsons, Olga Stoddard, and Glen Waddell, Marianne Wanamaker for helpful comments on earlier drafts of this paper. We also appreciate feedback from other seminar participants at the University of Oregon, University of TennesseeKnoxville, San Diego State, Census and conference participants at the Southern Economics Association and the Eastern Economics Association The views expressed herein are those of the authors and do not necessarily reflect the views of the National Bureau of Economic Research.

NBER working papers are circulated for discussion and comment purposes. They have not been peer-reviewed or been subject to the review by the NBER Board of Directors that accompanies official NBER publications.

(C) 2020 by Benjamin Hansen and Drew McNichols. All rights reserved. Short sections of text, not to exceed two paragraphs, may be quoted without explicit permission provided that full credit, including $\odot$ notice, is given to the source. 
Information and the Persistence of the Gender Wage Gap: Early Evidence from California's Salary History Ban

Benjamin Hansen and Drew McNichols

NBER Working Paper No. 27054

April 2020

JEL No. J16,J3,J31,J42,J48,J58,J7,K0

\begin{abstract}
Aiming to reduce the gender wage gap, several states and cities have recently adopted legislation that prohibits employers from asking about previously earned salaries. The advocates of these salary history bans (SHBs) have suggested pay history perpetuates past discrimination. We study the early net impact of the first state-wide SHBs. Using both difference-in-difference and synthetic control approaches, we find the gender earnings ratio increased by 1 percent in states with SHBs. We find these population wide increases are driven by an increase of the gender earnings ratio for households with all children over 5 years old, by workers over 35, and are principally driven by those who have recently switched jobs.
\end{abstract}

\author{
Benjamin Hansen \\ Department of Economics \\ 1285 University of Oregon \\ Eugene, OR 97403 \\ and NBER \\ bchansen@uoregon.edu \\ Drew McNichols \\ Center for Health Economics \\ \& Policy Studies (CHEPS) \\ University of San Diego-California \\ 9500 Gilman Drive \#0508 \\ La Jolla, CA 92093-0043 \\ dmcnichols@ucsd.edu
}




\section{Introduction}

While researchers have debated the underlying causes of the gender wage gap for decades, recently it has attracted mainstream political attention. With that attention, cities and states have begun to experiment with "Salary History Bans" (SHB). Proponents of these laws have been fairly agnostic about what the deeper causes of the gender wage gap may be. Instead, they have concluded that whatever has caused discrimination in the past continues to be perpetuated by questions about current salaries that are commonplace for job applicants in today's labor markets (Barach \& Horton (2017) find over $80 \%$ of respondents to a nationally representative Google Survey were asked by their employer about past wages). This paper offers quasi-experimental evidence on the effect of statewide salary history bans, primarily using a synthetic control. We particularly focus on California, a large state and prominent economic region that enacted a state-wide salary history ban on January 1, 2018. We also study the aggregation of all states and cities that enacted SHBs through January of 2019.

Banning questions on salary history is a blunt instrument to a seemingly complex problem. While this may have seemed natural to policy makers given questions on salary history are ubiquitous for job seekers, the natural reaction of probably every economist is to consider the unintended consequences. Indeed, Agan \& Starr (2018) and Doleac \& Hansen (2020) provide evidence limiting information on criminal history in labor markets resulted in decreased labor market opportunities for black men due to statistical discrimination. 1 Likewise restricting drug tests resulted in lower employment for black men (Wozniak, 2015). However, while concerns about blunt policy instruments are warranted, even blunt policies can

\footnotetext{
${ }^{1}$ These recent papers on "Ban the Box" laws echoes other related work based on the availability background checks Holzer et al. (2007), Stoll (2009), and Finlay (2009)
} 
sometimes on net have their intended effects. For instance, Cengiz et al. (2019) find minimum wages have decreased poverty and increased earnings for low-skill workers (footnote about debate surrounding minimum wages). This paper provides early quasi-experimental evidence regarding SHBs. Are they closing the gender wage gap? If so, for which workers and industries? Naturally we expect an avalanche of new papers in coming years to investigate how these bans may distort labor markets in unexpected ways. Those negative impacts and labor market distortions, whatever they may be, should be weighed against whether SHBs have their intended benefit.

While policy makers have only proactively taken actions aimed at the gender wage gap recently, researchers have probed potential underlying causes for decades. Despite a massive surge in female college attainment, the convergence of the gender gap has slowed recently (Goldin et al., 2006; Goldin, 2014). Researchers have investigated the role of occupational sorting given recent trends towards a long-hours premium Blau \& Kahn (2000); Goldin (2014) and gender-specific preferences regarding the competitiveness of the work environment Niederle \& Vesterlund (2007); Buser et al. (2014). Other approaches have sought to measure whether productivity differentials could explain part of the gap Blau \& Kahn, 2017). However, Sarsons (2017a b and have found evidence of discrimination against female workers in male-dominated labor markets. Goldin (2014) explores the role of long-hours premiums in the origin of the gender wage gap. Recent event-study approaches by Chung et al. (2017) in the United States, and Kleven et al. (2019) in Denmark echo this potential mechanism. They both find evidence the gender earnings gap widens at the birth of a first child, and the gap remains throughout the next two decades. So while there is compelling evidence that the gender wage gap expands at childbirth, current research is inconclusive that policies tied to 
children can ameliorate the situation. For instance, Bailey et al. (2019) finds that parental leave results in decreased female labor participation, while (Nix et al., 2019) find access to childcare may increase reentry into the labor force.

Given the complex issues factoring into the gender earnings gap, its unclear whether a blunt policy like a SHB would be effective in reducing the gender wage gap, or affecting salaries at all. Indeed, in the simplest of labor market models, perfect competition, workers are paid according to the marginal revenue product, and past salary does not factor into this at all. However, it could be that absent full-information, salary history sends strong signals about productivity (Kotlikoff \& Gokhale, 1992; Altonji \& Pierret, 2001; Oyer et al., 2011; Lange, 2007). Other models of labor markets such as job posting or wage bargaining raise more questions instead of provide simple answers about the predicted effects of salary history bans. In a job posting world, the question comes back to whether SHBs change the information firms post about jobs. In a wage bargaining world, its unclear how a SHB affects wage bargaining. Moreover, Exley et al. (2020) find evidence that women are more effective negotiators when they choose to negotiate. We discuss details of the laws more in the background section, but SHBs vary in whether they legally allow firms to consider salaries if they are volunteered by a worker. If a past salary is a strong signal of both productivity and their reservation wage, we might expect all workers to reveal their salary to avoid being lumped in with workers with lower prior earnings Agan et al. (2020b). If firms have some level of monopsony power, its unclear exactly how a SHB changes the relative power of firms. Indeed, recent research on pay transparency finds in some settings it could increase compression (Mas, 2017), while in others it could decrease the gender pay gap through increases in female earnings Baker et al. 2019). Ultimately, from a policy 
perspective, whether SHBs affect labor market outcomes is an empirical question which we aim to answer.

To estimate whether SHBs affect labor markets, we focus on a synthetic control approach using labor market outcomes from the Current Population Survey (CPS) Abadie et al. (2010) ? $^{2}$ With this approach we consider the net impact of SHBs on the gender earnings ratio in both $\mathrm{CA}$, and the aggregation of treated units based on Appendix Table A.2. This approach is well suited to the nature of this policy change. The policy is implemented at the state level, with (currently) very few treated units and a relatively short after period. Given we were in the middle of a large expansionary economic period through the end of 2019, we also might be concerned that the common trends assumption a difference-indifference design would be violated. We construct our synthetic comparison with this critical assumption in mind by matching on the lagged values of the dependent variable and using both level and demeaned data to confirm the robustness of our results (Botosaru \& Ferman, 2019; Ferman \& Pinto, 2019).

We find early evidence female earnings have increased relative to male earnings in states passing SHBs. The estimated effects on the overall population are small and we fail to reject that the impact is zero. However, subgroup analyses based on the age of workers, the age of their children and job changers reveal strong heterogeneity. When we focus on CA's SHB alone, we estimate that women over 35 see 2.3 percentage point increase in their earnings

\footnotetext{
${ }^{2}$ We also find similar, albeit much larger results using a standard generalized difference-in-difference models. Moreover, when we use a Goodman-Bacon (2018) decomposition, we find the estimated coefficients in the difference-in-difference models are largely driven by the comparison of treated to untreated units. This is not surprising given that the there is little variation in the timing of adoption given the recent passage of SHBs. This makes construction of counterfactuals of treated units of first order to draw appropriate causal inference. Moreover, Californias population represents over share of the population of treated units. The weight OLS gives to CA is even larger given it was one of the first states to adopt a SHB. These issues motivate our primary approach based on synthetic controls.
} 
ratio relative to males, and that married women with all of their children over 5 see a 4.7 percentage point increase in their relative earnings ratio. Moreover, although the information on job-switchers is limited in the CPS, our point estimates suggest that the SHB could close the gender earnings gap by over 20 percent for those switching jobs. We find similar evidence when using the aggregation of all treated states $3^{3}$

Our findings contribute to a growing literature about the role of information in labor markets. Barach \& Horton (2017) find evidence wage history affects hiring patterns in online labor markets. They find reducing information on salary history resulting in employers screening more applicants and hiring applicants with lower salaries at previous positions. Agan et al. (2020a) use a field experiment to test how hiring managers respond to salary history bans, finding that hiring professionals responses to a lack of salary information vary by the gender of the applicant and the amount being disclosed. Thus, we have some reasons to be concerned about unintended consequences, such as statistical discrimination, or that salary history bans might affect the ability of firms to match with workers. However, our findings suggest at least on net, SHBs appear to be having their intended impact, increasing the earnings for women, particularly at an age where they likely experienced an earnings penalty due to childbirth.4

In Section 2, we discuss SHBs and their short history. In Section 3, we discuss our data and methodology. In Section 4 we review our results and in Section 5 we conclude.

\footnotetext{
${ }^{3}$ In this approach, we are by design assuming a common treatment date, 1/1/2018 for all regions. Given some states began their policies either later in 2018 or the beginning of 2019, this approach should be biased towards zero. Generally, these estimates are all qualitatively similar to those form focusing on CA alone, albeit slightly smaller in magnitude which should be expected.

${ }^{4}$ Our results are also similar to another recent working paper by Sinha $(2019)$ that replicated most of our key findings using generalized difference-in-difference models. However, we generally find smaller and more reasonable estimates using synthetic controls.
} 


\section{Background}

Salary history bans (SHBs) prohibit employers from inquiring about a candidates former or current compensation. Currently, SHBs have been adopted by a growing number of cities and states as a new tool to address potential discrimination in labor markets. Some affect the entire population, some only state employees, and some only city employees. The rapid uptake of SHBs suggest that many policy makers believe SHBs will improve gender pay inequalities. Figure 1 and Appendix Tables A.2 and A.3 summarize different cities and states with SHB laws.

California's SHB became effective January 1, 2018. Under California's SHB employers are prevented from seeking compensation history directly or through an agent. Applicants may volunteer, without prompting, their own salary history. However, California restricts employers from basing salary solely on the grounds of prior salary. That is, even if salary history is voluntarily provided, employers may not use this information alone to determine a workers' salary 5 . Most SHBs also require employers to provide a salary range at the request of the applicant. In some cases, after an offer has been extended, employers may seek the applicant's compensation history.

Each SHB adopting entity has publicly stated that they have adopted the SHB to promote pay equality. However, the cities and states adopting SHBs have tended to be more progressive on the other laws policies pay equality. Thus we might expect naive comparisons between treated and untreated regions to arrive at estimated impacts that may be upwardly biased. Indeed, with the recent uptake of SHBs, other more conserative leaning states have

\footnotetext{
${ }^{5}$ Oregon's SHB also prevents employers from using voluntarily provided salary information.
} 
implemented laws that prevent SHBs from being passed. These states include Michigan, Wisconsin, Iowa, and Tennessee. Philadelphia prevented the implementation of a SHB when a district judge found the SHB to be in violation of the First Amendment's free-speech clause. Generally, states preventing the adoption of SHBs have done so with employer compliance in mind. They argue that allowing employment law to change across regions is costly for small business owners.

This policy has a potential to be binding on multiple margins. In a wage bargaining world, removing past salary from early question may change the bargaining process Exley \& Kessler (2019). In a model of wage posting, does a SHB change how employers post salaries or how they screen for applicants (Agan et al., 2020b)? However, on net, it could be that firms change which workers they hire when salary history is removed Barach \& Horton (2017). Given the numerous channels through which salary history bans can affect the process of hiring in labor markets, the net impact of SHB ban is at its core empirical question.

\section{Data and Methods}

We use data from the Basic Monthly Current Population Survey (CPS). Earnings data are collected from the outgoing rotation group of monthly CPS, also referred to as the earner study. The CPS is a comprehensive survey containing monthly labor force statistics. Other potential useful data sources for employment measures include the American Community Survey, the Quarterly Workforce Indicators, and the Current Employment Statistics, but each of these alternative data sources have a delayed release schedule $\rfloor^{6}$ The CPS is published

\footnotetext{
${ }^{6}$ Even thought the 2018 ACS recently became available, the earnings question focus on earnings over the last calendar year, conflating earnings from 2017 and 2018.
} 
roughly 10 days after each month's end. This makes it particularly useful given that the rollout of SHBs is so recent 7 . It samples roughly 60,000 households each month using a rotating panel design and has a response rate averaging around 90 percent. We use the micro-level data, which has responses by all household members as reported by the call recipient. Our sample includes data from 2006 to the end of 2019. We restrict our sample to prime working age individuals between the ages of 25 and 548

Figure 1 illustrates the roll-out of SHB policies 9

We create statewide average weekly earnings ratios of female to male earnings by state (or the aggregation of all treated regions). Additionally, we calculate earnings ratios by age, and by industry of employment. We also calculate employment and the likelihood of beginning work at a new job in the last month.

We use the synthetic control method introduced by Abadie et al. (2010) to infer the causal impact of SHBs. This method uses pretreatment data to create a counterfactual group similar in outcomes to entities experiencing a discrete change in policy. This approach has been used to study many different policy changes including decriminalization of prostitution $(\overline{C u n}-$ ningham \& Shah, 2017), highway police budget cuts (DeAngelo \& Hansen, 2014), economic liberalization (Billmeier \& Nannicini, 2013), and increases in minimum wage (Jardim et al., 2017). We follow the work of Botosaru \& Ferman (2019) and create synthetic control groups matching on outcomes only for each treated entity, both constraining ourselves to avoid

\footnotetext{
${ }^{7}$ We obtained these data using the lowdown package for $\mathrm{R}$. The data are available for download almost immediately after the end of a month.

${ }^{8}$ The CPS is administered by the Census Bureau through personal and telephone interviews. Individuals must be 15 years of age or over and not in the Armed Forces. The person who responds to the phone call is the reference person. They answer questions about all persons in the household. In the case that the reference person is not knowledgeable, the Census Bureau attempts to contact those individuals in the household directly.

${ }^{9}$ More detail provided in Tables A.2 and A.3
} 
'p-hacking' to avoid biasing our estimates and our hypothesis testing.

Consider an outcome of interest $Y_{i t}$ that is measured over $T$ years, where $t$ indexes the time and the state is indexed by $i$ if its treated and $j$ if its not treated, among $I$ treated states and $J$ untreated states. The synthetic control approach aims to estimate the treatment effect, which is the difference between the treated state, and the unobserved counterfactual. The estimate for the unobserved counterfactual for state $i$ in time period $\mathrm{t}$ is $\sum_{j} w_{j} Y_{j t}$, where $w_{j}$ is the weight assigned to donor state $j$. The donor states chosen belong to the donor pool of potential control states. The chosen weights $w_{j}^{*}$ minimize the distance between $Y_{i t}$ and $\sum_{j} w_{j} Y_{j t}$ for all pretreatment time periods. For treatment in period $\tau$, the treatment effect $\alpha_{i}$ for state $i$ in time period $t$ is estimated as $\alpha_{i t}=Y_{i t}-\sum_{j} w_{j}^{*} Y_{j t}$ for $t \in[\tau, T]$. For each treated state, We create a synthetic control using lagged values of the dependent variable from 2006 to 2018.

To conduct hypothesis tests, we run a set of placebo tests following the method suggested by Abadie et al. (2010). We apply the same synthetic control method with the donor state removed, and the treated states added to the donor pool to create $S y n t h_{j t}$ for each donor state $j$ and time period $t$. We compare the pre-treatment and post-treatment mean squared prediction error (MSPE) for each state. We calculate the MSPE ratio as follows:

$$
M S P E \operatorname{ratio}_{j}=\frac{\sum_{t=\tau}^{T}\left(Y_{j t}-\text { Synth }_{j t}\right)^{2}}{\sum_{t=1}^{\tau-1}\left(Y_{j t}-\text { Synth }_{j t}\right)^{2}} .
$$

The MSPE measures a relative goodness of fit of the synthetic outcome generated for each state. It provides a metric of pre-treatment fit relative to post treatment fit for each state. 
A high MSPE ratio can be interpreted as poor post-treatment fit relative to pre-treatment fit. The ranking of the treated states relative to the placebo states provides a permutation based p-value.

We include a relatively long pre-treatment window from 2006 to 2017. This allows us to match on pre-treatment outcomes only and capture the average labor market dynamics of states heading into and out of the Great Recession. Botosaru \& Ferman (2019) show that matching on covariates is not necessary if the match is made on a long set of pre-treatment outcomes. All states that adopt a SHB prior to 2020 are excluded from the donor pool. The donor pool consists of 36 possible states and Washington D.C.

The synthetic control approach creates an estimate of the counterfactual for each of the treated states. Absent treatment, the predicted synthetic outcome should match the actual outcome. We test the ability of the synthetic control approach to forecast in the windows prior to treatment actually beginning. We do this by progressively rolling back a placebo treatment, matching on fewer and fewer years. Cross validation exercises are provided for each outcome in the appendix.

The composition of the synthetic controls chosen for California and all treated states can be seen in Appendix Figures B.1a and B.1d. States are shaded according to the amount they contribute to the synthetic outcome. All other donor states are assigned a weight of zero.

Using the detailed industry codes, we classify each industry in the CPS as male or female dominated. We use the industry gender compositions reported by the Equal Employment Opportunity Commission in Cartwright et al. (2011) to classify each industry as male or female dominated. Male dominated industries are those with more than $50 \%$ male workers and those industries with more than $50 \%$ female workers are female dominated. Female 
dominated industries are in the service producing domain and male dominated industries tend to be in the goods producing domain.

\section{Results}

\subsection{California}

Figure 2 panel (a) illustrates the female to male earnings ratio for California and its synthetic counterpart. The actual earnings ratio is represented by the solid line and the synthetic counterpart is represented by the dashed line. The point estimate and permutation based p-value are reported in Table 1. The first two columns represent the point estimates using only $\mathrm{CA}$, and the right columns are the point estimates for aggregation of all treated states. For first two years after the SHB the female to male earnings ratio increases an average of 0.0099 from its synthetic counterpart. A decrease in the gap of 0.01 from a base if 0.21 yields and effect size of $4.7 \%$ of the prior gender pay gap. The permutation of placebo states is illustrated in Appendix Figure B.1b. The MSPE ratio distribution is illustrated in Appendix Figure B.1c. The permutation based p-value of 0.45 indicates the point estimate is not statistically different from zero.

Figure 3 panels (a) through (d) compares the trends for the gender earning ratio based on gender composition of the industry, or the age of workers. While the synthetic controls closely parallel California prior the SHB, the only meaningful divergence in the post period is for either male dominated industries or workers over 35. The distribution of MSPE for hypothesis testing for these figures and the weights for their averages are provided in Appendix Figures 
B.3, B.4, B.7, and B.8.

In Table 1 we reported estimates based on by industry type, and demographics. Among male-dominated industries the point estimate is 0.031 with an empirical p-value of 0.225 . Among female-dominated industries we find point estimate is 0.0095 with an empirical pvalue in 0.325 . These differences could reflect that the effects might be heterogeneous based on the gender balance in an industry.

When we focus the age of children in married households, stark differences emerge. We split household into those with at least 1 child under 5, and households with all children over 5 due to the profound effects public school enrollment can have on labor supply due to childcare costs (Blau \& Robins, 1988; Gelbach, 2002). For households that have any children under five we estimate the gender earnings ratio changes by 0.0024 with a p-value of [1.000]. For those with all of their children over 5 , we find the earnings ratio increases by 0.0471 , a 15.1 percent shift, with a p-value of 0.025 .

It could be SHBs affect salaries among women more generally who have faced past earnings penalties due to the birth of previous children, or past discrimination. We explore this by using splitting the age distribution of workers into those 35 and under (down to 25), and those older than 35 (up to 54 year given that we focus on prime age workers). We find for workers under 35, the gender earnings ratio falls by -0.023 with an empirical p-value of 0.650. For workers over 35 , the gender earnings ratio increases by 0.023 , a 9.5 percent shift, with an empirical p-value of [0.075]. In the next row, when we split the workers by education, those with a high school degree or less and those with at least a BA, the precision of the point estimates do not suggest meaningful differences, while the estimates are more precise for college-educated workers. 
In the final row, we investigate whether or not the estimate effects of SHBs vary by recent job changes, focusing the sample of workers over 35. Not however, while we expect the effect to be higher for those who have switched jobs, the question in the CPS is unfortunately too imprecise to make sharper predictions, as it focuses on starting a new job in the last month 10 . Thus some of the individuals we classify as "same job" workers may may have switched jobs sometime earlier and could have also been directly affected by the SHB during the post-treatment window. While the sample of job switchers is smaller (only 2 percent of workers start a new job in most months), we estimate that for job switchers the gender earnings ratio as increased by .20, closing the gap by 99.9 percent. This point estimate has an empirical p-value of 0.150 . For individuals above 35 at the same job, we estimate the gender earnings ratio increased by .035 with an empirical p-value of 0.025 , suggesting their earnings gap closed by 14.3 percent.

In Table 2 we estimate the effect of SHB's on a variety of labor market outcomes directly related to the gender earnings ratio. The two columns on the left focus on California for Female and Male prime age workers. We find little evidence the employment has shifted. Because the rate of monthly turnover is so small (0.02 percent on average each month), we multiple monthly turnover levels by 12 to approximate annual turnover. Generally there's little evidence of a change in the labor market participation or turnover. In the other rows of the table we report the impact on wages, hours worked, weekly earnings. Generally the point estimates are small and noisy much like the effect on the overall gender earnings ratio. When we focus on households with all children over 5, individuals over 35, and those starting

\footnotetext{
${ }^{10}$ The wording on turnover asks "Last month, it was reported that you worked for employer. Do you still work for employer as your main job?"
} 
new jobs we find estimates in line with Table 1. The point estimates are more noisy which might be because the gender earnings ratio by construction adjusts for fixed state level differences in absolute pay. In the robustness section, we explore this further demeaning the data. Regardless, the point estimates are consistent with larger effects for individuals starting new jobs, who are over 35, and have all of their children older than 5 .

\subsection{All States}

As mentioned earlier, the Abadie et al. (2010) approach only works when there is a single treated unit. That leaves two approaches to deal with multiple treated units. If there are similar treatment begin dates, the multiple treated units can be aggregated into a single treated entity. $\mathrm{Xu}(2017)$ also offers an alternative approach, which counterfactuals for each of the treated units using a linear interactive fixed effects approach. We use both of these approaches. The generalized synthetic control results are discussed in the robustness section.

Figure 2 panel (b) illustrates the female to male earnings ratio for the average and its synthetic counterpart. The actual earnings ratio is represented by the solid line and the synthetic counterpart is represented by the dashed line. The point estimate and permutation based p-value are reported in the first row of Table 1. For first year after the SHB the female to male earnings ratio increases an average of 0.0151 from its synthetic counterpart. A decrease in the gap of 0.0151 from a base if 0.23 yields and effect size of $6.6 \%$ of the prior gender pay gap. The permutation of placebo states is illustrated in Appendix Figure B.1e. The MSPE ratio distribution is illustrated in Appendix Figure B.1f. The permutation based $\mathrm{p}$-value is 0.500 . 
Figure 3 panels (e) through (h) compares the trends for the gender earning ratio based on gender composition of the industry, or the age of workers. Again, the largest increases in the gender earnings ratio emerge for male dominated industries and workers over 35 . The right columns of Tables 1 and 2 present the estimated effect of SHBs on the gender earnings ratio, and the labor market outcomes which determine the gender earnings ratio. Generally when using the aggregation of all treated units, we find very similar estimates to those we get when using California alone.

\subsection{Robustness}

In the Appendix we explore the robustness of our estimates to two primary changes.

In the Appendix Section A.4. we explore the sensitivity of the estimated effects to demeaning the data. In Appendix Tables A.5 and A.6 we demean the state level averages. Ferman \& Pinto (2019) also discuss demeaning as an option to help improve match quality and reduce convex hull violations (increasing the likelihood that a linear combination of control states matches with the treatment state). Generally the point estimates are similar in magnitude and often are more precise using this approach. This is particularly true for the labor market absolute earnings, where we find evidence that absolute earnings have increase for women over 35 , or who have all of their children older than 5 , and who started new jobs in the last month.

In the Appendix Section A.5. we explore the sensitivity of the estimated effects to aggregating the data using CPS weights. Appendix Tables A.7, A.9 report the estimates using level data aggregated with CPS weights respectively for earnings ratios and labor market 
outcomes. Appendix Tables A.8, and A.10 report the estimates using demeaned data aggregated with CPS weights respectively for earnings ratios and labor market outcomes. Again the estimates are similar in magnitude and often more precise. They suggest SHBs may increase female earnings relative to men, particularly for women over 35, those starting new jobs, and those with all of their children over 5 .

In Appendix Table A.4 we utilize the generalized synthetic control approach of $\mathrm{Xu}$ (2017). We replicate our earlier Table1. The left panel aggregates data without CPS weights while the right panel uses CPS weights. Importantly, instead of empirical p-values, this approach provides standard errors which we report in parentheses. Generally most of the point estimates are qualitative similar, although slightly smaller in magnitude. Again, there are much larger effects for those starting new jobs early than those who have switched jobs in the last month.

We also perform basic diff-in-diff models fully explained in Appendix Section A.1. Generally these estimates are much larger, but lead to similar policy conclusions. Moreover, the Goodman-Bacon (2018) decomposition suggest the diff-in-diff estimates are larger driven by the comparison between treated and untreated units. This is not too surprising given the fairly tight windows in which these policies have rolled out.

\section{Conclusions and Policy Implications}

In this paper we provide early evidence on whether SHBs are having their intended goal of increasing female earnings. The point estimates from generalized diff-in-diff models suggest female earnings are increasing relative to male earnings in states adopting SHBs. These 
estimated increase in earnings is larger for those who have switched jobs recently. However, this approach heavily weights $\mathrm{CA}$ given its size and that it was a relatively early adopter ${ }^{11}$ Our synthetic control approach also offers evidence SHB's are associated with increases in the gender earnings ratio. This is particularly true for women beyond peak fertility years (over 35) and those in married households with all of their children older than 5.

While this early evidence on SHBs suggests they may be a promising intervention on at least one dimension, many questions remain. For instance, exactly how are SHBs affecting the labor market? The primary mechanism could be happening through changes in the wage bargaining process (Exley et al., 2020). However, it could also change how employees are screened and chosen (Barach \& Horton, 2017; Agan et al., 2020a). Future research should investigate these mechanisms. Moreover, it is still possible and even likely that a blunt instrument that profoundly changes how firms recruit and screen employees will also have unintended effects, which will prove an important area for future research in the years to come. Indeed, another question considering is whether full public transparency is reasonable alternative to salary history bans. The recent research on this alternative information public policy innovation is mixed. Mas (2017) find pay transparency for municipal managers increases pay compression, while Baker et al. (2019) find that pay transparency in Canada decreases the gender pay gap, chiefly through female earnings increases. Perhaps this suggests providing full information can help workers in the bargaining process. But if the information is particularly one sided, with employers asking for information but not providing it themselves, employers may use that asymmetry to increase their monopsonistic power.

\footnotetext{
${ }^{11}$ Moreover, a Goodman-Bacon (2018) decomposition suggests that most of the generalized diff-in-diff models essentially is driven by a comparison between states that have passed laws and those that have not (as opposed to comparing states that just vary in their timing). This is not surprising given that most these laws are relatively new, so there is not much variation in the timing of laws at this point.
} 
However, the period in which SHBs have been implemented now intersects with the SARS-COV-2 pandemic and the resulting economic shutdown and all but guaranteed economic recession. We do not yet know how firms and hiring will respond in the future, and if SHBs will further close the gender pay gap for individuals returning to work. It's possible that firms may now begin to engage in statistical discrimination, similar to BTB policies, as gender may be more correlated with decreases in the ability of individuals to work from

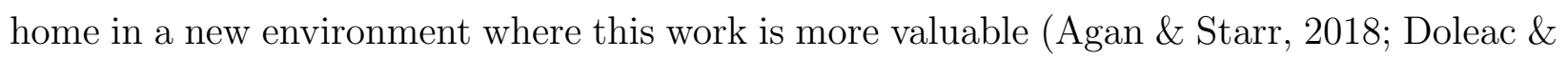
Hansen, 2020). This could emerge if markets place increased weight on the ability of workers to work remotely and if female workers are less productive due to school closures (Houghton, 2020), as markets adapt to life of prolonged closures or social distancing is required (Fauci et al., 2020; Li et al., 2020). However in incredibly loose labor markets, it could be that firm owners or managers engage in more bias in who they hire (Zeltzer, 2020) or are biased in how they interpret labor market signals of productivity (Sarsons, 2017a), which makes it difficult to forecast the longer term effects of SHBs and whether these short-term effects on closing the gender wage gap will persist. 


\section{References}

Abadie, A., Diamond, A., and Hainmueller, J. Synthetic control methods for comparative case studies: Estimating the effect of california's tobacco control program. Journal of the American Statistical Association, 105(490), pp. 493-505, 2010.

Agan, A., Cowgill, B., and Gee, L. K. Salary disclosure and hiring: Field experimental evidence from a two-sided audit study. Working paper, 2020.

Agan, A. and Starr, S. Ban the box, criminal records, and racial discrimination: A field experiment. The Quarterly Journal of Economics, 133(1), pp. 191-235, 2018.

Agan, A. Y., Cowgill, B., and Gee, L. Do workers comply with salary history bans? a survey on voluntary disclosure, adverse selection, and unraveling. AEA Papers $\&$ Proceedings, 110, 2020.

Altonji, J. G. and Pierret, C. R. Employer learning and statistical discrimination. The Quarterly Journal of Economics, 116(1), pp. 313-350, 2001.

Bailey, M. J., Byker, T. S., Patel, E., and Ramnath, S. The long-term effects of californias 2004 paid family leave act on womens careers: Evidence from us tax data. Technical report, National Bureau of Economic Research, 2019.

Baker, M., Halberstam, Y., Kroft, K., Mas, A., and Messacar, D. Pay transparency and the gender gap. Technical report, National Bureau of Economic Research, 2019.

Barach, M. and Horton, J. J. How do employers use compensation history?: Evidence from a field experiment. Journal of Labor Economics, Under Review, 2017.

Billmeier, A. and Nannicini, T. Assessing economic liberalization episodes: A synthetic control approach. Review of Economics and Statistics, 95(3), pp. 983-1001, 2013.

Blau, D. M. and Robins, P. K. Child-care costs and family labor supply. The Review of Economics and Statistics, pp. 374-381, 1988.

Blau, F. D. and Kahn, L. M. Gender differences in pay. Journal of Economic perspectives, 14(4), pp. 75-99, 2000.

Blau, F. D. and Kahn, L. M. The gender wage gap: Extent, trends, and explanations. Journal of Economic Literature, 55(3), pp. 789-865, 2017.

Botosaru, I. and Ferman, B. On the role of covariates in the synthetic control method. The Econometrics Journal, 22(2), pp. 117-130, 2019.

Buser, T., Niederle, M., and Oosterbeek, H. Gender, competitiveness, and career choices. The Quarterly Journal of Economics, 129(3), pp. 1409-1447, 2014.

Cartwright, B., Edwards, P. R., and Wang, Q. Job and industry gender segregation: Naics categories and eeo-1 job groups. Monthly Labor Review, 134(11), pp. 37-50, 2011. 
Cengiz, D., Dube, A., Lindner, A., and Zipperer, B. The effect of minimum wages on lowwage jobs. The Quarterly Journal of Economics, 134(3), pp. 1405-1454, 2019.

Chung, Y., Downs, B., Sandler, D. H., Sienkiewicz, R., et al. The parental gender earnings gap in the united states. Center for Economic Studies Working Paper, 2017.

Cunningham, S. and Shah, M. Decriminalizing indoor prostitution: Implications for sexual violence and public health. The Review of Economic Studies, 85(3), pp. 1683-1715, 2017.

DeAngelo, G. and Hansen, B. Life and death in the fast lane: Police enforcement and traffic fatalities. American Economic Journal: Economic Policy, 6(2), pp. 231-57, 2014.

Doleac, J. L. and Hansen, B. Does "ban the box" help or hurt low-skilled workers? statistical discrimination and employment outcomes when criminal histories are hidden. Journal of Labor Economics, 2020.

Exley, C. L. and Kessler, J. B. The gender gap in self-promotion. Technical report, National Bureau of Economic Research, 2019.

Exley, C. L., Niederle, M., and Vesterlund, L. Knowing when to ask: The cost of leaning in. Journal of Political Economy, 0(0), pp. 000-000, 2020.

Fauci, A. S., Lane, H. C., and Redfield, R. R. Covid-19 navigating the uncharted. New England Journal of Medicine, 382(13), pp. 1268-1269, 2020.

Ferman, B. and Pinto, C. Synthetic controls with imperfect pre-treatment fit. arXiv preprint arXiv:1911.08521, 2019.

Finlay, K. Effect of employer access to criminal history data on the labor market outcomes of ex-offenders and non-offenders. In Studies of labor market intermediation pp. 89-125. University of Chicago Press, 2009.

Gelbach, J. B. Public schooling for young children and maternal labor supply. American Economic Review, 92(1), pp. 307-322, 2002.

Goldin, C. A grand gender convergence: Its last chapter. American Economic Review, 104(4), pp. 1091-1119, 2014.

Goldin, C., Katz, L. F., and Kuziemko, I. The homecoming of american college women: The reversal of the college gender gap. Journal of Economic perspectives, 20(4), pp. 133-156, 2006.

Goodman-Bacon, A. Difference-in-differences with variation in treatment timing. Technical report, National Bureau of Economic Research, 2018.

Holzer, H. J., Raphael, S., and Stoll, M. A. The effect of an applicant's criminal history on employer hiring decisions and screening practices: Evidence from los angeles. Barriers to reentry, pp. 117-150, 2007. 
Houghton, K. Who will watch the kids? evidence from tech workers of gender gaps in work timing and elasticity. Technical report, Working Paper, 2020.

Jardim, E., Long, M. C., Plotnick, R., Van Inwegen, E., Vigdor, J., and Wething, H. Minimum wage increases, wages, and low-wage employment: Evidence from seattle. Technical report, National Bureau of Economic Research, 2017.

Kleven, H., Landais, C., and Søgaard, J. E. Children and gender inequality: Evidence from denmark. American Economic Journal: Applied Economics, 11(4), pp. 181-209, 2019.

Kotlikoff, L. J. and Gokhale, J. Estimating a firm's age-productivity profile using the present value of workers' earnings. The Quarterly Journal of Economics, 107(4), pp. 1215-1242, 1992.

Lange, F. The speed of employer learning. Journal of Labor Economics, 25(1), pp. 1-35, 2007.

Li, R., Pei, S., Chen, B., Song, Y., Zhang, T., Yang, W., and Shaman, J. Substantial undocumented infection facilitates the rapid dissemination of novel coronavirus (sars-cov2). Science, 2020.

Mas, A. Does transparency lead to pay compression? Journal of Political Economy, 125(5), pp. 1683-1721, 2017.

Niederle, M. and Vesterlund, L. Do women shy away from competition? do men compete too much? The quarterly journal of economics, 122(3), pp. 1067-1101, 2007.

Nix, E., Andresen, M. E., et al. What causes the child penalty? evidence from same sex couples and policy reforms. Technical report, Discussion Papers, 2019.

Oyer, P., Schaefer, S., et al. Personnel economics: Hiring and incentives. Handbook of Labor Economics, 4, pp. 1769-1823, 2011.

Sarsons, H. Interpreting signals in the labor market: evidence from medical referrals. Working Paper, 2017.

Sarsons, H. Recognition for group work: Gender differences in academia. American Economic Review, 107(5), pp. 141-45, 2017.

Sinha, S. Salary history ban: Gender pay gap and spillover effects. Available at SSRN $3458194,2019$.

Stoll, M. A. Ex-offenders, criminal background checks, and racial consequences in the labor market. In University of Chicago Legal Forum, HeinOnline, pp. 381, 2009.

Wozniak, A. Discrimination and the effects of drug testing on black employment. Review of Economics and Statistics, 97(3), pp. 548-566, 2015.

$\mathrm{Xu}, \mathrm{Y}$. Generalized synthetic control method: Causal inference with interactive fixed effects models. Political Analysis, 25(1), pp. 57-76, 2017. 
Zeltzer, D. Gender homophily in referral networks: Consequences for the medicare physician earnings gap. American Economic Journal: Applied Economics, 12(2), pp. 169-97, 2020. 


\section{$6 \quad$ Figures and Tables}

\section{Figure 1}

Timeline of State-wide SHB Adoptions

2017

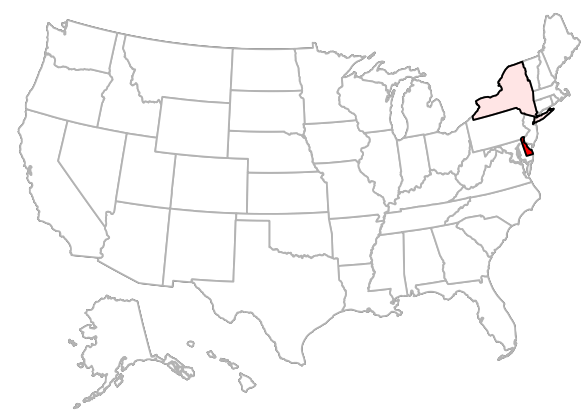

New York 01/09/2017 Public Employers Delaware 12/14/2017 All Employers

\section{9}

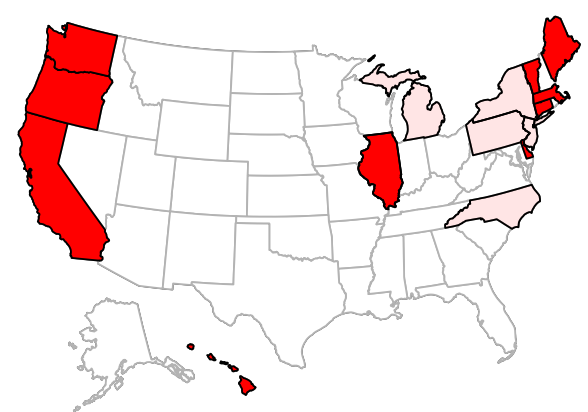

Hawaii

Connecticut

Oregon

Michigan

Illinois

Washington

North Carolina

Maine

Illinois
01/01/2019 All Employers 01/01/2019 All Employers 01/01/2019 All Employers* 01/08/2019 Public Employers 01/08/2019 Public Employers 07/28/2019 All Employers 01/08/2019 Public Employers 09/17/2019 All Employers 09/29/2019 All Employers
2018

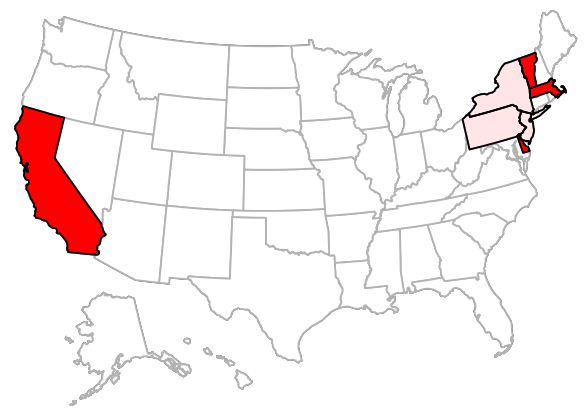

California 01/01/2018 All Employers New Jersey 02/01/2018 Public Employers Massachusetts 07/01/2018 All Employers Vermont 07/01/2018 All Employers Pennsylvania 09/04/2018 Public Employers

2020

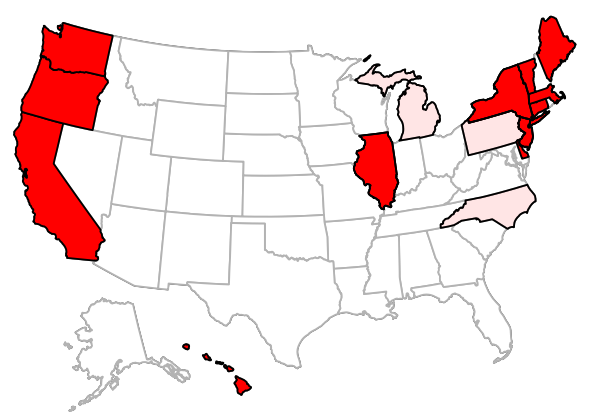

New Jersey 01/01/2020 All Employers New York 01/06/2020 All Employers

Notes: This figure illustrates the roll-out of salary history bans. Dark states have SHBs effective for the entire population, while shaded states have SHBs effective for state employees.

*Oregon's SHB was effective 10/06/2017 and enforced 01/01/2019 


\section{Figure 2}

California and All Treated Synthetic Control for Female to Male Earnings, Level Data

(a) California

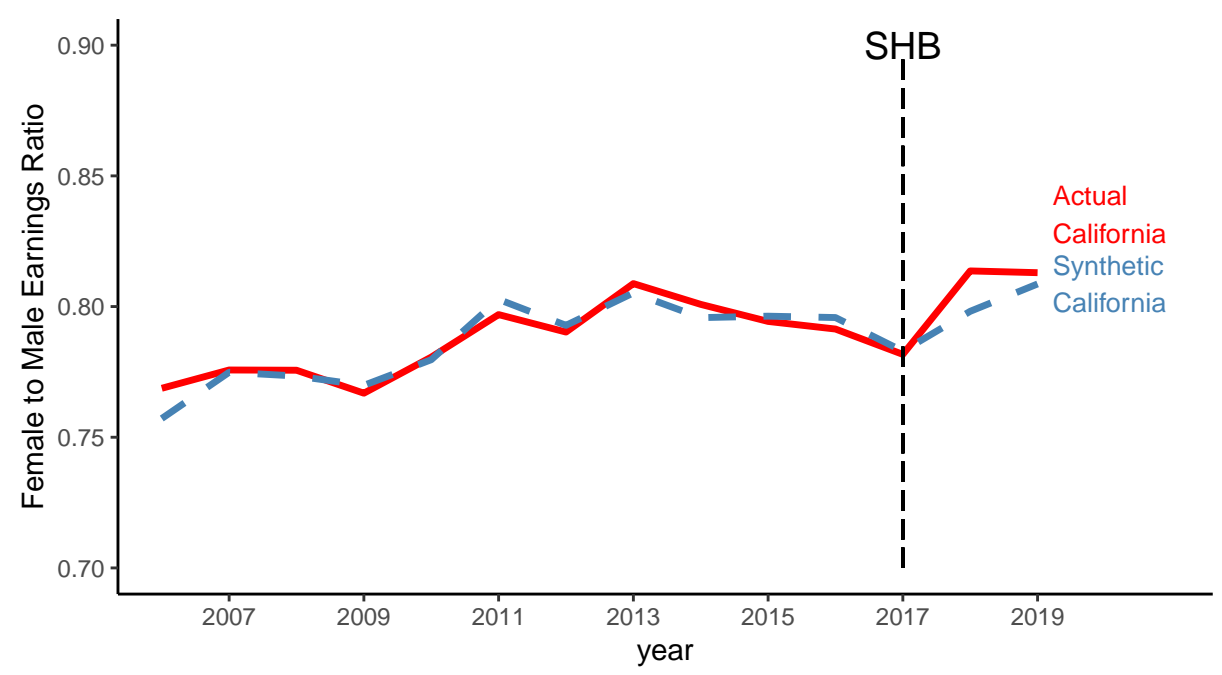

(b) All Treated States

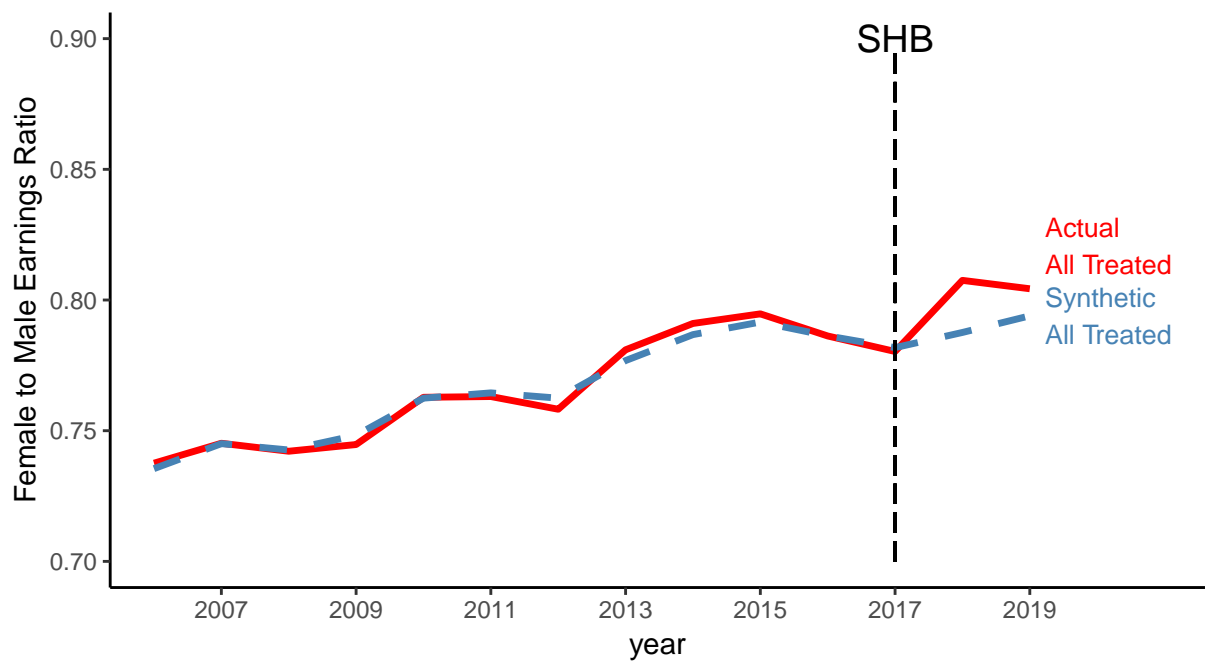

Notes: This figure illustrates difference between the Female to Male earnings ratio and the synthetic control for both California and for all treated states. Each synthetic control is generated by matching on pre-treatment outcomes only. Corresponding point estimates and permutation based p-values can be found in Table 1 


\section{Figure 3}

Labor; Female to Male Earnings Ratio, Level Data

\section{California}

(a) Female Dominated Industries

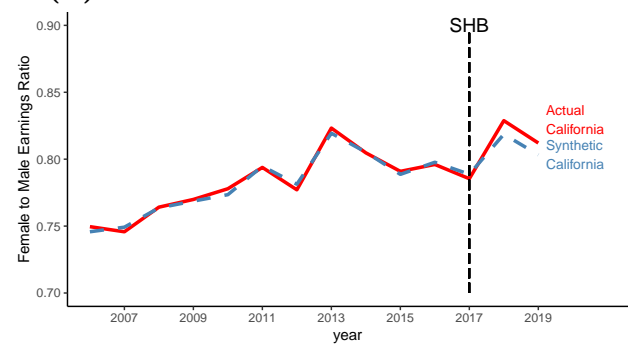

(c) Below Age 35

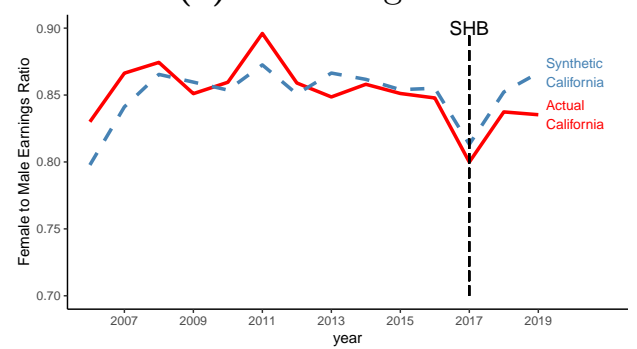

(b) Male Dominated Industries

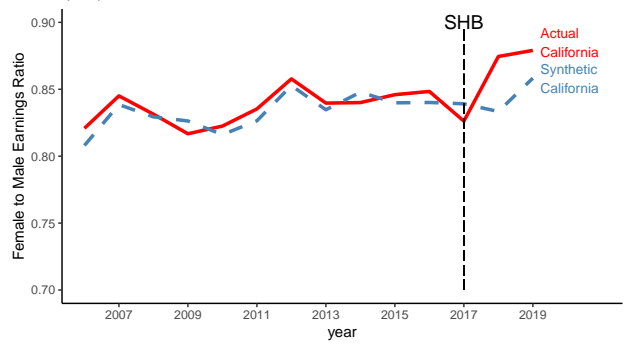

(d) Above Age 35

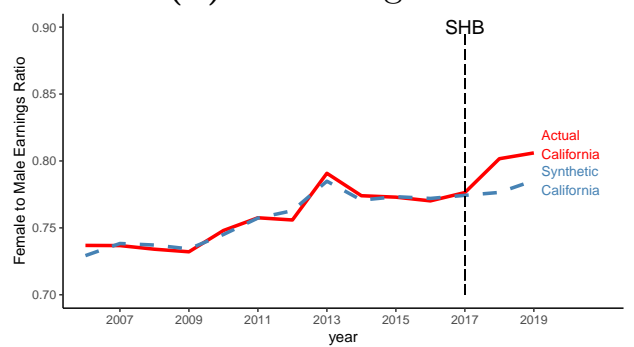

All Treated States

(e) Female Dominated Industries

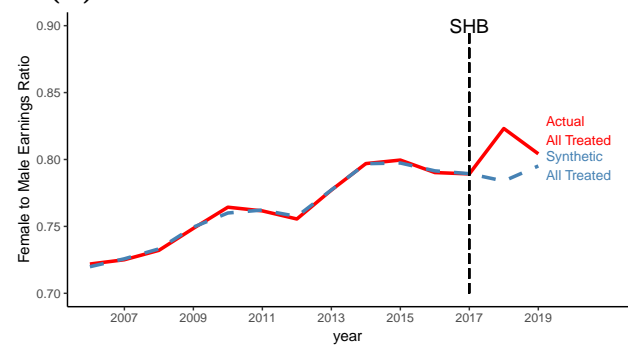

(g) Below Age 35

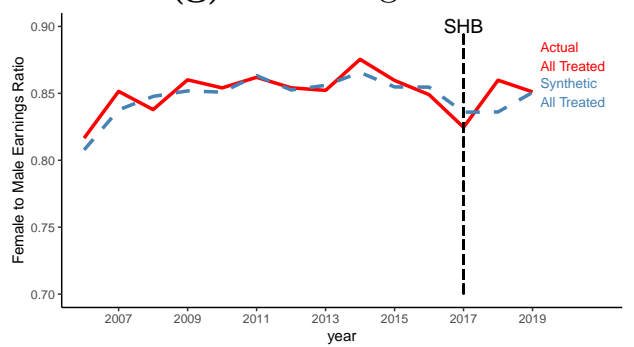

(f) Male Dominated Industries

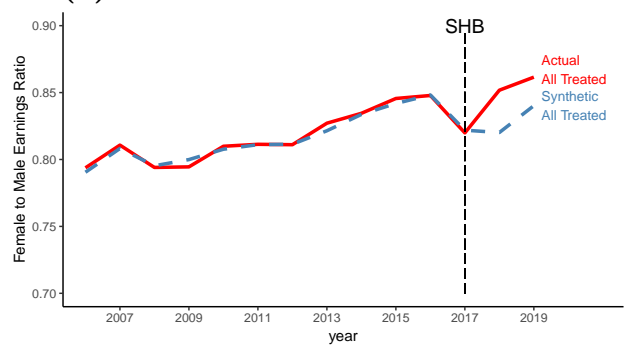

(h) Above Age 35

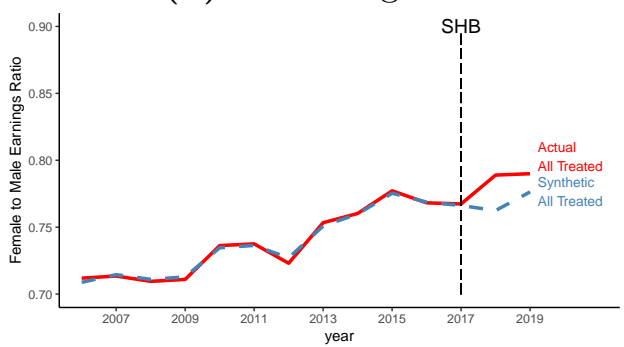

Notes: Each synthetic control is generated by matching on pre-treatment outcomes only. Corresponding point estimates and permutation based p-values can be found in Table 1 . 
Table 1

The Effect of Salary History Bans on the Female to Male Earnings Ratio

\begin{tabular}{|c|c|c|c|c|}
\hline & \multicolumn{2}{|c|}{ California } & \multicolumn{2}{|c|}{ All Treated States } \\
\hline \multicolumn{5}{|c|}{ State-wide } \\
\hline $\begin{array}{l}\text { SHB } \\
\text { P-Value }\end{array}$ & \multicolumn{2}{|c|}{$[0.450]$} & \multicolumn{2}{|c|}{$[0.500]$} \\
\hline \multicolumn{5}{|c|}{ By Industry Type } \\
\hline & $\begin{array}{c}\text { Female } \\
\text { Dominated }\end{array}$ & $\begin{array}{c}\text { Male } \\
\text { Dominated }\end{array}$ & $\begin{array}{c}\text { Female } \\
\text { Dominated }\end{array}$ & $\begin{array}{c}\text { Male } \\
\text { Dominated }\end{array}$ \\
\hline $\begin{array}{l}\text { SHB } \\
\text { P-Value }\end{array}$ & $\begin{array}{l}0.0095 \\
{[0.325]}\end{array}$ & $\begin{array}{l}0.0309 \\
{[0.225]}\end{array}$ & $\begin{array}{c}0.0242^{* *} \\
{[0.025]}\end{array}$ & $\begin{array}{c}0.0265^{*} \\
{[0.050]}\end{array}$ \\
\hline \multicolumn{5}{|c|}{ By Age of Children in Household } \\
\hline $\begin{array}{l}\text { SHB } \\
\text { P-Value }\end{array}$ & $\begin{array}{c}\text { Any } \leq 5 \\
0.0024 \\
{[1.000]}\end{array}$ & $\begin{array}{c}\text { All }>5 \\
0.0471^{* *} \\
{[0.025]}\end{array}$ & $\begin{array}{c}\text { Any } \leq 5 \\
-0.0121 * * \\
{[0.025]}\end{array}$ & $\begin{array}{c}\text { All }>5 \\
0.0190 * * \\
{[0.025]}\end{array}$ \\
\hline \multicolumn{5}{|l|}{ By Age } \\
\hline $\begin{array}{l}\text { SHB } \\
\text { P-Value }\end{array}$ & $\begin{array}{c}\text { Below } 35 \\
-0.0231 \\
{[0.650]}\end{array}$ & $\begin{array}{c}\text { Above } 35 \\
0.0229^{*} \\
{[0.075]}\end{array}$ & $\begin{array}{c}\text { Below } 35 \\
0.0121 \\
{[0.975]}\end{array}$ & $\begin{array}{c}\text { Above } 35 \\
0.0201^{*} \\
{[0.050]}\end{array}$ \\
\hline \multicolumn{5}{|c|}{ By Education for Individuals Older than 35} \\
\hline $\begin{array}{l}\text { SHB } \\
\text { P-Value }\end{array}$ & $\begin{array}{l}\leq \mathrm{HSD} \\
0.0496 \\
{[0.400]}\end{array}$ & $\begin{array}{c}\geq \mathrm{BA} \\
0.0334^{* *} \\
{[0.025]}\end{array}$ & $\begin{array}{c}\leq \mathrm{HSD} \\
0.0153^{* *} \\
{[0.024]}\end{array}$ & $\begin{array}{c}\geq \mathrm{BA} \\
0.0469^{* *} \\
{[0.024]}\end{array}$ \\
\hline \multicolumn{5}{|c|}{ By Job Change in the Last Month for Individuals Older than 35} \\
\hline $\begin{array}{l}\text { SHB } \\
\text { P-Value }\end{array}$ & $\begin{array}{c}\text { New Job } \\
0.2042 \\
{[0.150]}\end{array}$ & $\begin{array}{c}\text { Same Job } \\
0.0348^{* *} \\
{[0.025]}\end{array}$ & $\begin{array}{c}\text { New Job } \\
0.0533^{* *} \\
{[0.024]}\end{array}$ & $\begin{array}{c}\text { Same Job } \\
0.0257^{* *} \\
{[0.024]}\end{array}$ \\
\hline \multicolumn{5}{|c|}{$\begin{array}{l}\text { Notes: This table provides point estimates to the synthetic control estimates illustrated } \\
\text { in Figures } 2 \text { and } 3 \text { The placebo based p-values are included in brackets below each point } \\
\text { estimate. The data used to create these estimates are annual state averages of the female to } \\
\text { male earnings ratio taken from the monthly CPS files. The synthetic control matches on pre- } \\
\text { treatment outcomes only. The composition of each synthetic state is illustrated in Appendix } \\
\text { Figures B.1a and B.1d }\end{array}$} \\
\hline
\end{tabular}


Table 2

The Effect of Salary History Bans on Labor Market Outcomes

\begin{tabular}{|c|c|c|c|c|}
\hline & \multicolumn{2}{|c|}{ California } & \multicolumn{2}{|c|}{ All Treated States } \\
\hline & Female & Male & Female & Male \\
\hline \multicolumn{5}{|c|}{ Probability of Employment } \\
\hline $\begin{array}{l}\text { SHB } \\
\text { P-Value }\end{array}$ & $\begin{array}{l}-0.002 \\
{[1.000]}\end{array}$ & $\begin{array}{l}-0.008 \\
{[0.525]}\end{array}$ & $\begin{array}{c}0.010 \\
{[0.550]}\end{array}$ & $\begin{array}{l}-0.005 \\
{[0.225]}\end{array}$ \\
\hline \multicolumn{5}{|c|}{ Rate of Turn Over } \\
\hline $\begin{array}{l}\text { SHB } \\
\text { P-Value }\end{array}$ & $\begin{array}{l}-0.007 \\
{[0.150]}\end{array}$ & $\begin{array}{c}-0.001^{* *} \\
{[0.025]}\end{array}$ & $\begin{array}{c}-0.032^{* *} \\
{[0.025]}\end{array}$ & $\begin{array}{c}0.006 * * \\
{[0.025]}\end{array}$ \\
\hline \multicolumn{5}{|c|}{ Hourly Wage } \\
\hline $\begin{array}{l}\text { SHB } \\
\text { P-Value }\end{array}$ & $\begin{array}{c}0.255 \\
{[0.225]}\end{array}$ & $\begin{array}{c}0.127 \\
{[0.675]}\end{array}$ & $\begin{array}{l}-0.087 \\
{[0.275]}\end{array}$ & $\begin{array}{c}0.333 \\
{[0.125]}\end{array}$ \\
\hline \multicolumn{5}{|c|}{ Weekly Hours Worked } \\
\hline $\begin{array}{l}\text { SHB } \\
\text { P-Value }\end{array}$ & $\begin{array}{c}0.084 \\
{[0.325]}\end{array}$ & $\begin{array}{l}-0.579 \\
{[0.500]}\end{array}$ & $\begin{array}{c}-0.018^{* *} \\
{[0.025]}\end{array}$ & $\begin{array}{l}-0.265 \\
{[0.350]}\end{array}$ \\
\hline \multicolumn{5}{|c|}{ Weekly Earnings } \\
\hline $\begin{array}{l}\text { SHB } \\
\text { P-Value }\end{array}$ & $\begin{array}{c}-12.863 \\
{[0.375]}\end{array}$ & $\begin{array}{c}9.434 \\
{[0.875]}\end{array}$ & $\begin{array}{l}10.361 \\
{[0.775]}\end{array}$ & $\begin{array}{c}-16.920 \\
{[0.750]}\end{array}$ \\
\hline \multicolumn{5}{|c|}{ Earnings of Individuals with All Children Older than 5} \\
\hline $\begin{array}{l}\text { SHB } \\
\text { P-Value }\end{array}$ & $\begin{array}{l}30.099 \\
{[0.175]}\end{array}$ & $\begin{array}{c}-10.593 \\
{[0.250]}\end{array}$ & $\begin{array}{l}15.691 \\
{[0.275]}\end{array}$ & $\begin{array}{c}3.753^{* *} \\
{[0.025]}\end{array}$ \\
\hline \multicolumn{5}{|c|}{$\begin{array}{l}\text { Earnings of Individuals Above Age } 35 \\
\text { Working in a Male Dominated Industries }\end{array}$} \\
\hline $\begin{array}{l}\text { SHB } \\
\text { P-Value }\end{array}$ & $\begin{array}{l}75.115 \\
{[0.150]}\end{array}$ & $\begin{array}{l}5.554 \\
{[0.950]}\end{array}$ & $\begin{array}{l}35.446 \\
{[0.125]}\end{array}$ & $\begin{array}{r}-20.755 \\
{[0.100]}\end{array}$ \\
\hline \multicolumn{5}{|c|}{ Earnings of Individuals Above Age 35 with a New Job } \\
\hline $\begin{array}{l}\text { SHB } \\
\text { P-Value }\end{array}$ & $\begin{array}{c}274.341 \\
{[0.225]}\end{array}$ & $\begin{array}{l}82.527 \\
{[0.500]}\end{array}$ & $\begin{array}{l}114.741 \\
{[0.350]}\end{array}$ & $\begin{array}{c}28.581^{* *} \\
{[0.025]}\end{array}$ \\
\hline \multicolumn{5}{|c|}{$\begin{array}{l}\text { Notes: This table provides point estimates to the synthetic control estimates for various } \\
\text { labor market outcomes. The permutation based p-values are included in brackets below each } \\
\text { point estimate. The data used to create these estimates are annual state averages of male } \\
\text { and female labor market outcomes taken from the monthly CPS files. The synthetic control } \\
\text { matches on pre-treatment outcomes only. }\end{array}$} \\
\hline
\end{tabular}




\section{Appendix A}

\section{A.1 Differences in Differences Approaches}

We exploit the micro-data using a differences in differences strategy. Our analysis suggests identification is coming from the difference between treated and untreated states. However, majority of treated observations stem from one state alone, California, which motivates using a synthetic control approach so that the treated and untreated states look as similar as possible absent treatment. Our base equation estimates the effect of a SHB for males, and then interacts a dummy variable for SHB with an indicator for female, while controlling for state fixed effects and year fixed effects.

$$
\ln (\text { earnings })_{i s t}=\beta_{0}+\beta_{1} * S H B_{s t}+\beta_{2} * \text { female }_{i s t}+\beta_{3} * S H B_{s t} * \text { female }_{i s t}+S_{s}+t_{t}+\epsilon_{i s t}
$$

In Table A.1, we report the point estimates based on generalized difference-in-difference models as discussed above, similar to those estimated by Sinha (2019). In these models three parameters are of interest. The coefficient on female is the average wage or earnings penalties for female workers. The coefficient on $S H B$ is the average estimated impact of a SHB on male wages or earnings, while the coefficient on the interaction between female and $S H B$ informs about the effect of SHBs on the gender wage or earnings ratio.

First we focus on all workers. Not surprisingly, female workers always both a wage and earnings penalty. In only one of the models do we find evidence that SHBs reduce male earnings. However, in each model the point estimates suggest that SHBs increase female earnings and wages relative to males. In the models using $\log$ (earnings) and $\log$ (wages), the estimates are more precise. Taken at face value they would suggest a SHB closes more than 26 of the wage gap and 35 percent of the earnings gap. While this is evidence supportive of SHBs having their intended effect, we also might be worried about the magnitude of the estimates. If we consider the likely impact of SHB should happen when individuals change jobs, then you should scale up this point estimates by annual turnover rates, which are 
usually close to 20 percent. This back of the envelope calculation would suggest SHBs might entirely be closing the gender wage gap for those changing jobs and perhaps reversing the gap the other direction.

While the CPS does not record employment histories for all participants, it does ask individuals on whether they changed jobs in the last month. We use this restriction in the lower panel to see if SHBs are associated with larger changes in earnings among those switching jobs. Again, we find consistent earnings and wage penalties for those switching jobs. The point estimates provide little evidence SHB are negatively affecting men in this smaller subsample. Moreover, the point estimates are all positive for the interaction between female and SHB. Although the point estimates are noisier for this smaller sample, they suggest a SHB is associated with a 25 percent increase in female wage ratio. Moreover, the estimates on the interactions suggest female earnings ratio increase by 29 to 52 percent in states adopting SHBs.

These point estimates are large, and suggestive SHBs may be improving female labor market outcomes. However, given the number of states passing SHBs is limited, the estimates are largely driven by CA (which represents 45 percent of observations among the treated units). Moreover, Goodman-Bacon (2018) shows this weight is increased if treatment effects are heterogenous as California was an earlier adopter. We report the results of the GoodmanBacon decomposition in Figure A.1. This decomposition reports the point estimates resulting if the late adopters are the control units for the earlier adopting states, if the early adopters are the control units for the late adopters, and if the never treated states are the control for either the early or late adopting states. It shows the overall generalized diff-in-diff estimate is closest to the diff-in-diff models comparing either the early or late adopters to the units that are never treated. Moreover, this decomposition suggests the generalized diff-in-diff attaches 96 percent of the weight to the treated vs. never treated comparisons. This implies it is of first order important to ensure the control units are similar to the treated units. In turn it also motivates our next approach: synthetic controls. 
Table A.1

The Effect of Salary History Bans on Labor Market Outcomes: Generalized Diff-in-Diff Models

\begin{tabular}{|c|c|c|c|c|}
\hline & $\ln$ (Wages) & Wages & $\ln$ (Earnings) & Earnings \\
\hline \multicolumn{5}{|l|}{ All Workers } \\
\hline $\mathrm{SHB}$ & $\begin{array}{l}-0.011 \\
(0.007)\end{array}$ & $\begin{array}{c}0.121 \\
(0.242)\end{array}$ & $\begin{array}{c}-0.027^{* *} \\
(0.008)\end{array}$ & $\begin{array}{l}4.615 \\
(8.72)\end{array}$ \\
\hline SHB*Female & $\begin{array}{c}0.037^{* *} \\
(0.016)\end{array}$ & $\begin{array}{c}0.147 \\
(0.449)\end{array}$ & $\begin{array}{c}0.077^{* * *} \\
(0.009)\end{array}$ & $\begin{array}{c}17.35 \\
(10.94)\end{array}$ \\
\hline Female & $\begin{array}{c}-0.14^{* * *} \\
(0.006)\end{array}$ & $\begin{array}{c}-3.351^{* * *} \\
(0.086)\end{array}$ & $\begin{array}{c}-0.222^{* * *} \\
(0.007)\end{array}$ & $\begin{array}{c}-269.5^{* *} \\
(4.79)\end{array}$ \\
\hline Obs. & 607,202 & 607,202 & $1,183,336$ & $1,183,336$ \\
\hline \multicolumn{5}{|l|}{ Job Switchers } \\
\hline SHB 0.063 & $\begin{array}{c}1.556 \\
(0.034)\end{array}$ & $\begin{array}{l}0.004 \\
(1.10)\end{array}$ & $\begin{array}{l}-0.006 \\
(0.033)\end{array}$ & $\begin{array}{c}32.22 \\
(39.44)\end{array}$ \\
\hline SHB*Female & $\begin{array}{c}0.042 \\
(0.037)\end{array}$ & $\begin{array}{c}0.409 \\
(1.306)\end{array}$ & $\begin{array}{c}0.144^{* *} \\
(0.058)\end{array}$ & $\begin{array}{c}71.99 \\
(58.38)\end{array}$ \\
\hline Female & $\begin{array}{c}-0.170^{* * *} \\
(0.01)\end{array}$ & $\begin{array}{c}-2.983^{* * *} \\
(0.185)\end{array}$ & $\begin{array}{c}-0.270^{* * *} \\
(0.012)\end{array}$ & $\begin{array}{c}-248.6^{* * *} \\
(8.846)\end{array}$ \\
\hline Obs. & 11,963 & 11,963 & 20,592 & 20,592 \\
\hline $\begin{array}{l}\text { Notes: This table } \\
\text { the impact of SHBs } \\
\text { clustered at the sta } \\
\text { observations for the }\end{array}$ & $\begin{array}{l}\text { ides point estim } \\
\text { earnings and wa } \\
\text { vel. The data us } \\
\text { or market outco }\end{array}$ & $\begin{array}{l}\text { for generalized } \\
\text { Standard error } \\
\text { o create these e } \\
\text { taken from the }\end{array}$ & $\begin{array}{l}\text {-in-diff models that } \\
\text { reported in parent } \\
\text { ates are based on m } \\
\text { nthly CPS files. }\end{array}$ & $\begin{array}{l}\text { estimate } \\
\text { eses and } \\
\text { cro level }\end{array}$ \\
\hline
\end{tabular}


Figure A.1

Bacon Decomposition

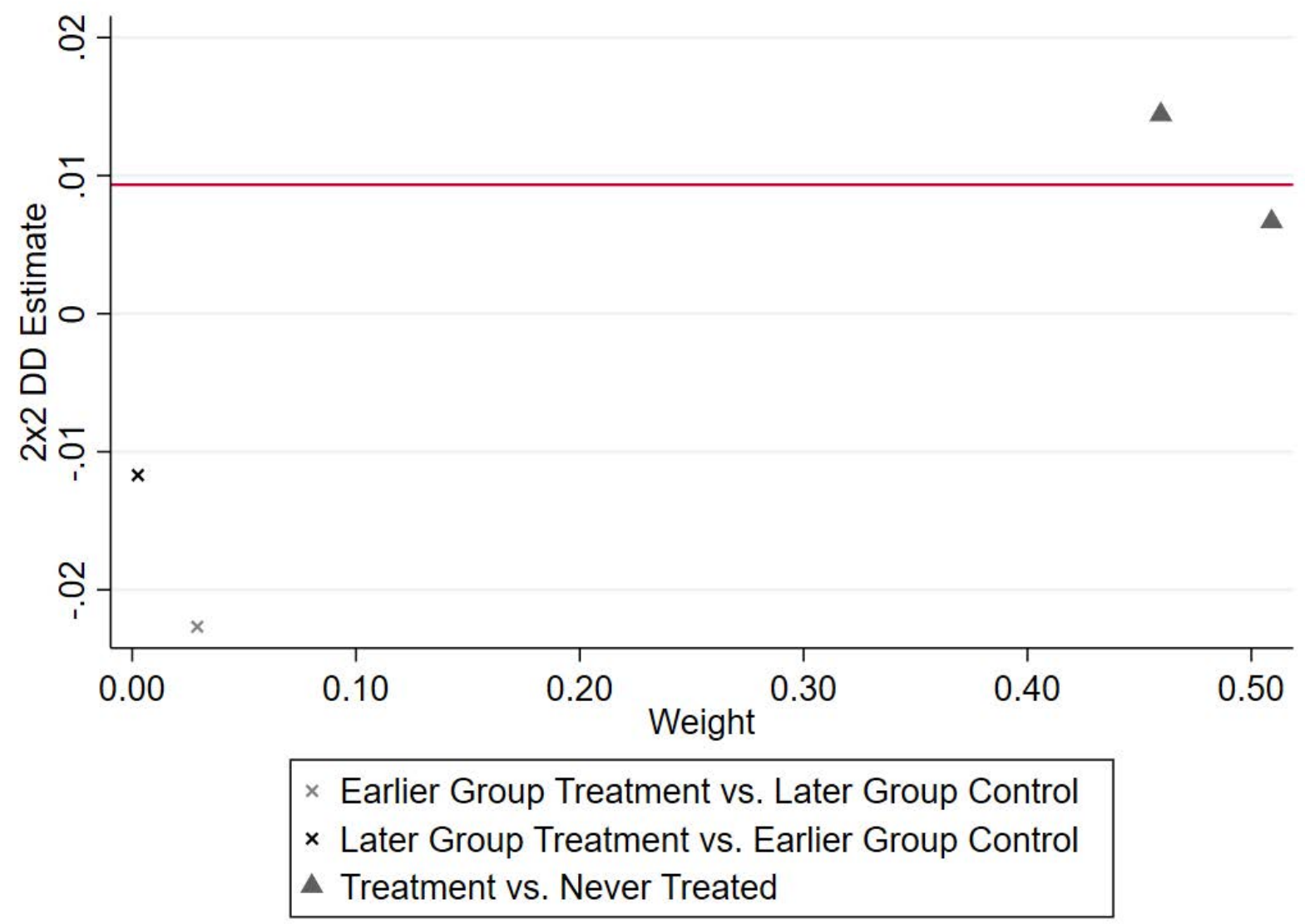

Notes: This figure illustrates the point estimates provided by the Goodman-Bacon decomposition (2018). This approach compares the point estimates produces using the late adopters as controls for the early adopters, the early adopters as controls for the late adopters, the never treated as controls for the early adopters, and the never treated as controls for the late adopters. This approach suggests the treated vs. never treated comparison received 96.1 percent of the weight in a generalized diff-in-diff model. 


\section{A.2 Detailed Timeline of Treatment}

\begin{tabular}{|c|c|c|c|}
\hline \multirow[b]{2}{*}{ State } & $\begin{array}{r}\text { Table } \\
\text { State-wide }\end{array}$ & $\begin{array}{l}.2 \\
\text { B Laws }\end{array}$ & \multirow[b]{2}{*}{ Documentation } \\
\hline & Effective Date & $\begin{array}{c}\text { Employers } \\
\text { Affected }\end{array}$ & \\
\hline Delaware & $12-14-2017$ & All & link \\
\hline California & 01-01-2018 & All & link \\
\hline Vermont & 07-01-2018 & All & link \\
\hline Massachusetts & 07-01-2018 & All & link \\
\hline Connecticut & 01-01-2019 & All & link \\
\hline Hawaii & 01-01-2019 & All & $\overline{\operatorname{link}}$ \\
\hline Oregon & 01-01-2019* & All & link \\
\hline Washington & 07-28-2019 & All & link \\
\hline Maine & 09-17-2019 & All & link \\
\hline Illinois & 09-29-2019 & All & $\overline{l i n k}$ \\
\hline New Jersey & 01-01-2020 & All & $\overline{l i n k}$ \\
\hline New York & 01-06-2020 & All & link \\
\hline Colorado & 01-01-2021 & All & link \\
\hline New York & 01-09-2017 & State & link \\
\hline New Jersey & 02-01-2018 & State & $\overline{l i n k}$ \\
\hline Pennsylvania & 09-04-2018 & State & link \\
\hline Michigan & 01-08-2019 & State & link \\
\hline Illinois & 01-15-2019 & State & link \\
\hline North Carolina & 04-02-2019 & State & link \\
\hline
\end{tabular}


Table A.3

City and County SHB Laws

\begin{tabular}{|c|c|c|c|}
\hline City or County & Effective Date & $\begin{array}{c}\text { Employers } \\
\text { Affected }\end{array}$ & Documentation \\
\hline New Orleans, LA & $01-25-2017$ & City & link \\
\hline Pittsburgh, PA & 01-30-2017 & City & link \\
\hline New York City, NY & $10-31-2017$ & All & link \\
\hline Salt Lake City, UT & 03-01-2018 & City & link \\
\hline Chicago, IL & $04-10-2018$ & City & link \\
\hline Louisville, KY & $05-17-2018$ & City & link \\
\hline San Francisco, CA & 07-01-2018 & All & link \\
\hline Kansas City, KS & 02-18-2019 & City & link \\
\hline Atlanta, GA & 06-13-2019 & City & $\overline{l i n k}$ \\
\hline Jackson, MS & 01-01-2020 & City & link \\
\hline Columbia, SC & 08-06-2019 & City & link \\
\hline Kansas City, KS & 10-31-2019 & City & link \\
\hline Cincinnati, OH & 03-26-2020 & $>15$ employees & link \\
\hline Toledo, $\mathrm{OH}$ & $06-25-2020$ & City & link \\
\hline Albany County, NY & $12-17-2017$ & All & link \\
\hline Westchester County, NY & 07-09-2018 & All & link \\
\hline Richland County, SC & 05-23-2019 & County & link \\
\hline Suffolk County, NY & 06-30-2019 & All & link \\
\hline Montgomery County, MD & 07-14-2019 & County & $\overline{l i n k}$ \\
\hline
\end{tabular}




\section{A.3 Generalized Synthetic Control}

Table A.4

The Effect of Salary History Bans on the Female to Male Earnings Ratio

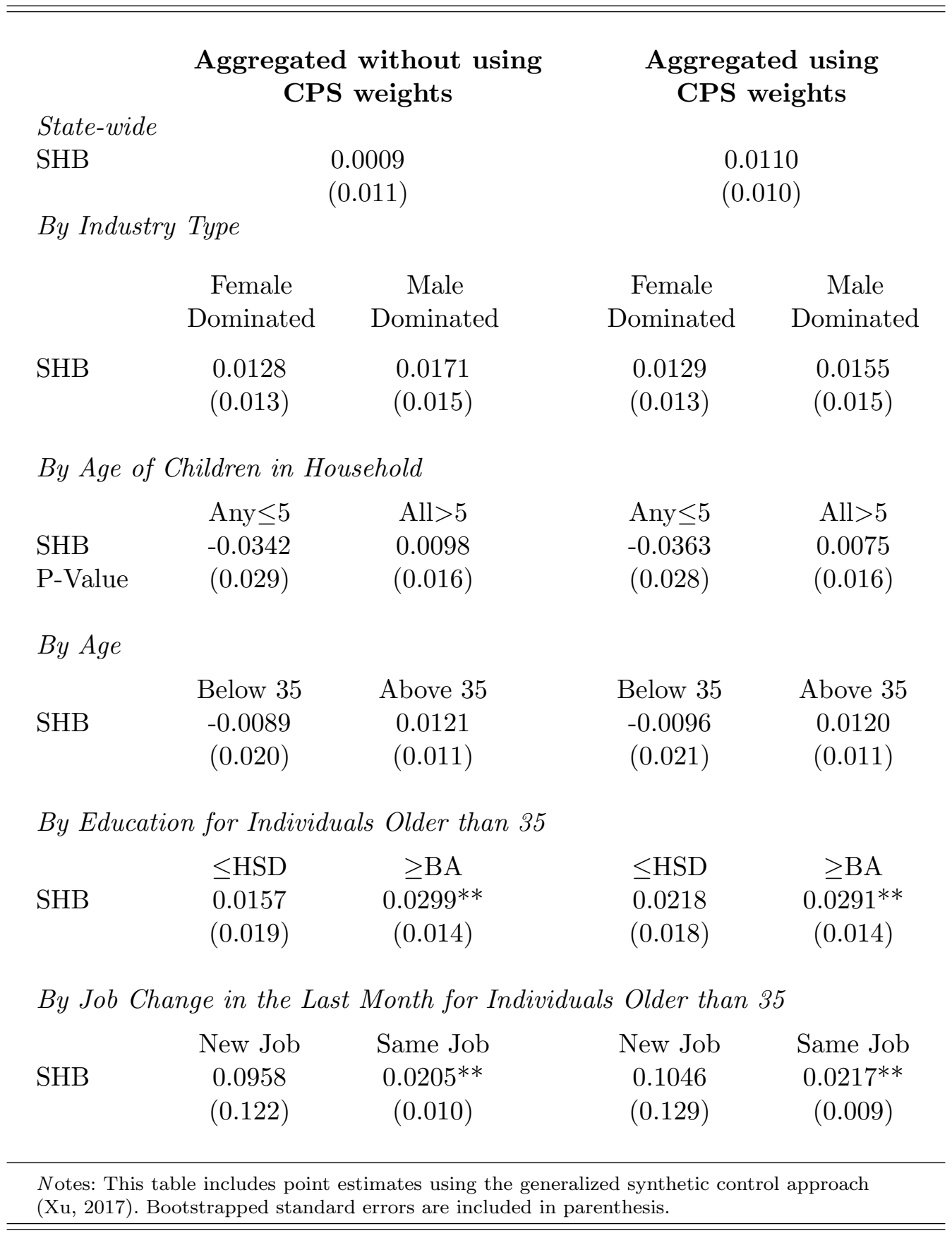




\title{
A.4 Synthetic Control Using Demeaned Data
}

\author{
Table A.5
}

The Effect of Salary History Bans on the Female to Male Earnings Ratio, Demeaned Data

\begin{tabular}{|c|c|c|c|c|}
\hline & \multicolumn{2}{|c|}{ California } & \multicolumn{2}{|c|}{ All Treated States } \\
\hline \multicolumn{5}{|c|}{ State-wide } \\
\hline SHB & \multicolumn{2}{|c|}{0.0019} & \multicolumn{2}{|c|}{$0.0187^{*}$} \\
\hline P-Value & \multicolumn{2}{|c|}{$[0.171]$} & \multicolumn{2}{|c|}{$[0.098]$} \\
\hline \multicolumn{5}{|c|}{ By Industry Type } \\
\hline & Female & Male & Female & Male \\
\hline & Dominated & Dominated & Dominated & Dominated \\
\hline SHB & $-0.0052^{*}$ & $0.0440^{* *}$ & $0.0137^{* *}$ & $0.0225^{* *}$ \\
\hline P-Value & {$[0.073]$} & {$[0.024]$} & {$[0.024]$} & {$[0.024]$} \\
\hline \multicolumn{5}{|c|}{ By Age of Children in Household } \\
\hline & Any $\leq 5$ & All $>5$ & Any $\leq 5$ & All $>5$ \\
\hline SHB & -0.0068 & $0.0318^{* *}$ & $-0.0138 * *$ & $0.0117^{* *}$ \\
\hline P-Value & {$[0.390]$} & {$[0.049]$} & {$[0.024]$} & {$[0.024]$} \\
\hline \multicolumn{5}{|l|}{ By Age } \\
\hline & Below 35 & Above 35 & Below 35 & Above 35 \\
\hline SHB & -0.0157 & $0.0279^{* *}$ & -0.0050 & $0.0214^{* *}$ \\
\hline P-Value & {$[0.463]$} & {$[0.024]$} & {$[0.171]$} & {$[0.024]$} \\
\hline \multicolumn{5}{|c|}{ By Education for Individuals Older than 35} \\
\hline & $\leq \mathrm{HSD}$ & $\geq \mathrm{BA}$ & $\leq \mathrm{HSD}$ & $\geq \mathrm{BA}$ \\
\hline SHB & 0.0301 & $0.0349 * *$ & $0.0153^{* *}$ & $0 . \overline{0} 469 * *$ \\
\hline P-Value & {$[0.463]$} & {$[0.024]$} & {$[0.024]$} & {$[0.024]$} \\
\hline \multicolumn{5}{|c|}{ By Job Change in the Last Month for Individuals Older than 35} \\
\hline & New Job & Same Job & New Job & Same Job \\
\hline SHB & $0.1228^{*}$ & $0.0322^{* *}$ & $0.0533^{* *}$ & $0.0257^{* *}$ \\
\hline P-Value & {$[0.073]$} & {$[0.024]$} & {$[0.024]$} & {$[0.024]$} \\
\hline \multicolumn{5}{|c|}{$\begin{array}{l}\text { Notes: This table provides point estimates to the synthetic control estimates illustrated } \\
\text { in Figures } 2 \text { and } 3 \text { The placebo based p-values are included in brackets below each point } \\
\text { estimate. The data used to create these estimates are annual state averages of the female } \\
\text { to male earnings ratio taken from the monthly CPS files. The synthetic control matches on } \\
\text { pre-treatment outcomes only. }\end{array}$} \\
\hline
\end{tabular}


Table A.6

The Effect of Salary History Bans on Labor Market Outcomes, Demeaned

\begin{tabular}{|c|c|c|c|c|}
\hline & \multicolumn{2}{|c|}{ California } & \multicolumn{2}{|c|}{ All Treated States } \\
\hline & Female & Male & Female & Male \\
\hline \multicolumn{5}{|c|}{ Probability of Employment } \\
\hline SHB & $0.016^{*}$ & -0.004 & 0.011 & -0.004 \\
\hline P-Value & {$[0.098]$} & {$[0.659]$} & {$[0.146]$} & {$[0.463]$} \\
\hline \multicolumn{5}{|c|}{ Rate of Turn Over } \\
\hline $\mathrm{SHB}$ & -0.005 & $-0.000 * *$ & $-0.032^{* *}$ & $0.005^{* *}$ \\
\hline P-Value & {$[0.195]$} & {$[0.024]$} & {$[0.024]$} & {$[0.024]$} \\
\hline \multicolumn{5}{|c|}{ Hourly Wage } \\
\hline SHB & $0.501^{* *}$ & -0.040 & $0.120^{*}$ & $0.063^{*}$ \\
\hline P-Value & {$[0.049]$} & {$[0.220]$} & {$[0.073]$} & {$[0.073]$} \\
\hline \multicolumn{5}{|c|}{ Weekly Hours Worked } \\
\hline $\mathrm{SHB}$ & 0.019 & -0.376 & $0.047^{* *}$ & -0.036 \\
\hline P-Value & {$[0.439]$} & {$[0.366]$} & {$[0.024]$} & {$[0.439]$} \\
\hline \multicolumn{5}{|c|}{ Weekly Earnings } \\
\hline $\mathrm{SHB}$ & 26.200 & 9.815 & $27.970^{* *}$ & $-9.536^{* *}$ \\
\hline P-Value & {$[0.244]$} & {$[0.512]$} & {$[0.049]$} & {$[0.024]$} \\
\hline \multicolumn{5}{|c|}{ Earnings of Individuals with All Children Older than 5} \\
\hline SHB & $34.705^{* *}$ & -2.868 & $19.113^{*}$ & $2.136^{* *}$ \\
\hline P-Value & {$[0.049]$} & {$[0.463]$} & {$[0.098]$} & {$[0.049]$} \\
\hline \multicolumn{5}{|c|}{$\begin{array}{l}\text { Earnings of Individuals Above Age } 35 \\
\text { Working in a Male Dominated Industries }\end{array}$} \\
\hline SHB & $85.745^{* *}$ & 12.519 & $37.674^{* *}$ & $-16.253^{* *}$ \\
\hline P-Value & {$[0.049]$} & {$[0.341]$} & {$[0.024]$} & {$[0.024]$} \\
\hline \multicolumn{5}{|c|}{ Earnings of Individuals Above Age 35 with a New Job } \\
\hline $\mathrm{SHB}$ & 158.562 & 45.743 & $136.679^{* *}$ & $42.882^{* *}$ \\
\hline P-Value & {$[0.317]$} & {$[0.512]$} & {$[0.049]$} & {$[0.024]$} \\
\hline \multicolumn{5}{|c|}{$\begin{array}{l}\text { Notes: This table provides point estimates to the synthetic control estimates for various } \\
\text { labor market outcomes. The permutation based p-values are included in brackets below each } \\
\text { point estimate. The data used to create these estimates are annual state averages of male } \\
\text { and female labor market outcomes taken from the monthly CPS files. The synthetic control } \\
\text { matches on pre-treatment outcomes only. }\end{array}$} \\
\hline
\end{tabular}




\section{A.5 Synthetic Control Using CPS Population Weights}

\section{Table A.7}

The Effect of Salary History Bans on the Female to Male Earnings Ratio Aggregated Using CPS Weights

\begin{tabular}{|c|c|c|c|c|}
\hline & \multirow{2}{*}{\multicolumn{2}{|c|}{ California }} & \multicolumn{2}{|c|}{ All Treated States } \\
\hline \multicolumn{3}{|c|}{ State-wide } & & \\
\hline $\begin{array}{c}\text { SHB } \\
\text { P-Value }\end{array}$ & \multicolumn{2}{|c|}{$\begin{array}{l}0.0067 \\
{[0.750]}\end{array}$} & \multicolumn{2}{|c|}{$\begin{array}{l}0.0114 \\
{[0.675]}\end{array}$} \\
\hline \multicolumn{5}{|c|}{ By Industry Type } \\
\hline & $\begin{array}{c}\text { Female } \\
\text { Dominated }\end{array}$ & $\begin{array}{c}\text { Male } \\
\text { Dominated }\end{array}$ & $\begin{array}{c}\text { Female } \\
\text { Dominated }\end{array}$ & $\begin{array}{c}\text { Male } \\
\text { Dominated }\end{array}$ \\
\hline $\begin{array}{l}\text { SHB } \\
\text { P-Value }\end{array}$ & $\begin{array}{l}0.0083 \\
{[0.700]}\end{array}$ & $\begin{array}{l}0.0255 \\
{[0.325]}\end{array}$ & $\begin{array}{l}0.0207 \\
{[0.100]}\end{array}$ & $\begin{array}{l}0.0157 \\
{[0.675]}\end{array}$ \\
\hline \multicolumn{5}{|c|}{ By Age of Children in Household } \\
\hline $\begin{array}{l}\text { SHB } \\
\text { P-Value }\end{array}$ & $\begin{array}{c}\text { Any } \leq 5 \\
-0.0198 \\
{[0.875]}\end{array}$ & $\begin{array}{c}\text { All }>5 \\
0.0425^{*} \\
{[0.075]}\end{array}$ & $\begin{array}{c}\text { Any } \leq 5 \\
-0.0213 \\
{[0.525]}\end{array}$ & $\begin{array}{c}\text { All }>5 \\
0.0411^{* *} \\
{[0.025]}\end{array}$ \\
\hline \multicolumn{5}{|l|}{ By Age } \\
\hline $\begin{array}{l}\text { SHB } \\
\text { P-Value }\end{array}$ & $\begin{array}{c}\text { Below } 35 \\
-0.0584 \\
{[0.175]}\end{array}$ & $\begin{array}{c}\text { Above } 35 \\
0.0245^{*} \\
{[0.050]}\end{array}$ & $\begin{array}{c}\text { Below } 35 \\
-0.0119 \\
{[0.950]}\end{array}$ & $\begin{array}{c}\text { Above } 35 \\
0.0216 \\
{[0.100]}\end{array}$ \\
\hline \multicolumn{5}{|c|}{ By Education for Individuals Older than 35} \\
\hline $\begin{array}{l}\text { SHB } \\
\text { P-Value }\end{array}$ & $\begin{array}{l}\leq \mathrm{HSD} \\
0.0367 \\
{[0.550]}\end{array}$ & $\begin{array}{c}\geq \mathrm{BA} \\
0.0375^{* *} \\
{[0.025]}\end{array}$ & $\begin{array}{c}\leq \mathrm{HSD} \\
0.0153^{* *} \\
{[0.024]}\end{array}$ & $\begin{array}{c}\geq \mathrm{BA} \\
0.0469 * * \\
{[0.024]}\end{array}$ \\
\hline \multicolumn{5}{|c|}{ By Job Change in the Last Month for Individuals Older than 35} \\
\hline $\begin{array}{l}\text { SHB } \\
\text { P-Value }\end{array}$ & $\begin{array}{c}\text { New Job } \\
0.2652^{*} \\
{[0.050]}\end{array}$ & $\begin{array}{c}\text { Same Job } \\
0.0354^{* *} \\
{[0.025]}\end{array}$ & $\begin{array}{c}\text { New Job } \\
0.0533^{* *} \\
{[0.024]}\end{array}$ & $\begin{array}{c}\text { Same Job } \\
0.0257^{* *} \\
{[0.024]}\end{array}$ \\
\hline \multicolumn{5}{|c|}{$\begin{array}{l}\text { Notes: This table provides point estimates to the synthetic control estimates illustrated } \\
\text { in Figures } 2 \text { and } 3 \text { The placebo based p-values are included in brackets below each point } \\
\text { estimate. The data used to create these estimates are annual state averages of the female } \\
\text { to male earnings ratio taken from the monthly CPS files. The synthetic control matches on } \\
\text { pre-treatment outcomes only. }\end{array}$} \\
\hline
\end{tabular}


Table A.8

The Effect of Salary History Bans on the Female to Male Earnings Ratio, Demeaned Data Aggregated Using CPS Weights

\begin{tabular}{|c|c|c|c|c|}
\hline & \multirow{2}{*}{\multicolumn{2}{|c|}{ California }} & \multicolumn{2}{|c|}{ All Treated States } \\
\hline \multicolumn{3}{|c|}{ State-wide } & & \\
\hline $\begin{array}{l}\text { SHB } \\
\text { P-Value }\end{array}$ & \multicolumn{2}{|c|}{$\begin{array}{c}-0.0004 \\
{[0.463]}\end{array}$} & \multicolumn{2}{|c|}{$\begin{array}{l}0.0153 \\
{[0.317]}\end{array}$} \\
\hline \multicolumn{5}{|c|}{ By Industry Type } \\
\hline & $\begin{array}{c}\text { Female } \\
\text { Dominated }\end{array}$ & $\begin{array}{c}\text { Male } \\
\text { Dominated }\end{array}$ & $\begin{array}{c}\text { Female } \\
\text { Dominated }\end{array}$ & $\begin{array}{c}\text { Male } \\
\text { Dominated }\end{array}$ \\
\hline $\begin{array}{l}\text { SHB } \\
\text { P-Value }\end{array}$ & $\begin{array}{c}-0.0117^{*} \\
{[0.098]}\end{array}$ & $\begin{array}{c}0.0323^{* *} \\
{[0.024]}\end{array}$ & $\begin{array}{l}0.0124 \\
{[0.366]}\end{array}$ & $\begin{array}{c}0.0308^{* *} \\
{[0.024]}\end{array}$ \\
\hline \multicolumn{5}{|c|}{ By Age of Children in Household } \\
\hline $\begin{array}{l}\text { SHB } \\
\text { P-Value }\end{array}$ & $\begin{array}{c}\text { Any } \leq 5 \\
-0.0193 \\
{[0.390]}\end{array}$ & $\begin{array}{c}\text { All }>5 \\
0.0066^{* *} \\
{[0.024]}\end{array}$ & $\begin{array}{c}\text { Any } \leq 5 \\
-0.0262^{* *} \\
{[0.024]}\end{array}$ & $\begin{array}{c}\text { All }>5 \\
0.0331^{* *} \\
{[0.024]}\end{array}$ \\
\hline \multicolumn{5}{|l|}{ By Age } \\
\hline $\begin{array}{l}\text { SHB } \\
\text { P-Value }\end{array}$ & $\begin{array}{c}\text { Below } 35 \\
-0.0137 \\
{[0.634]}\end{array}$ & $\begin{array}{c}\text { Above } 35 \\
0.0271^{* *} \\
{[0.024]}\end{array}$ & $\begin{array}{c}\text { Below } 35 \\
0.0149 \\
{[0.415]}\end{array}$ & $\begin{array}{c}\text { Above } 35 \\
0.0346^{* *} \\
{[0.024]}\end{array}$ \\
\hline \multicolumn{5}{|c|}{ By Education for Individuals Older than 35} \\
\hline $\begin{array}{l}\text { SHB } \\
\text { P-Value }\end{array}$ & $\begin{array}{l}\leq \mathrm{HSD} \\
0.0266 \\
{[0.512]}\end{array}$ & $\begin{array}{c}\geq \mathrm{BA} \\
0.0398^{* *} \\
{[0.024]}\end{array}$ & $\begin{array}{c}\leq \mathrm{HSD} \\
0.0037^{* *} \\
{[0.024]}\end{array}$ & $\begin{array}{c}\geq \mathrm{BA} \\
0.0329^{* *} \\
{[0.024]}\end{array}$ \\
\hline \multicolumn{5}{|c|}{ By Job Change in the Last Month for Individuals Older than 35} \\
\hline $\begin{array}{l}\text { SHB } \\
\text { P-Value }\end{array}$ & $\begin{array}{c}\text { New Job } \\
0.0574^{* *} \\
{[0.024]}\end{array}$ & $\begin{array}{c}\text { Same Job } \\
0.0268^{* *} \\
{[0.024]}\end{array}$ & $\begin{array}{c}\text { New Job } \\
0.0019^{* *} \\
{[0.024]}\end{array}$ & $\begin{array}{c}\text { Same Job } \\
0.0313^{* *} \\
{[0.024]}\end{array}$ \\
\hline \multicolumn{5}{|c|}{$\begin{array}{l}\text { Notes: This table provides point estimates to the synthetic control estimates illustrated } \\
\text { in Figures } 2 \text { and } 3 \text { The placebo based p-values are included in brackets below each point } \\
\text { estimate. The data used to create these estimates are annual state averages of the female } \\
\text { to male earnings ratio taken from the monthly CPS files. The synthetic control matches on } \\
\text { pre-treatment outcomes only. }\end{array}$} \\
\hline
\end{tabular}


Table A.9

The Effect of Salary History Bans on Labor Market Outcomes Aggregated Using CPS Weights

\begin{tabular}{|c|c|c|c|c|}
\hline & \multicolumn{2}{|c|}{ California } & \multicolumn{2}{|c|}{ All Treated States } \\
\hline & Female & Male & Female & Male \\
\hline \multicolumn{5}{|c|}{ Probability of Employment } \\
\hline $\begin{array}{l}\text { SHB } \\
\text { P-Value }\end{array}$ & $\begin{array}{c}0.007 \\
{[0.350]}\end{array}$ & $\begin{array}{l}-0.003 \\
{[0.350]}\end{array}$ & $\begin{array}{c}0.007 \\
{[0.800]}\end{array}$ & $\begin{array}{l}-0.003 \\
{[0.300]}\end{array}$ \\
\hline \multicolumn{5}{|c|}{ Rate of Turn Over } \\
\hline $\begin{array}{l}\text { SHB } \\
\text { P-Value }\end{array}$ & $\begin{array}{l}-0.017 \\
{[0.125]}\end{array}$ & $\begin{array}{c}-0.003^{* *} \\
{[0.025]}\end{array}$ & $\begin{array}{c}-0.029 * * \\
{[0.025]}\end{array}$ & $\begin{array}{c}0.011^{* *} \\
{[0.025]}\end{array}$ \\
\hline \multicolumn{5}{|c|}{ Hourly Wage } \\
\hline $\begin{array}{l}\text { SHB } \\
\text { P-Value }\end{array}$ & $\begin{array}{c}0.495 \\
{[0.150]}\end{array}$ & $\begin{array}{c}0.285 \\
{[0.225]}\end{array}$ & $\begin{array}{c}0.318 \\
{[0.125]}\end{array}$ & $\begin{array}{c}0.379 * * \\
{[0.025]}\end{array}$ \\
\hline \multicolumn{5}{|c|}{ Weekly Hours Worked } \\
\hline $\begin{array}{l}\text { SHB } \\
\text { P-Value }\end{array}$ & $\begin{array}{c}-0.077^{*} \\
{[0.050]}\end{array}$ & $\begin{array}{l}-0.449 \\
{[0.700]}\end{array}$ & $\begin{array}{c}-0.161^{* *} \\
{[0.025]}\end{array}$ & $\begin{array}{l}-0.325 \\
{[0.425]}\end{array}$ \\
\hline \multicolumn{5}{|c|}{ Weekly Earnings } \\
\hline $\begin{array}{l}\text { SHB } \\
\text { P-Value }\end{array}$ & $\begin{array}{c}2.853 \\
{[0.925]}\end{array}$ & $\begin{array}{l}10.312 \\
{[0.675]}\end{array}$ & $\begin{array}{c}9.385 \\
{[0.700]}\end{array}$ & $\begin{array}{r}-11.250 \\
{[0.750]}\end{array}$ \\
\hline \multicolumn{5}{|c|}{ Earnings of Individuals with All Children Older than 5} \\
\hline $\begin{array}{l}\text { SHB } \\
\text { P-Value }\end{array}$ & $\begin{array}{l}21.509 \\
{[0.200]}\end{array}$ & $\begin{array}{c}-23.078 \\
{[0.250]}\end{array}$ & $\begin{array}{l}28.838 \\
{[0.175]}\end{array}$ & $\begin{array}{c}-27.603^{*} \\
{[0.075]}\end{array}$ \\
\hline \multicolumn{5}{|c|}{$\begin{array}{l}\text { Earnings of Individuals Above Age } 35 \\
\text { Working in a Male Dominated Industries }\end{array}$} \\
\hline $\begin{array}{l}\text { SHB } \\
\text { P-Value }\end{array}$ & $\begin{array}{l}65.549 \\
{[0.325]}\end{array}$ & $\begin{array}{l}-8.127 \\
{[0.375]}\end{array}$ & $\begin{array}{l}25.449 \\
{[0.425]}\end{array}$ & $\begin{array}{c}-11.373 \\
{[0.875]}\end{array}$ \\
\hline \multicolumn{5}{|c|}{ Earnings of Individuals Above Age 35 with a New Job } \\
\hline $\begin{array}{l}\text { SHB } \\
\text { P-Value }\end{array}$ & $\begin{array}{l}308.590 \\
{[0.225]}\end{array}$ & $\begin{array}{l}117.184 \\
{[0.150]}\end{array}$ & $\begin{array}{l}100.365 \\
{[1.000]}\end{array}$ & $\begin{array}{l}47.396^{*} \\
{[0.075]}\end{array}$ \\
\hline \multicolumn{5}{|c|}{$\begin{array}{l}\text { Notes: This table provides point estimates to the synthetic control estimates for various } \\
\text { labor market outcomes. The permutation based p-values are included in brackets below each } \\
\text { point estimate. The data used to create these estimates are annual state averages of male } \\
\text { and female labor market outcomes taken from the monthly CPS files. The synthetic control } \\
\text { matches on pre-treatment outcomes only. }\end{array}$} \\
\hline
\end{tabular}


Table A.10

The Effect of Salary History Bans on Labor Market Outcomes, Demeaned Aggregated Using CPS Weights

\begin{tabular}{|c|c|c|c|c|}
\hline & \multicolumn{2}{|c|}{ California } & \multicolumn{2}{|c|}{ All Treated States } \\
\hline & Female & Male & Female & Male \\
\hline \multicolumn{5}{|c|}{ Probability of Employment } \\
\hline $\begin{array}{l}\text { SHB } \\
\text { P-Value }\end{array}$ & $\begin{array}{c}0.013^{* *} \\
{[0.024]}\end{array}$ & $\begin{array}{l}-0.005 \\
{[0.341]}\end{array}$ & $\begin{array}{l}0.013^{*} \\
{[0.098]}\end{array}$ & $\begin{array}{l}-0.005 \\
{[0.317]}\end{array}$ \\
\hline \multicolumn{5}{|c|}{ Rate of Turn Over } \\
\hline $\begin{array}{l}\text { SHB } \\
\text { P-Value }\end{array}$ & $\begin{array}{l}-0.014 \\
{[0.171]}\end{array}$ & $\begin{array}{c}-0.004^{* *} \\
{[0.024]}\end{array}$ & $\begin{array}{c}-0.028 * * \\
{[0.024]}\end{array}$ & $\begin{array}{c}0.008^{* *} \\
{[0.024]}\end{array}$ \\
\hline \multicolumn{5}{|c|}{ Hourly Wage } \\
\hline $\begin{array}{l}\text { SHB } \\
\text { P-Value }\end{array}$ & $\begin{array}{c}0.597^{* *} \\
{[0.024]}\end{array}$ & $\begin{array}{l}-0.034 \\
{[0.244]}\end{array}$ & $\begin{array}{c}0.409 * * \\
{[0.024]}\end{array}$ & $\begin{array}{c}0.071^{* *} \\
{[0.024]}\end{array}$ \\
\hline \multicolumn{5}{|c|}{ Weekly Hours Worked } \\
\hline $\begin{array}{l}\text { SHB } \\
\text { P-Value }\end{array}$ & $\begin{array}{c}-0.088^{* *} \\
{[0.024]}\end{array}$ & $\begin{array}{l}-0.120 \\
{[0.634]}\end{array}$ & $\begin{array}{c}-0.100^{* *} \\
{[0.024]}\end{array}$ & $\begin{array}{l}-0.084 \\
{[0.854]}\end{array}$ \\
\hline \multicolumn{5}{|c|}{ Weekly Earnings } \\
\hline $\begin{array}{l}\text { SHB } \\
\text { P-Value }\end{array}$ & $\begin{array}{c}42.033^{* *} \\
{[0.049]}\end{array}$ & $\begin{array}{c}2.512 \\
{[0.268]}\end{array}$ & $\begin{array}{c}34.130^{*} \\
{[0.073]}\end{array}$ & $\begin{array}{c}-12.609^{* *} \\
{[0.024]}\end{array}$ \\
\hline \multicolumn{5}{|c|}{ Earnings of Individuals with All Children Older than 5} \\
\hline $\begin{array}{l}\text { SHB } \\
\text { P-Value }\end{array}$ & $\begin{array}{c}30.991^{* *} \\
{[0.024]}\end{array}$ & $\begin{array}{c}-21.224 \\
{[0.244]}\end{array}$ & $\begin{array}{c}39.450^{* *} \\
{[0.049]}\end{array}$ & $\begin{array}{c}-18.868^{*} \\
{[0.098]}\end{array}$ \\
\hline \multicolumn{5}{|c|}{$\begin{array}{l}\text { Earnings of Individuals Above Age } 35 \\
\text { Working in a Male Dominated Industries }\end{array}$} \\
\hline $\begin{array}{l}\text { SHB } \\
\text { P-Value }\end{array}$ & $\begin{array}{l}87.968 \\
{[0.146]}\end{array}$ & $\begin{array}{c}-15.450^{* *} \\
{[0.024]}\end{array}$ & $\begin{array}{c}32.889^{* *} \\
{[0.024]}\end{array}$ & $\begin{array}{c}-10.624^{* *} \\
{[0.024]}\end{array}$ \\
\hline \multicolumn{5}{|c|}{ Earnings of Individuals Above Age 35 with a New Job } \\
\hline $\begin{array}{l}\text { SHB } \\
\text { P-Value }\end{array}$ & $\begin{array}{r}210.927 \\
{[0.171]}\end{array}$ & $\begin{array}{l}103.288 \\
{[0.195]}\end{array}$ & $\begin{array}{c}100.776^{* *} \\
{[0.049]}\end{array}$ & $\begin{array}{c}96.634^{* *} \\
{[0.024]}\end{array}$ \\
\hline \multicolumn{5}{|c|}{$\begin{array}{l}\text { Notes: This table provides point estimates to the synthetic control estimates for various } \\
\text { labor market outcomes. The permutation based p-values are included in brackets below each } \\
\text { point estimate. The data used to create these estimates are annual state averages of male } \\
\text { and female labor market outcomes taken from the monthly CPS files. The synthetic control } \\
\text { matches on pre-treatment outcomes only. }\end{array}$} \\
\hline
\end{tabular}




\section{Appendix B - Figures for Synthetic Controls}

\section{Figure B.1}

Synthetic Control Donor States and Placebo Tests

\section{California}

(a) Contributors to Synthetic Control

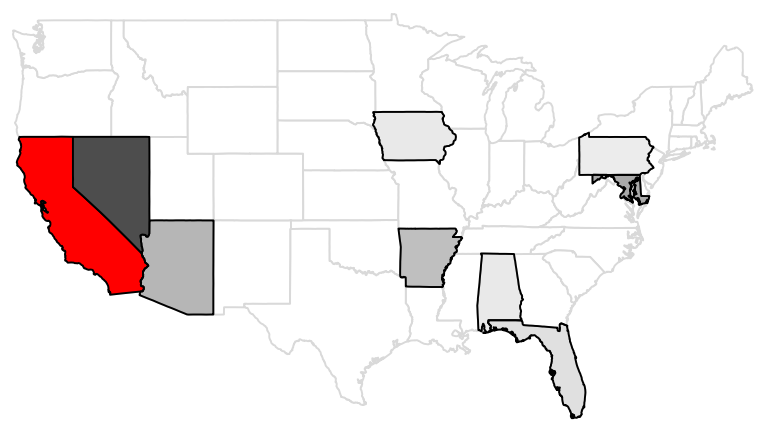

(b) Placebo Synthetic Controls

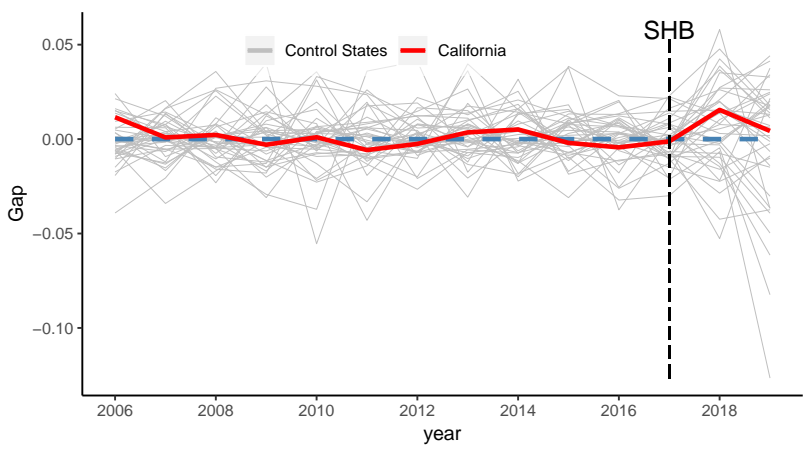

(c) MSPE Ratio Distribution

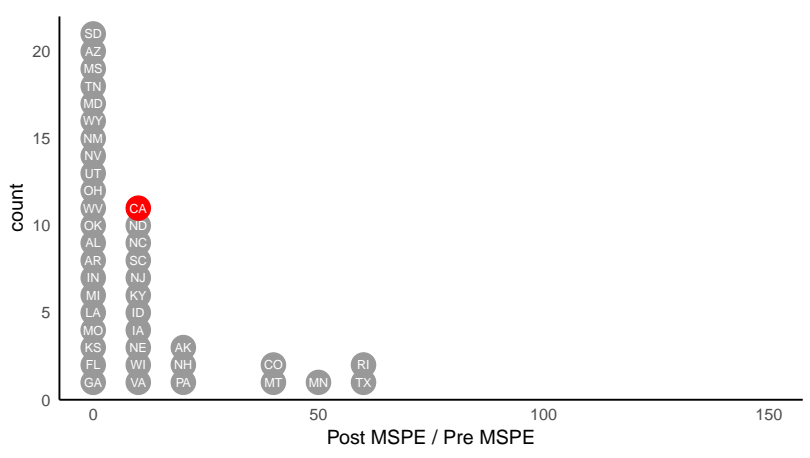

All Treated States

(d) Contributors to Synthetic Control

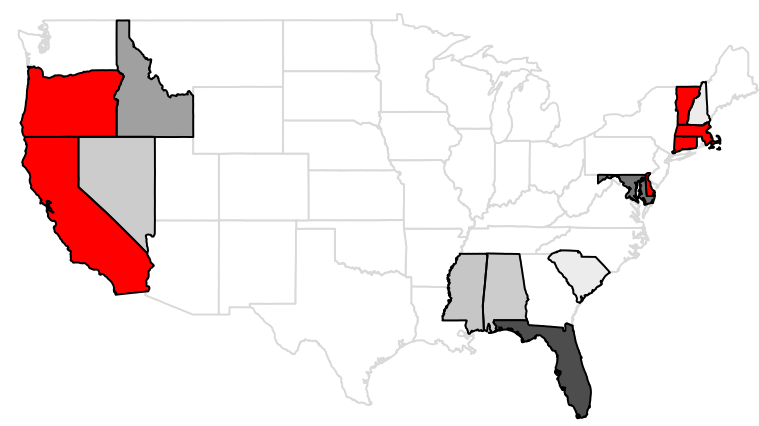

(e) Placebo Synthetic Controls

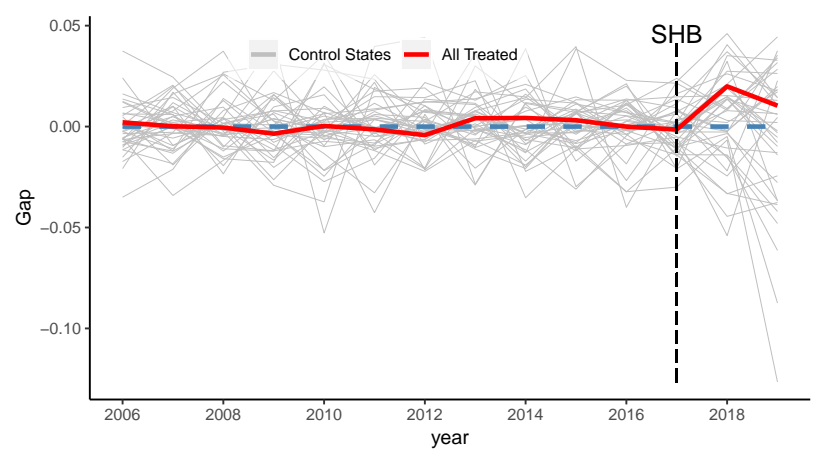

(f) MSPE Ratio Distribution

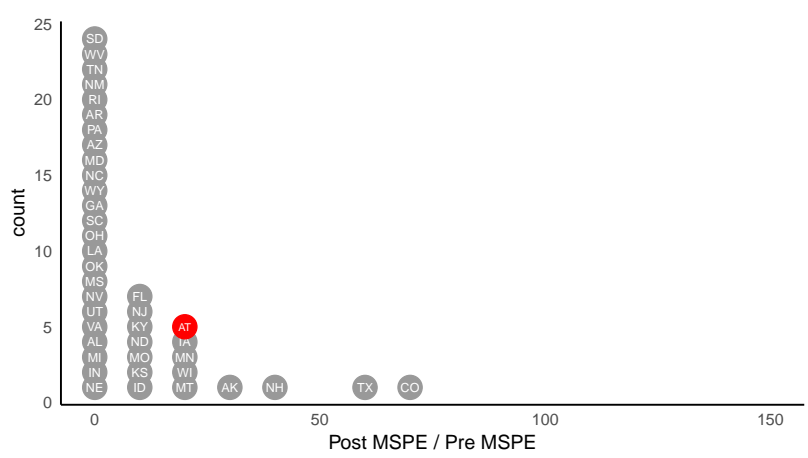

Notes: Panels (a) and (d) of this figure illustrate the composition of synthetic California and all treated states respectively. Each donor state is highlighted in grey and shaded by its contribution to the synthetic control. Panels (b) and (e) illustrate the difference between each treated state and its synthetic counterpart (red) compared to the each control states deviation from it's own synthetic counterpart (grey). Panels (c) and (f) illustrate the distributions of mean square prediction error ratio for each state. 


\section{B.1 California: Level Data}

Figure B.2

California Synthetic Control for Female to Male Earnings Ratio

(a) Synthetic versus Actual

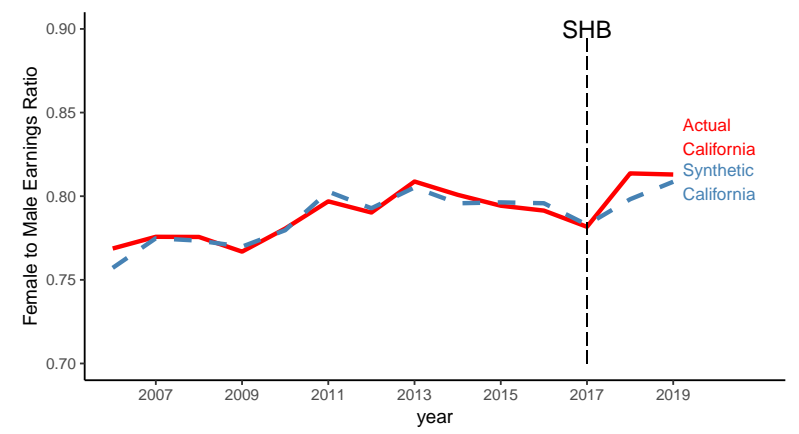

(c) Placebo Synthetic Controls

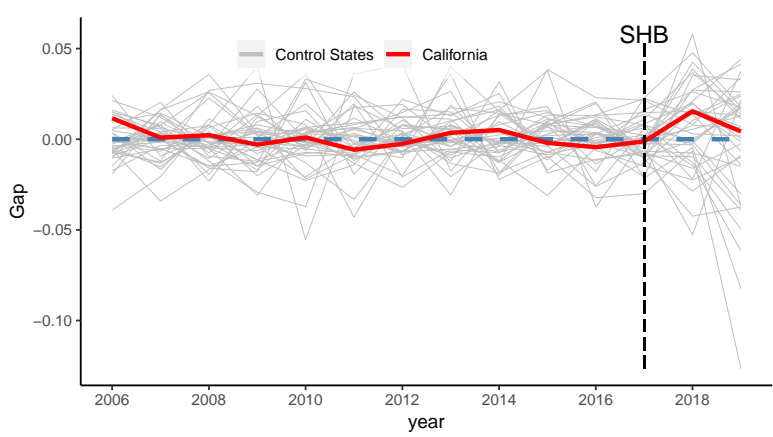

(e) Cross Validation

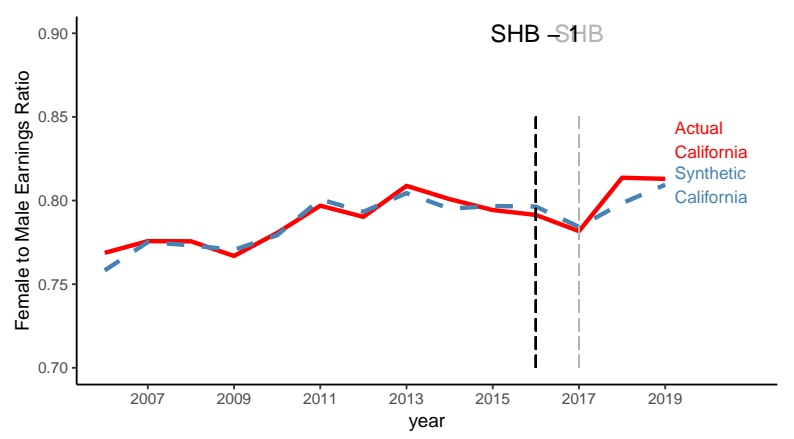

(b) Contributors to Synthetic Control

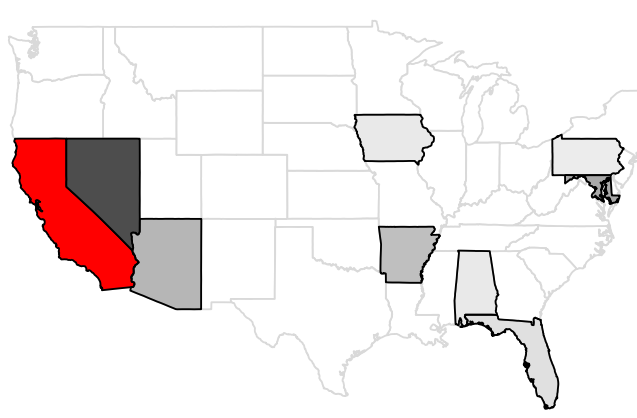

(d) MSPE Ratio Distribution

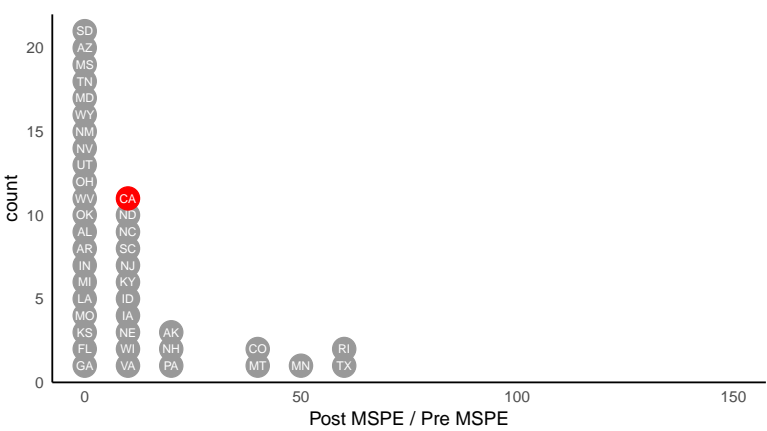

(f) Cross Validation

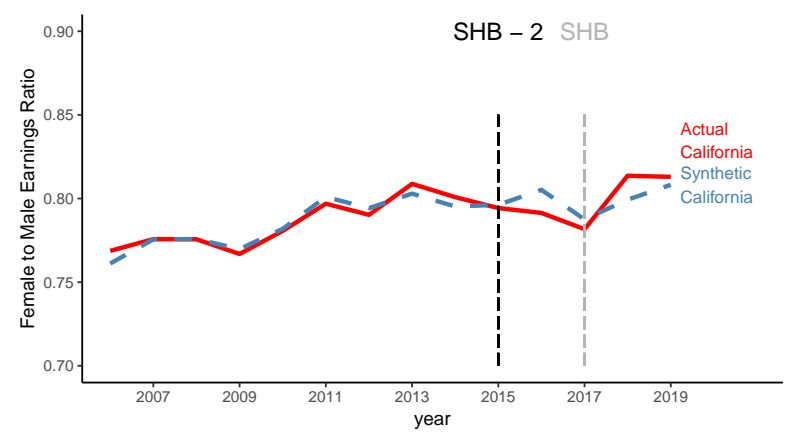




\section{Figure B.3}

California Synthetic Control for Female to Male Earnings Ratio Among Female Dominated Industries

(a) Synthetic versus Actual

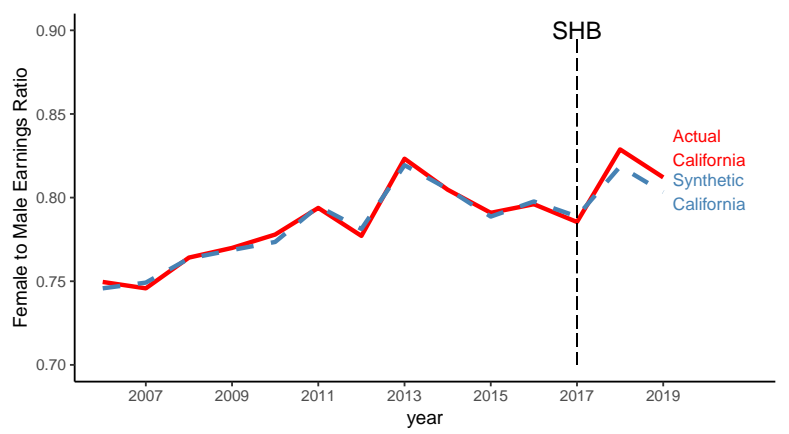

(c) Placebo Synthetic Controls

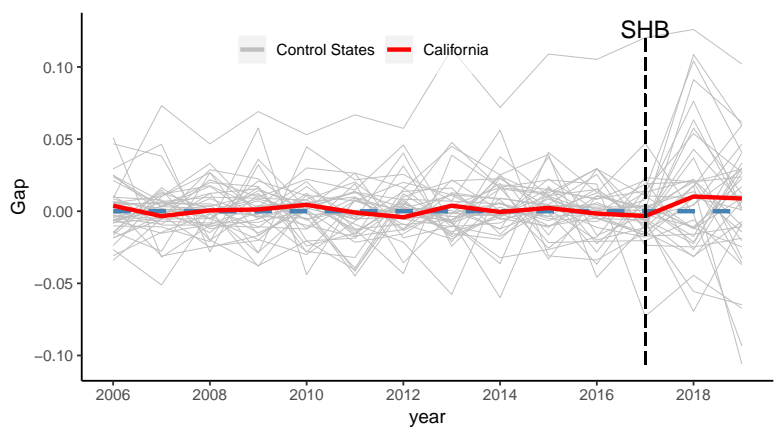

(e) Cross Validation

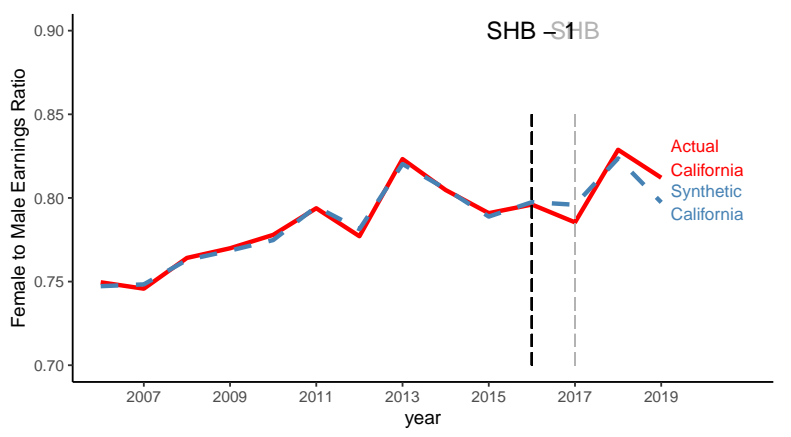

(b) Contributors to Synthetic Control

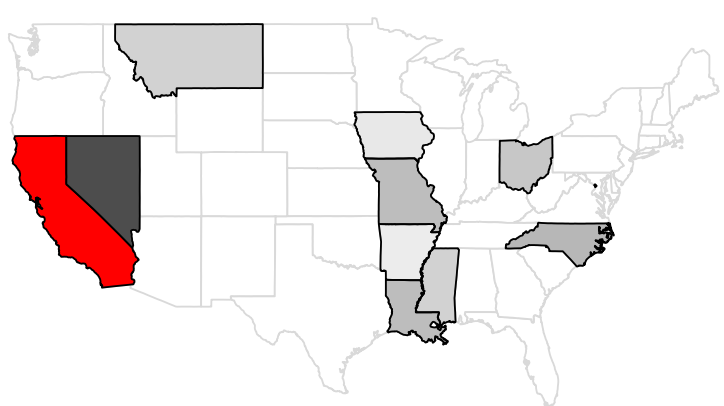

(d) MSPE Ratio Distribution

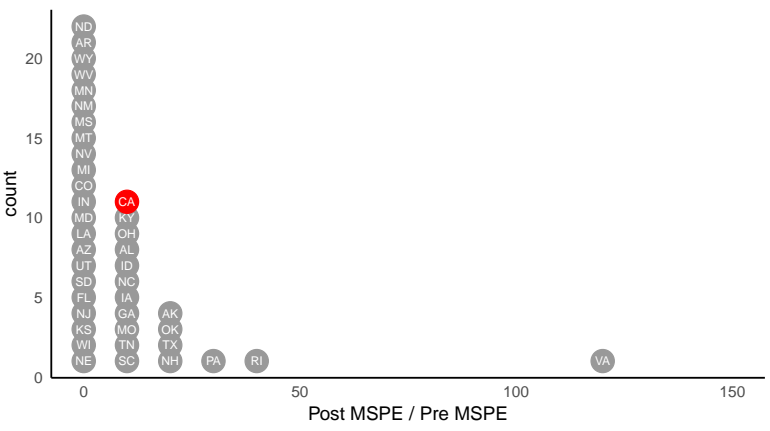

(f) Cross Validation

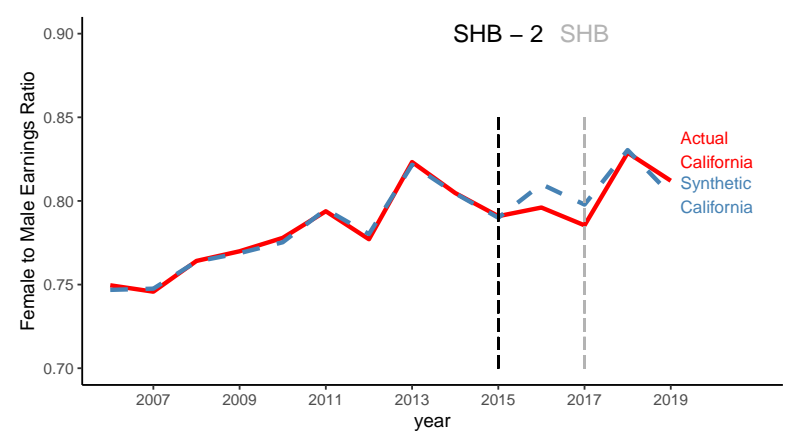




\section{Figure B.4}

California Synthetic Control for Female to Male Earnings Ratio Among Male Dominated Industries

(a) Synthetic versus Actual

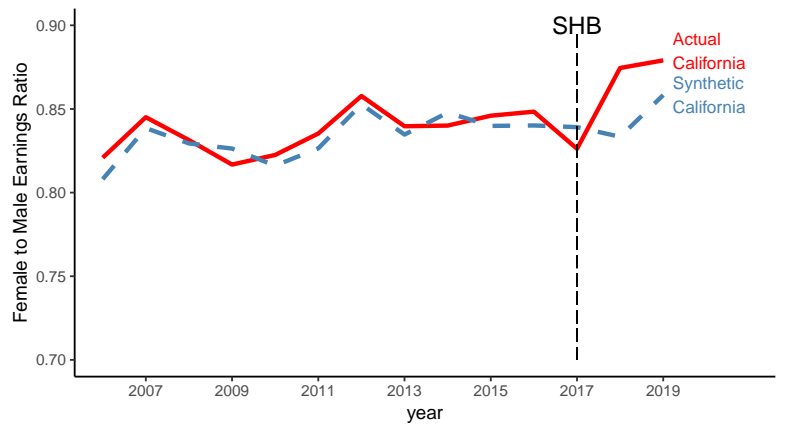

(c) Placebo Synthetic Controls

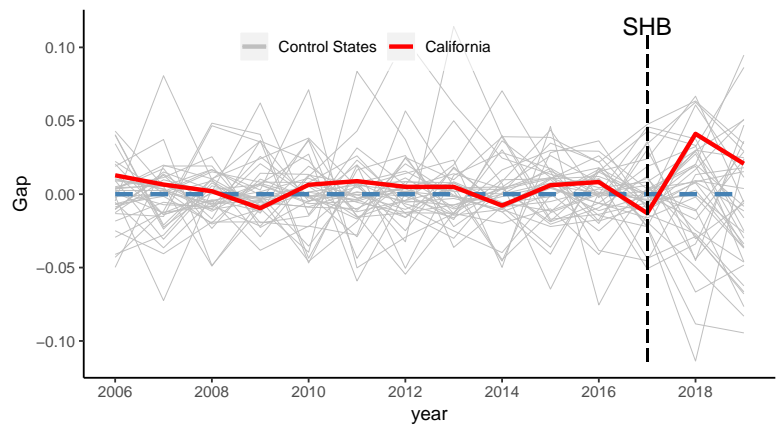

(e) Cross Validation

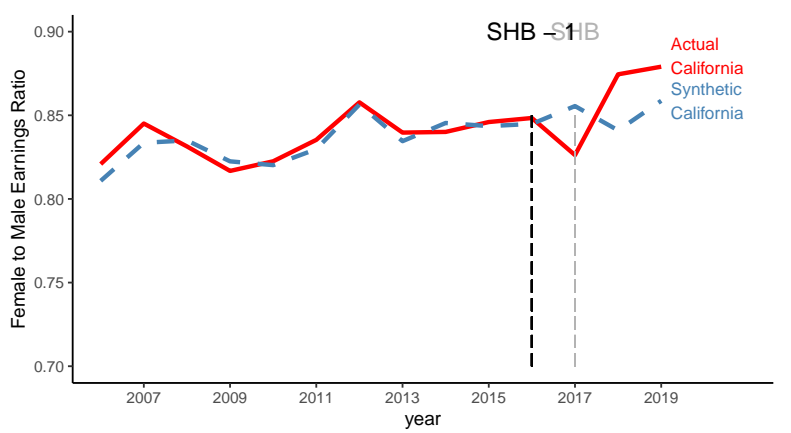

(b) Contributors to Synthetic Control

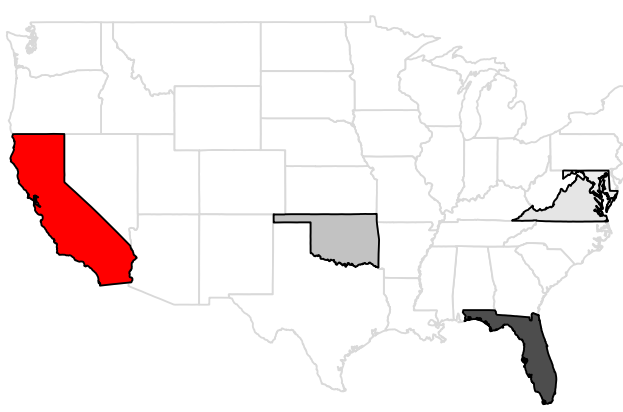

(d) MSPE Ratio Distribution

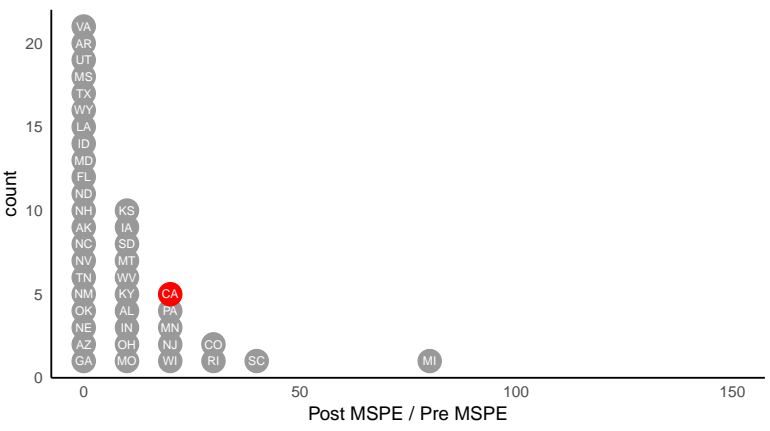

(f) Cross Validation

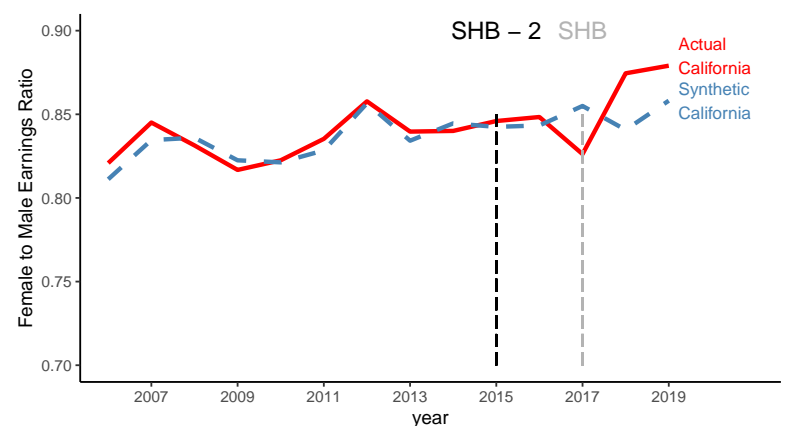




\section{Figure B.5}

California Synthetic Control for Female to Male Earnings Ratio Among Individuals with Children less than 5 Years Old

(a) Synthetic versus Actual

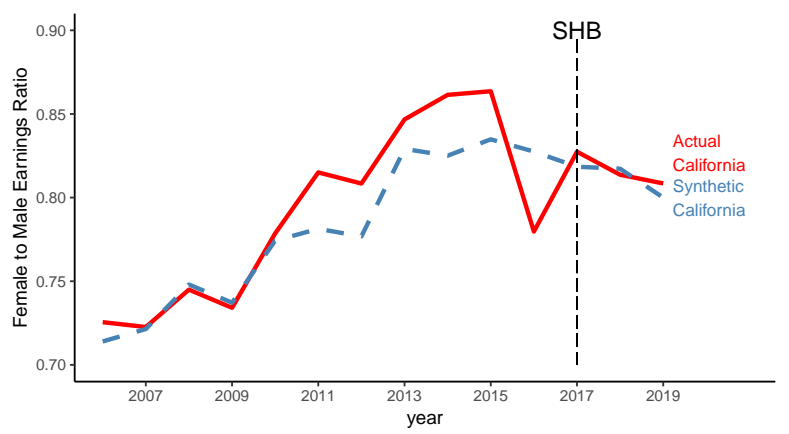

(c) Placebo Synthetic Controls

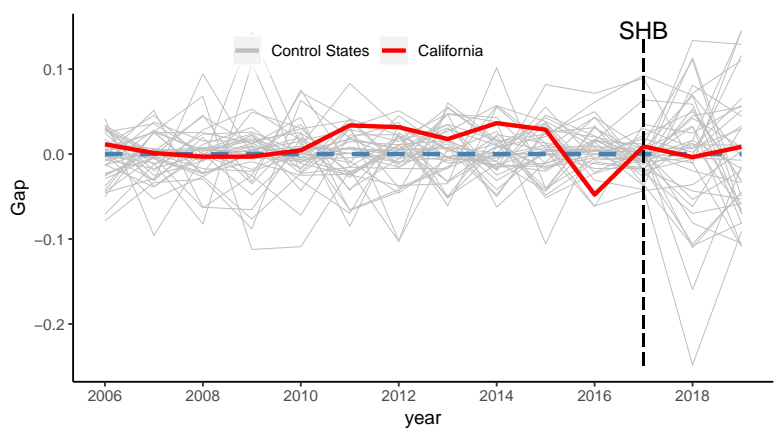

(e) Cross Validation

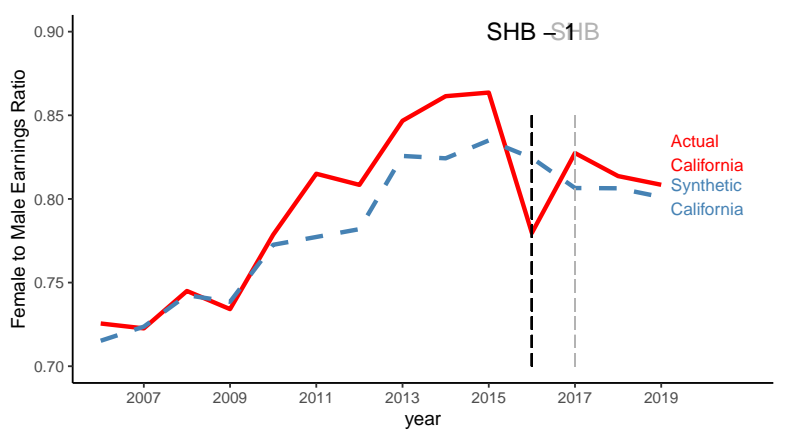

(b) Contributors to Synthetic Control

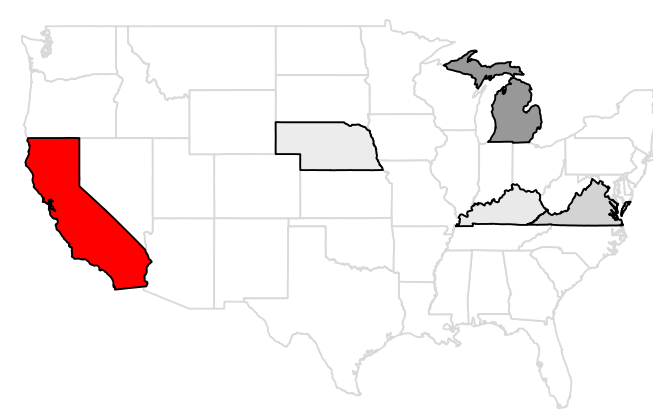

(d) MSPE Ratio Distribution

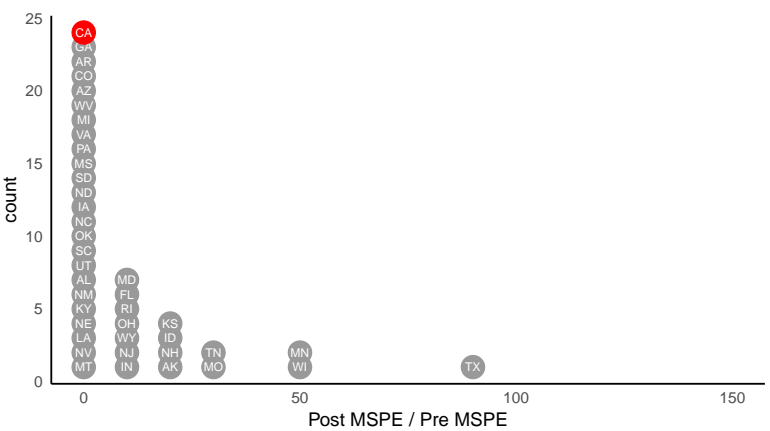

(f) Cross Validation

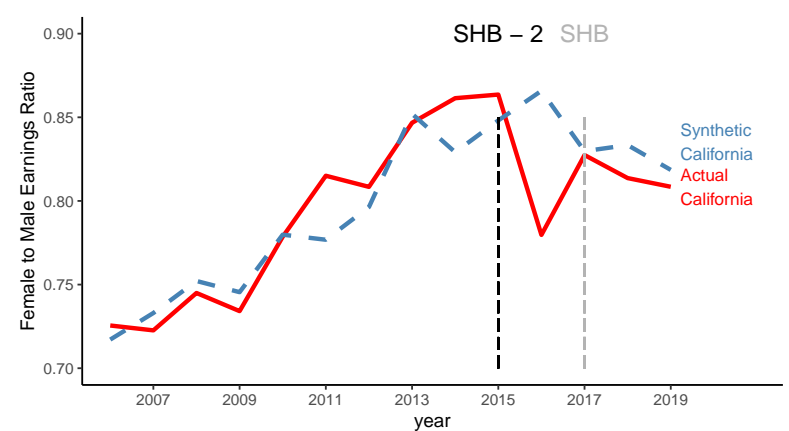




\section{Figure B.6}

California Synthetic Control for Female to Male Earnings Ratio Among Individuals with Children above 5 Years Old

(a) Synthetic versus Actual

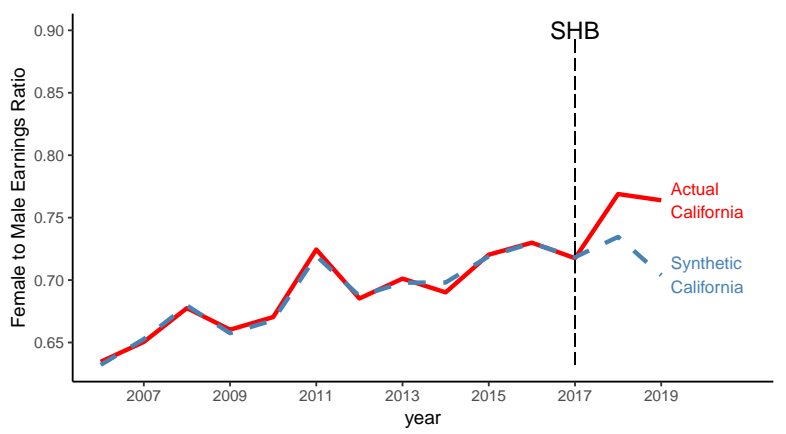

(c) Placebo Synthetic Controls

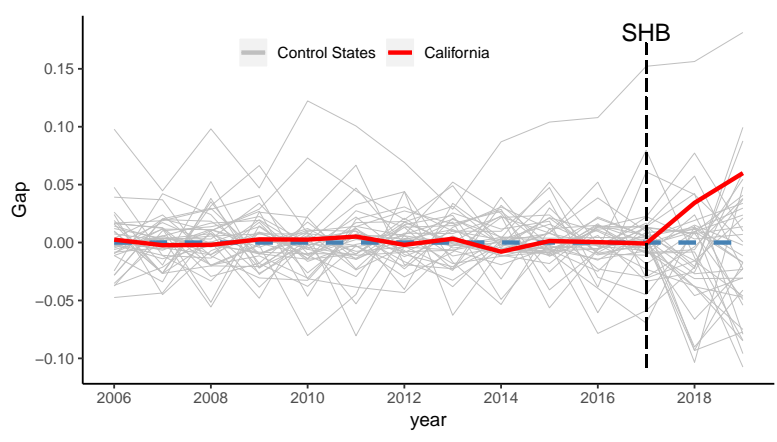

(e) Cross Validation

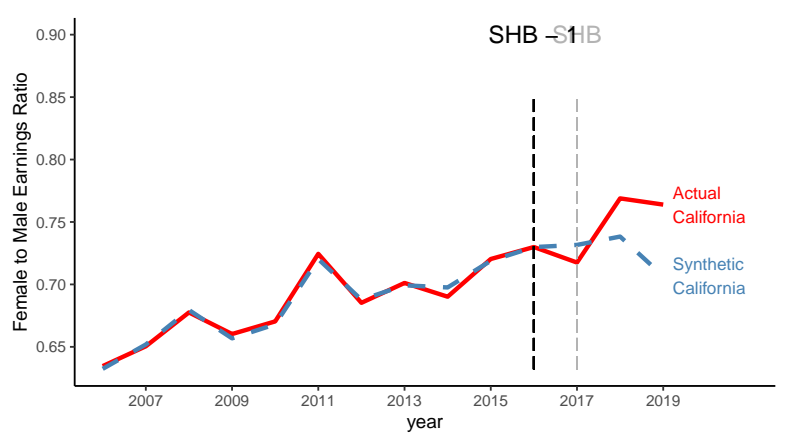

(b) Contributors to Synthetic Control

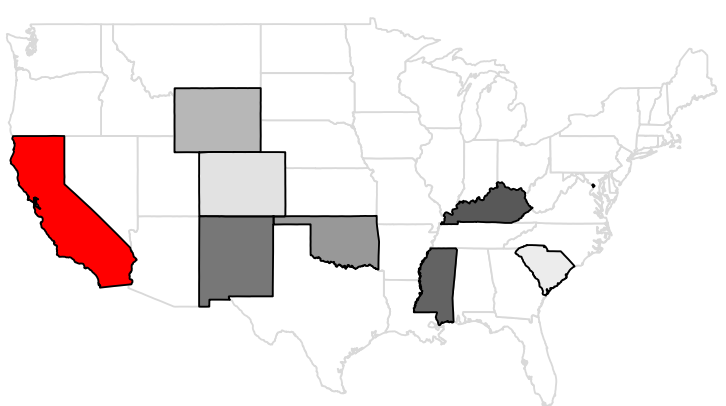

(d) MSPE Ratio Distribution

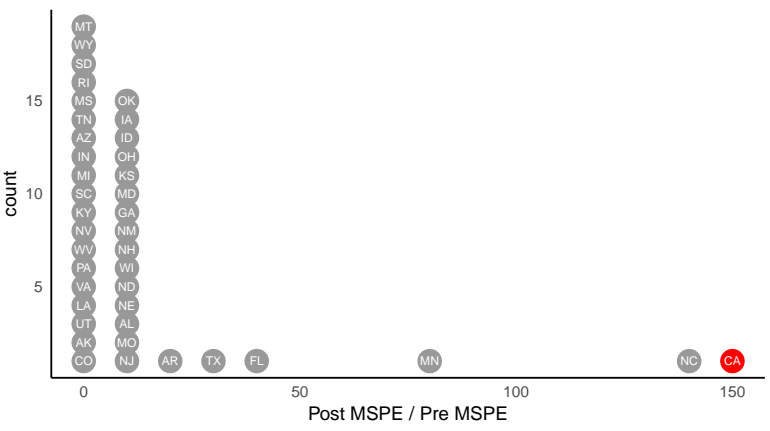

(f) Cross Validation

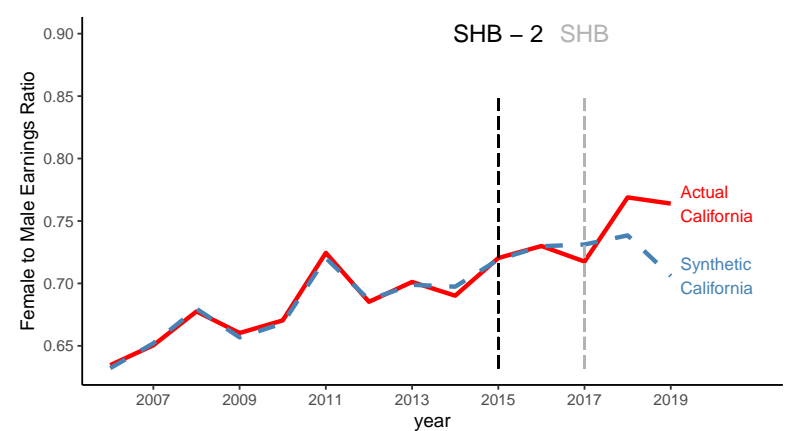




\section{Figure B.7}

California Synthetic Control for Female to Male Earnings Ratio Among Individuals Above Age 35

(a) Synthetic versus Actual

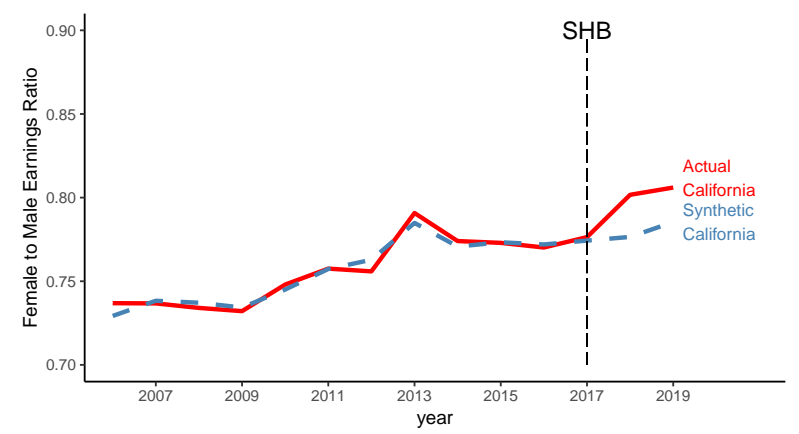

(c) Placebo Synthetic Controls

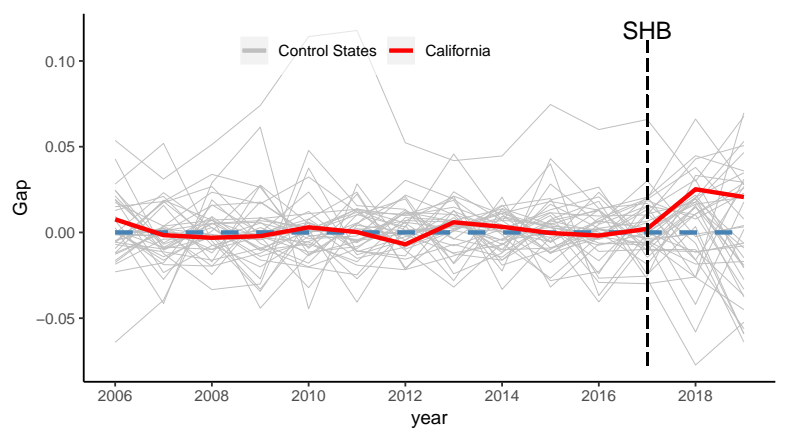

(e) Cross Validation

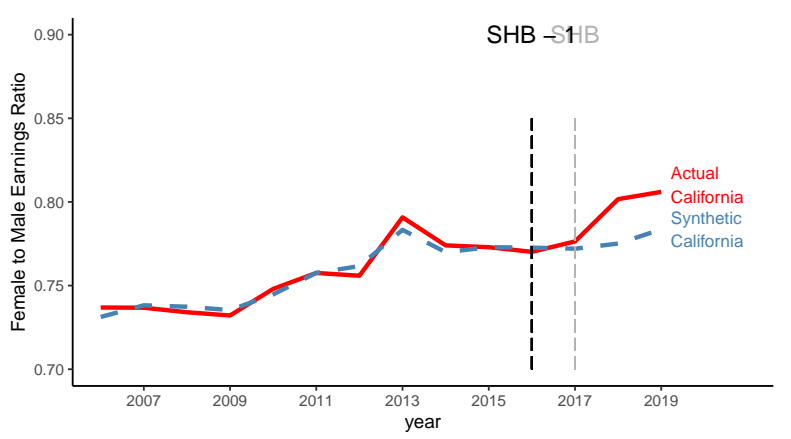

(b) Contributors to Synthetic Control

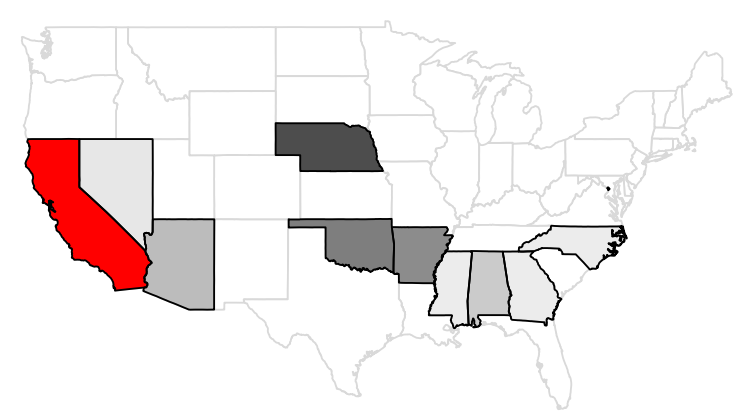

(d) MSPE Ratio Distribution

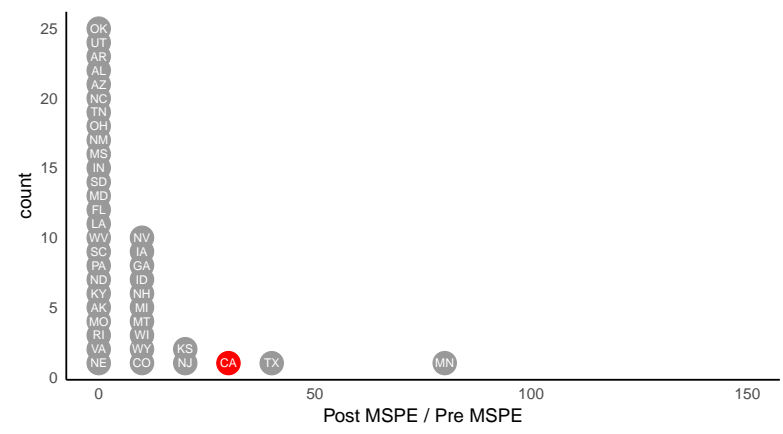

(f) Cross Validation

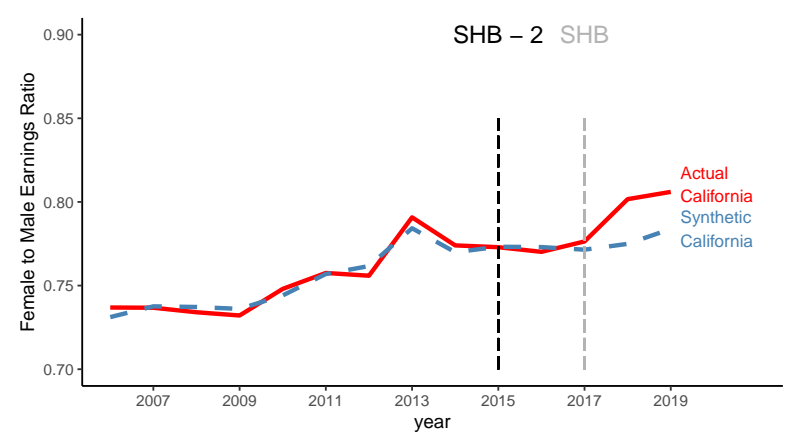




\section{Figure B.8}

California Synthetic Control for Female to Male Earnings Ratio Among Individuals Below Age 35

(a) Synthetic versus Actual

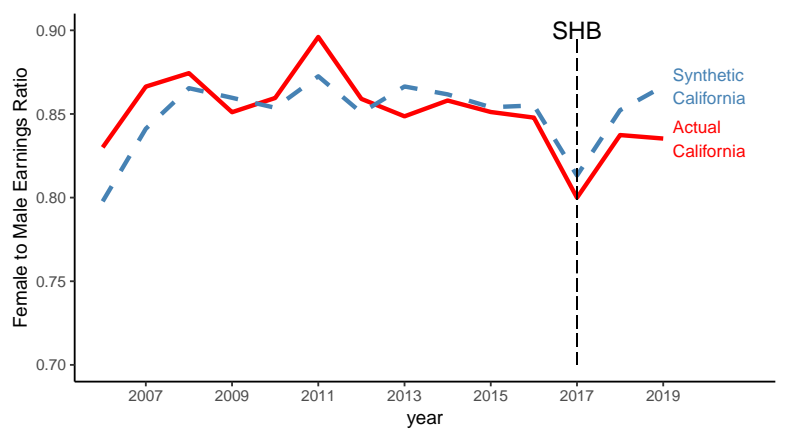

(c) Placebo Synthetic Controls

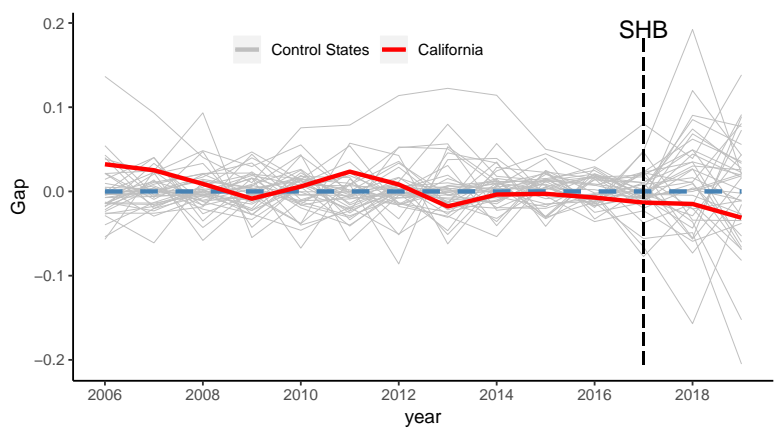

(e) Cross Validation

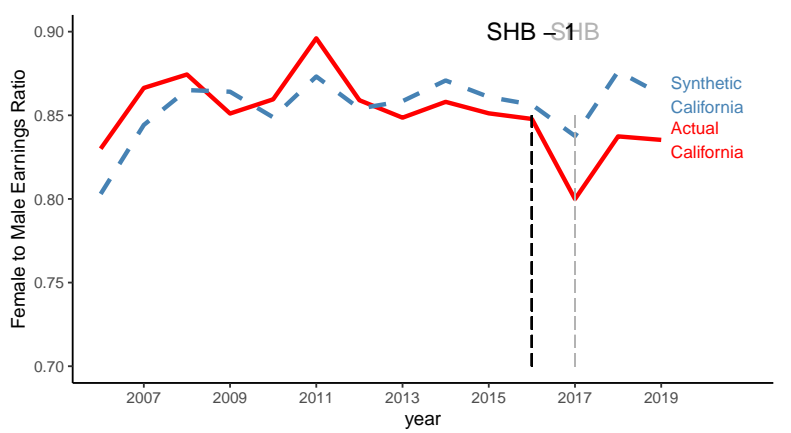

(b) Contributors to Synthetic Control

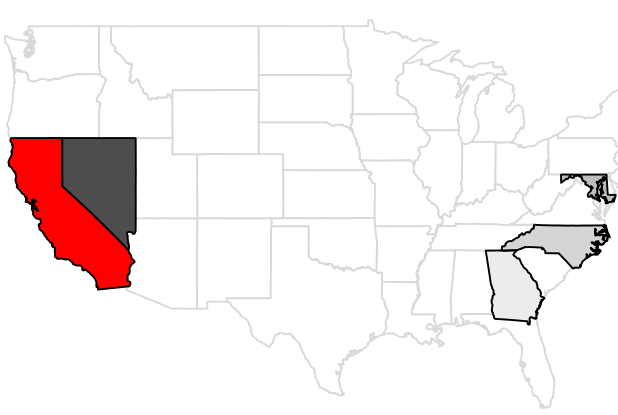

(d) MSPE Ratio Distribution

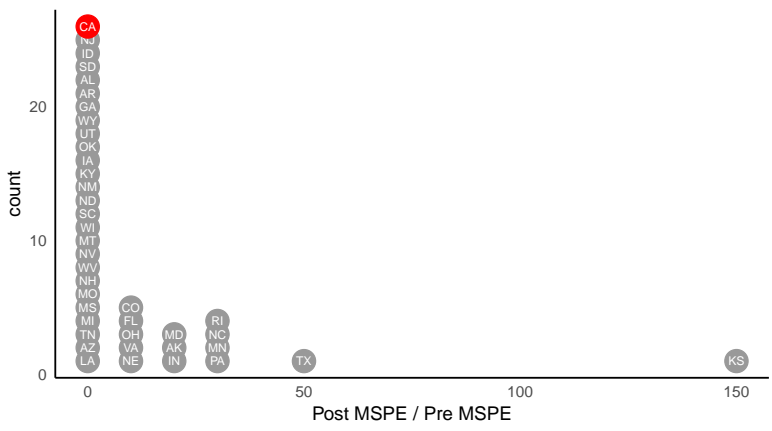

(f) Cross Validation

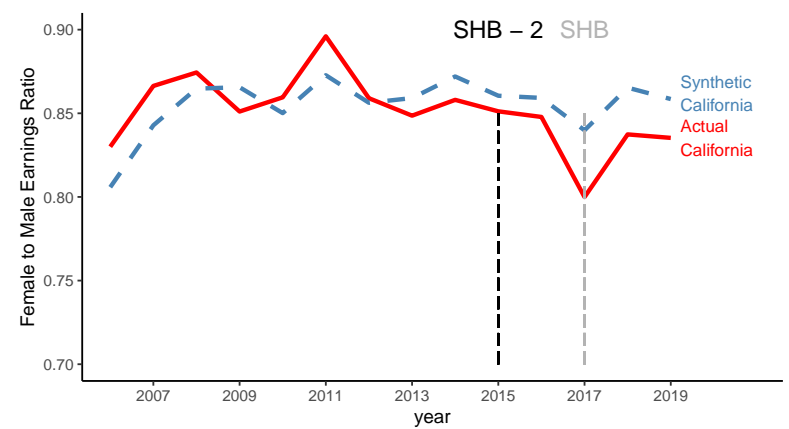




\section{Figure B.9}

California Synthetic Control for Female to Male Earnings Ratio Among Individuals With a New Job

(a) Synthetic versus Actual

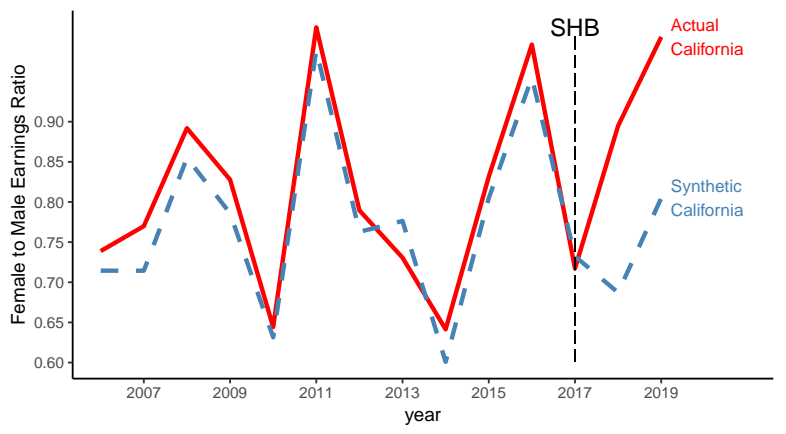

(c) Placebo Synthetic Controls

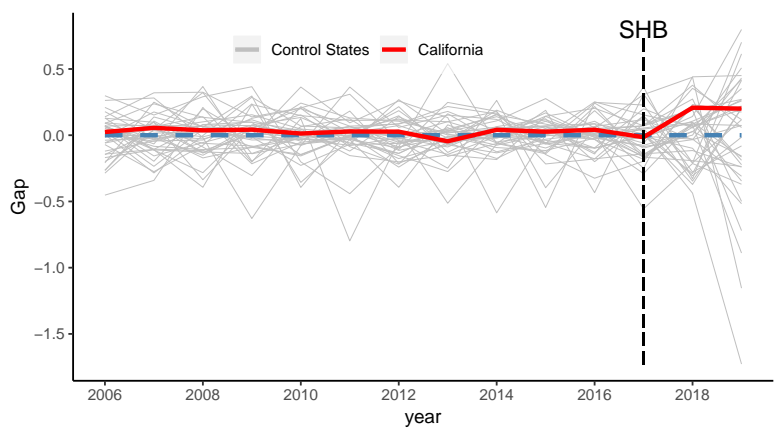

(e) Cross Validation

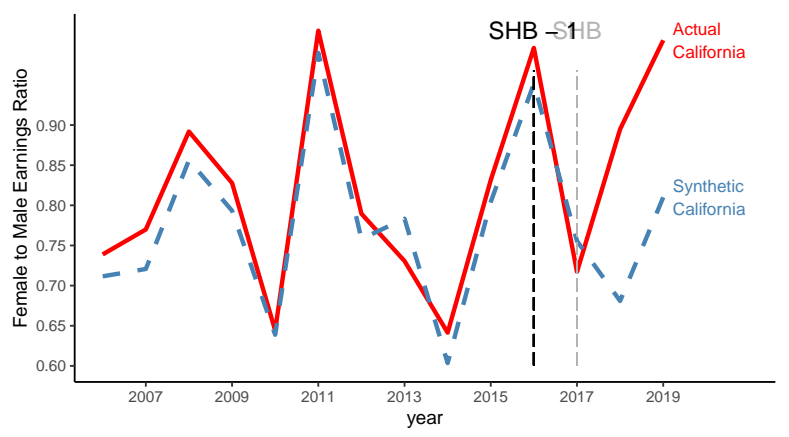

(b) Contributors to Synthetic Control

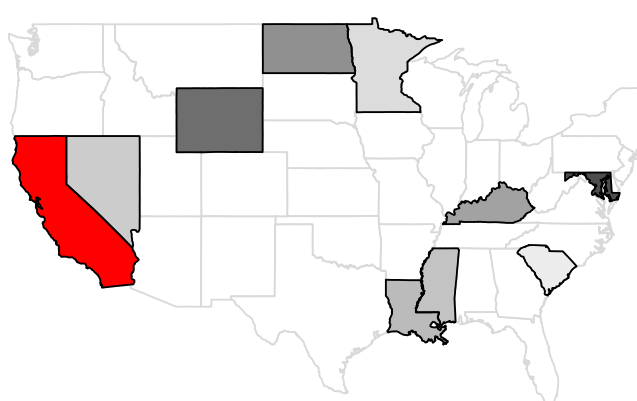

(d) MSPE Ratio Distribution

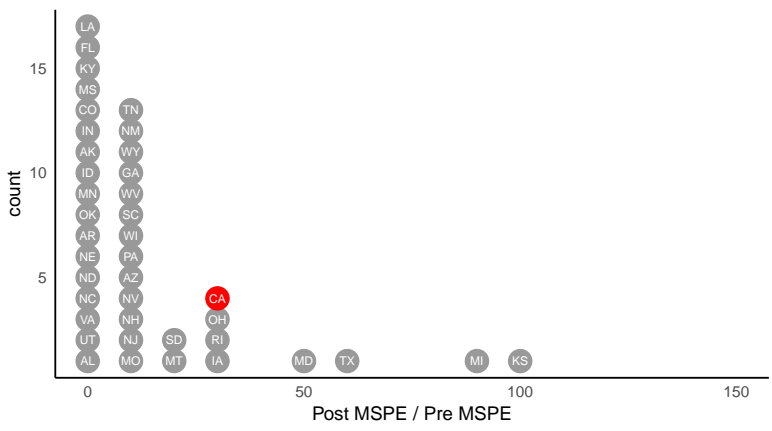

(f) Cross Validation

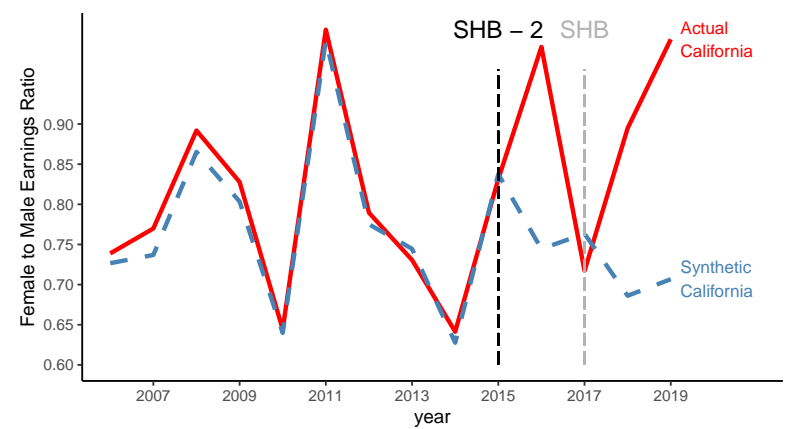




\section{Figure B.10}

California Synthetic Control for Female to Male Earnings Ratio Among Individuals With the Same Job

(a) Synthetic versus Actual

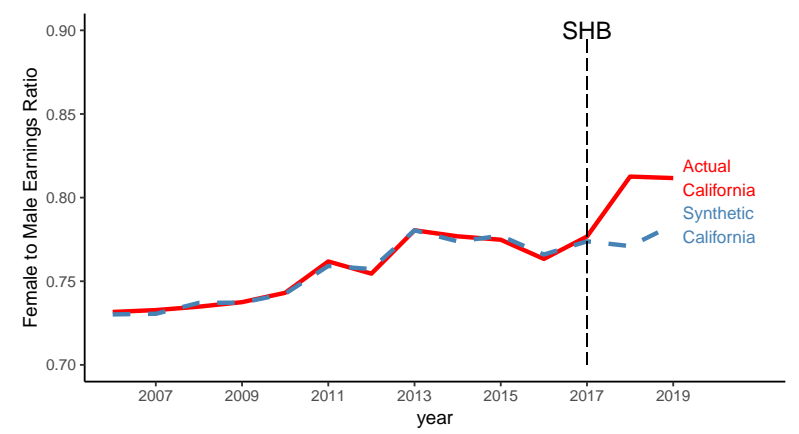

(c) Placebo Synthetic Controls

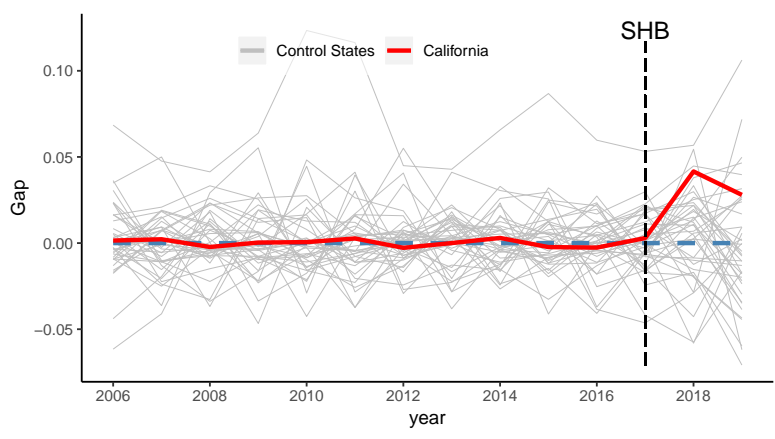

(e) Cross Validation

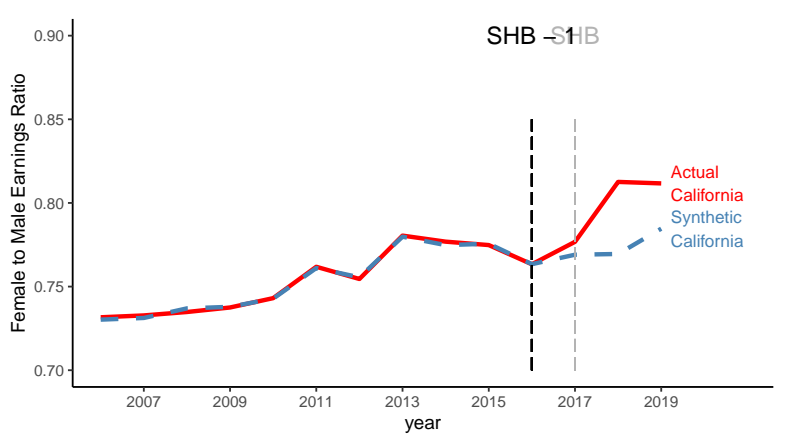

(b) Contributors to Synthetic Control

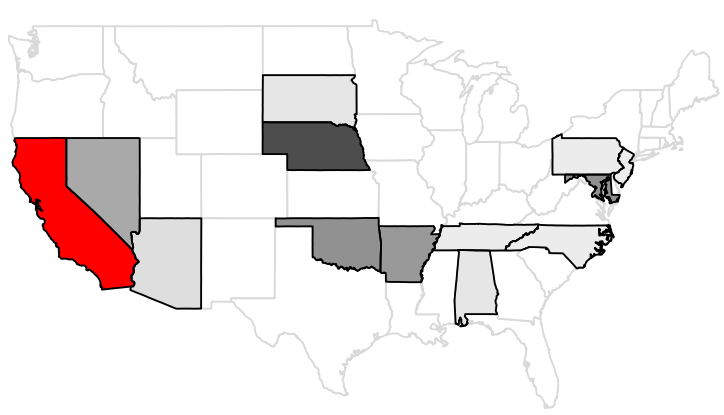

(d) MSPE Ratio Distribution

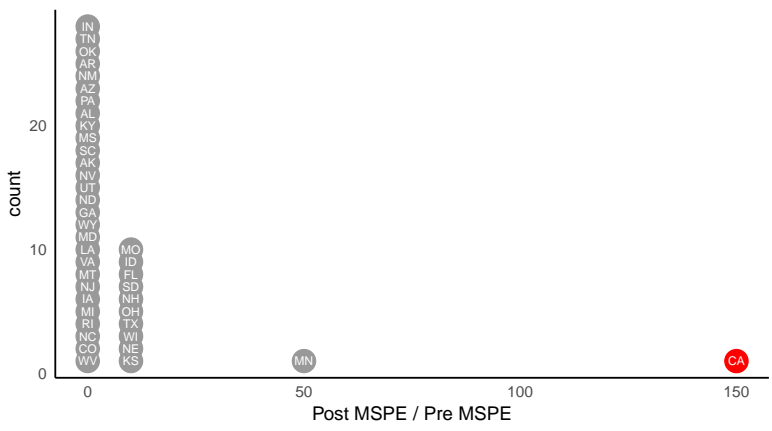

(f) Cross Validation

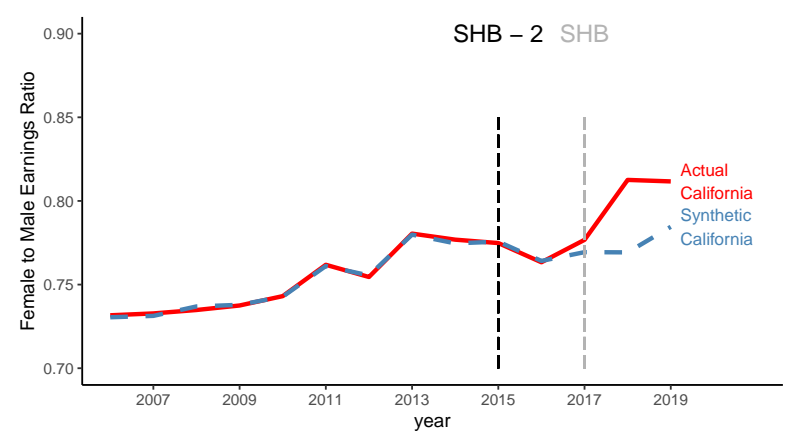




\section{B.2 California: Demeaned Data}

Figure B.11

California Synthetic Control for Female to Male Earnings Ratio, Demeaned

(a) Synthetic versus Actual

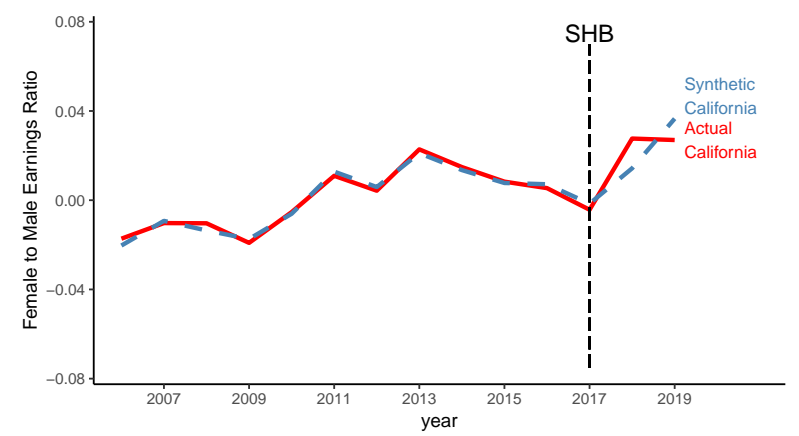

(c) Placebo Synthetic Controls

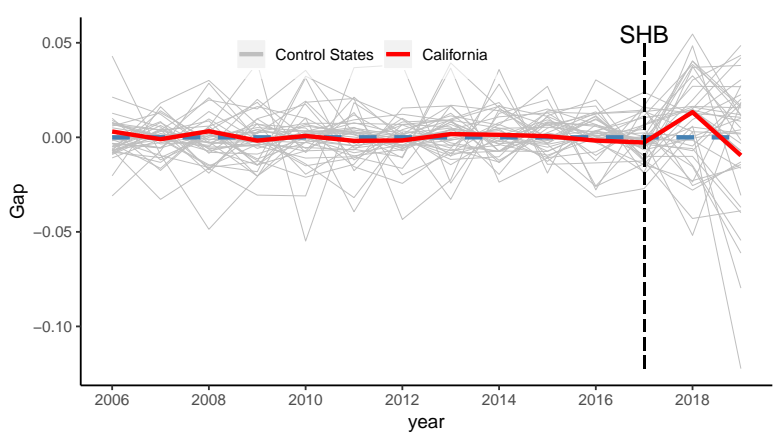

(e) Cross Validation

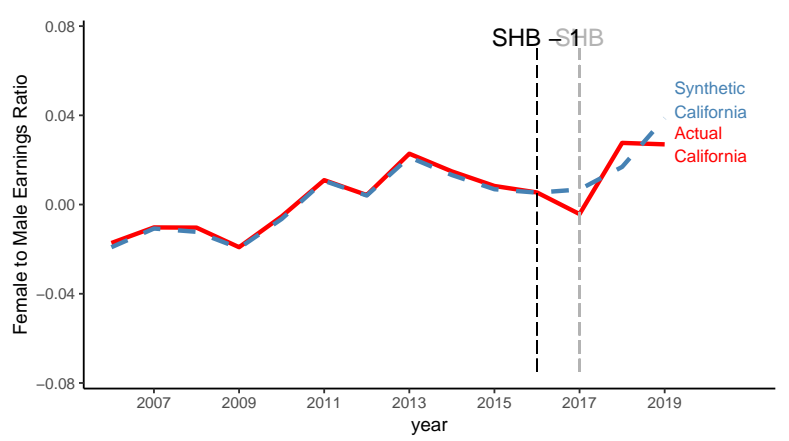

(b) Contributors to Synthetic Control

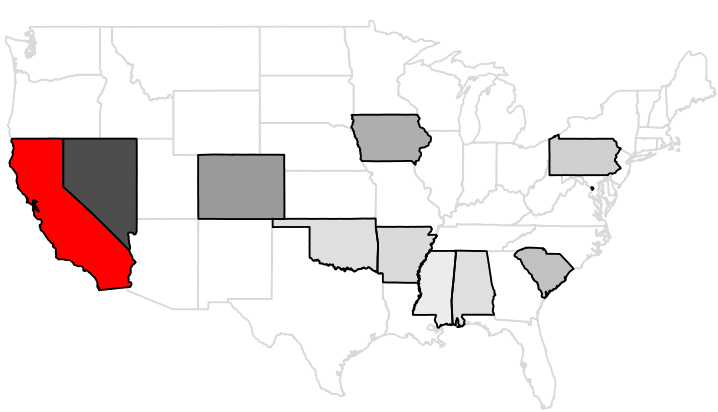

(d) MSPE Ratio Distribution

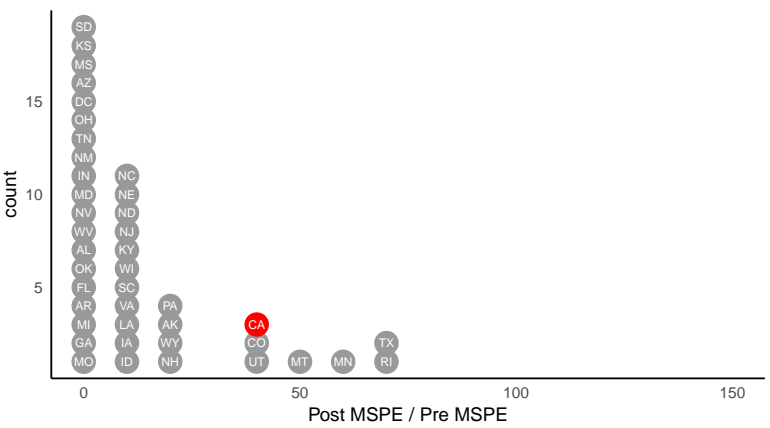

(f) Cross Validation

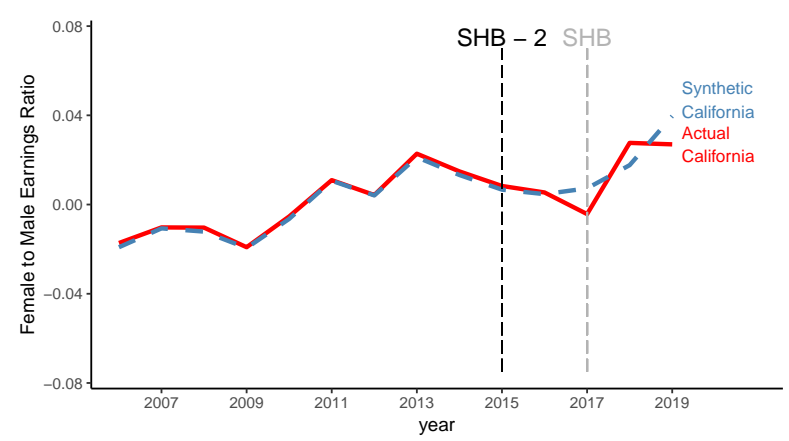




\section{Figure B.12}

California Synthetic Control for Female to Male Earnings Ratio Among Female Dominated Industries, Demeaned

(a) Synthetic versus Actual

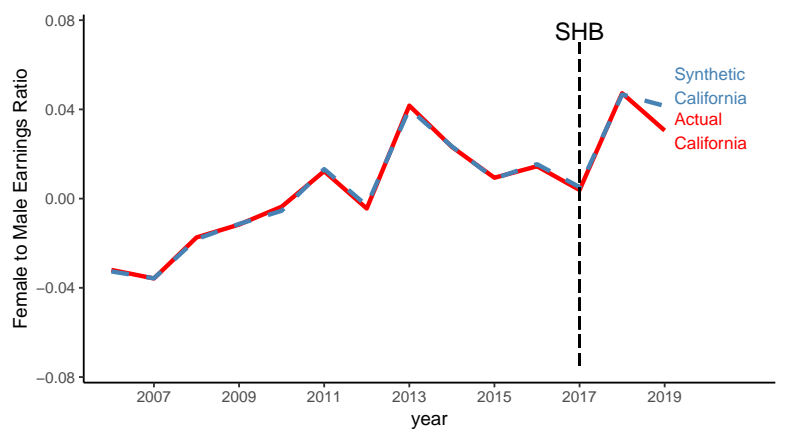

(c) Placebo Synthetic Controls

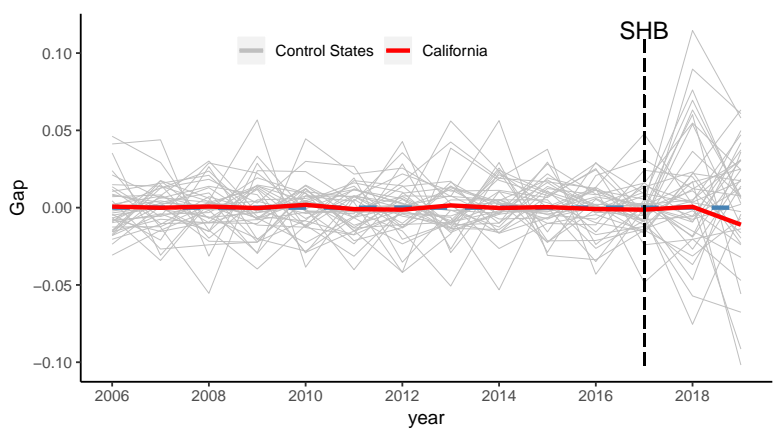

(e) Cross Validation

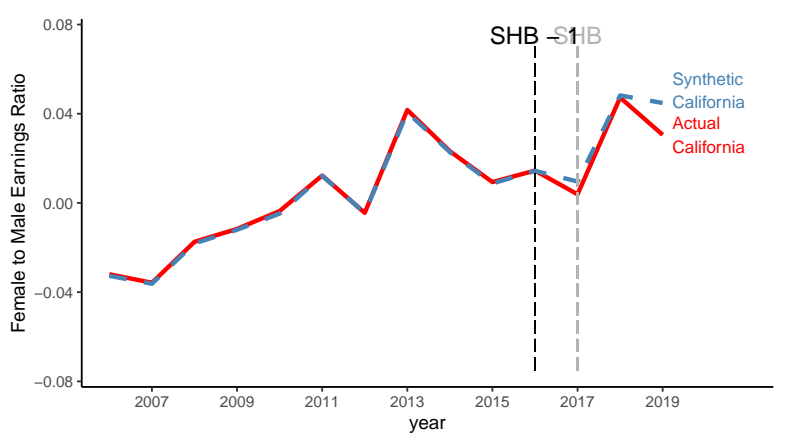

(b) Contributors to Synthetic Control

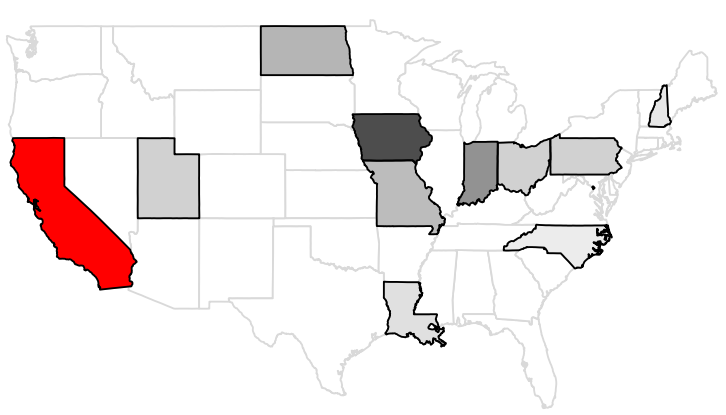

(d) MSPE Ratio Distribution

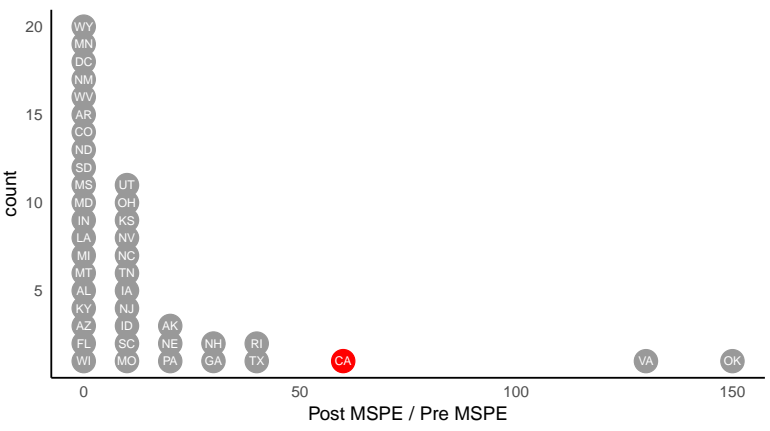

(f) Cross Validation

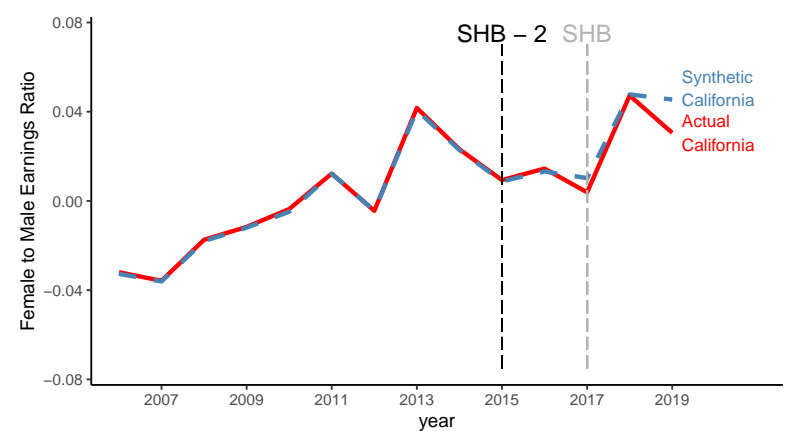




\section{Figure B.13}

California Synthetic Control for Female to Male Earnings Ratio Among Male Dominated Industries, Demeaned

(a) Synthetic versus Actual

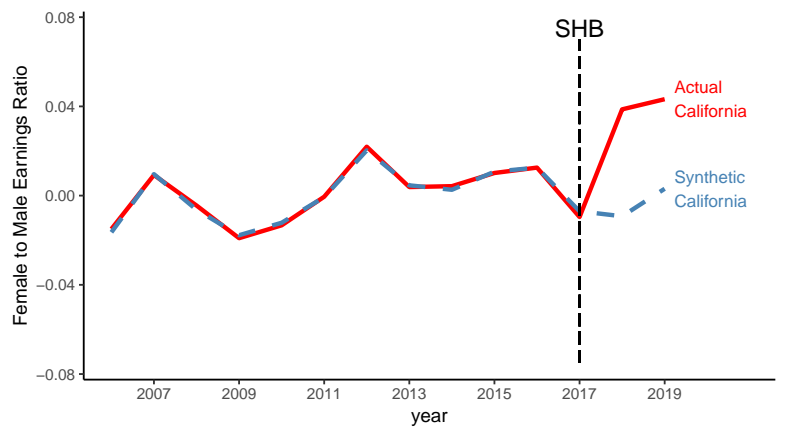

(c) Placebo Synthetic Controls

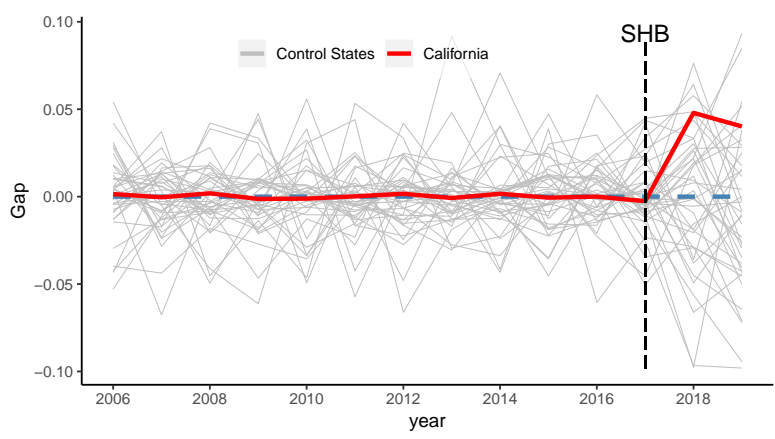

(e) Cross Validation

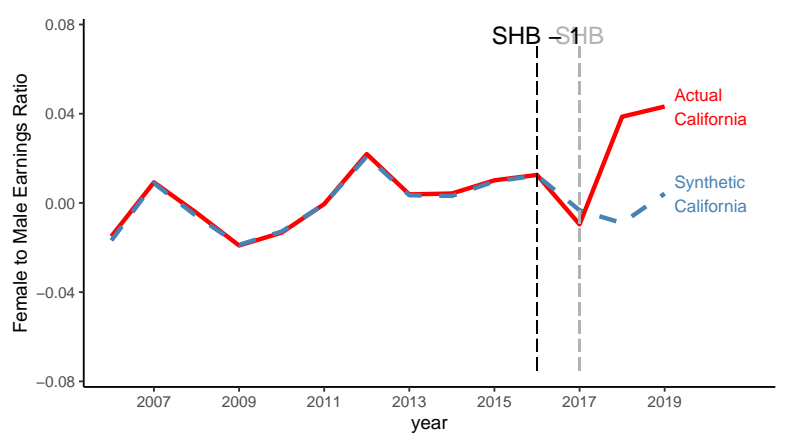

(b) Contributors to Synthetic Control

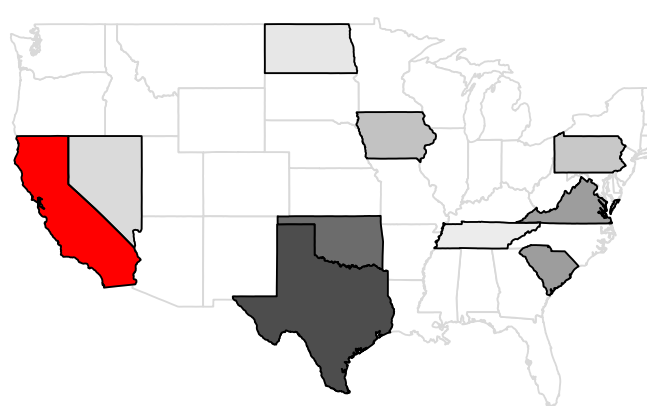

(d) MSPE Ratio Distribution

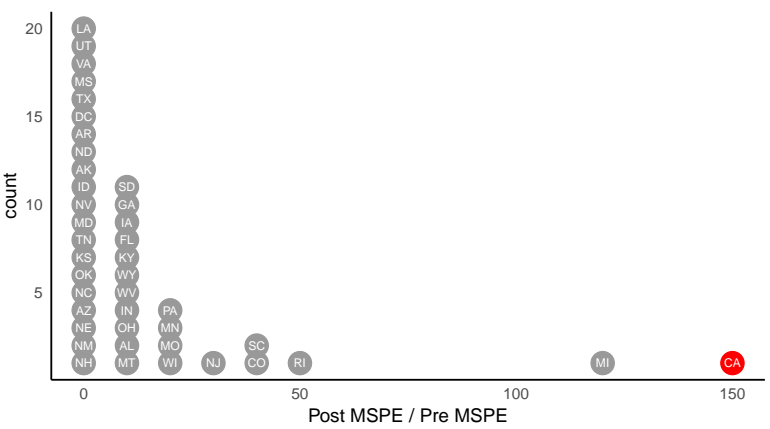

(f) Cross Validation

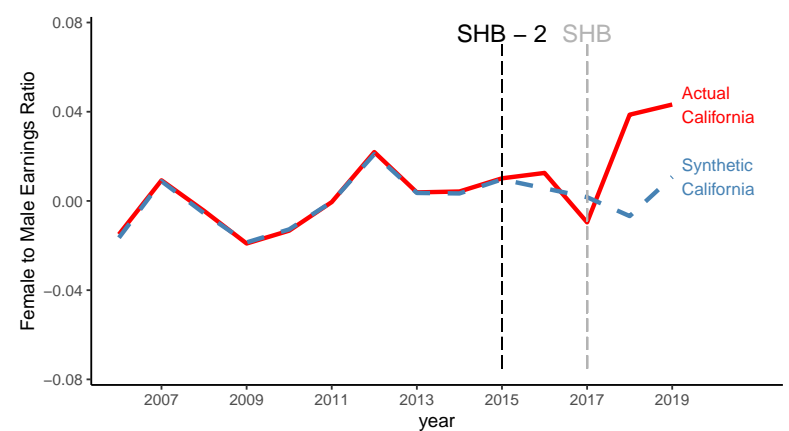




\section{Figure B.14}

California Synthetic Control for Female to Male Earnings Ratio Among Individuals with Children less than 5 Years Old, Demeaned

(a) Synthetic versus Actual

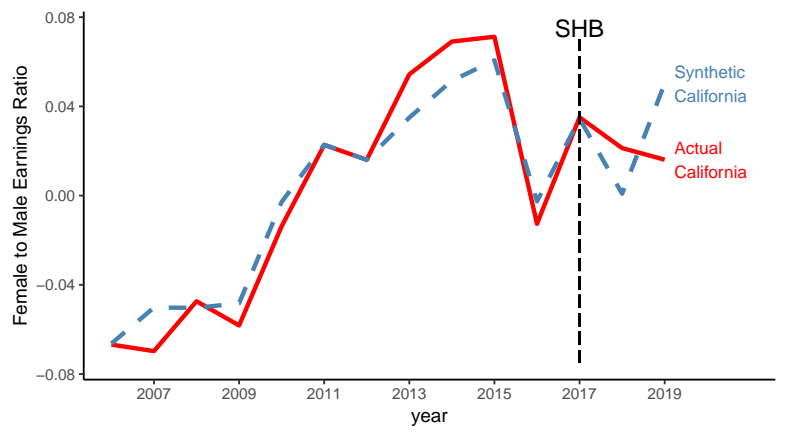

(c) Placebo Synthetic Controls

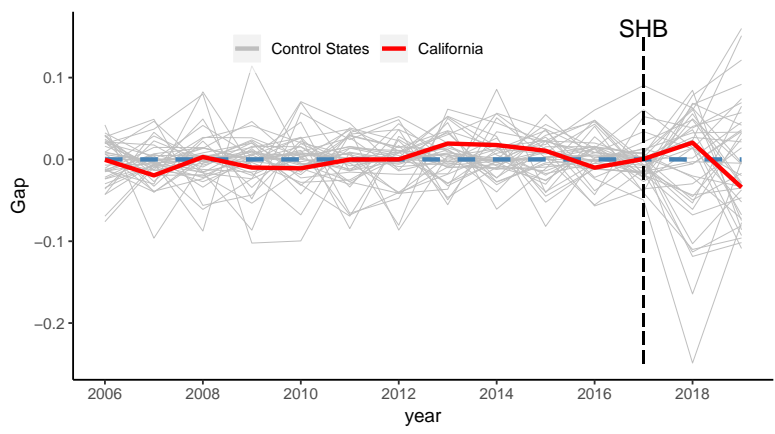

(e) Cross Validation

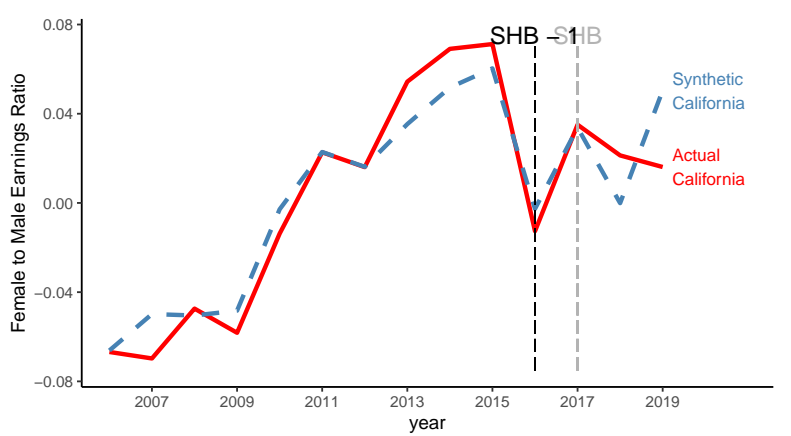

(b) Contributors to Synthetic Control

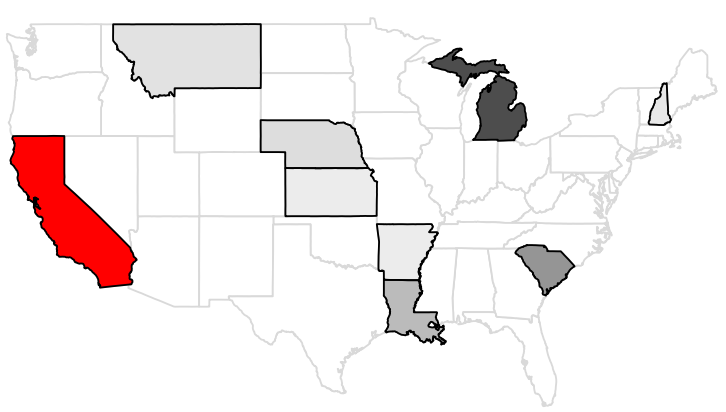

(d) MSPE Ratio Distribution

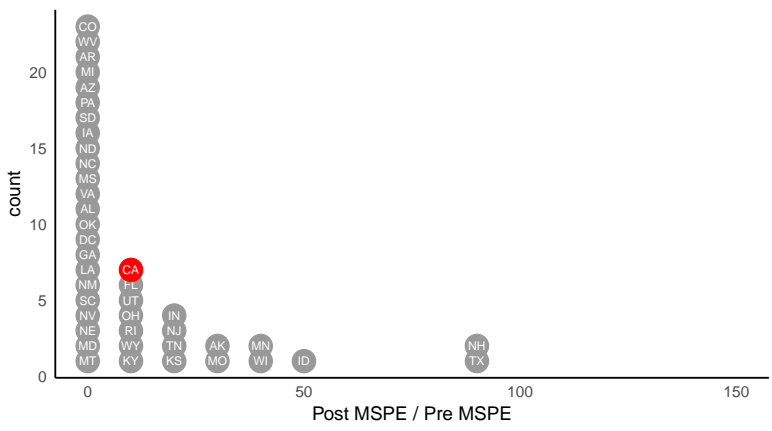

(f) Cross Validation

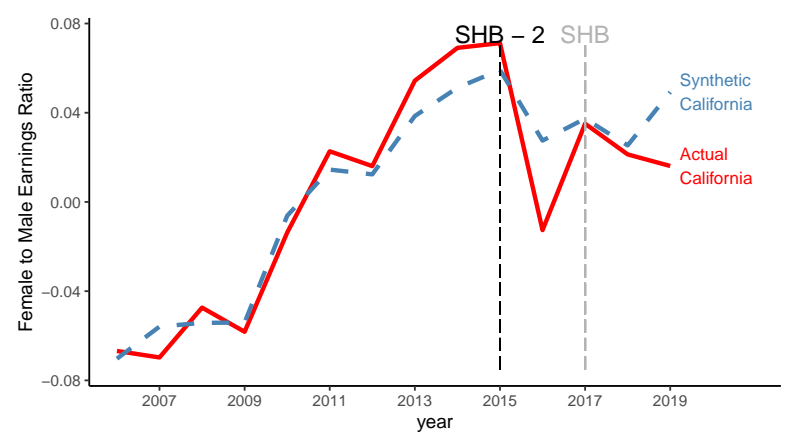




\section{Figure B.15}

California Synthetic Control for Female to Male Earnings Ratio Among Individuals with Children above 5 Years Old, Demeaned

(a) Synthetic versus Actual

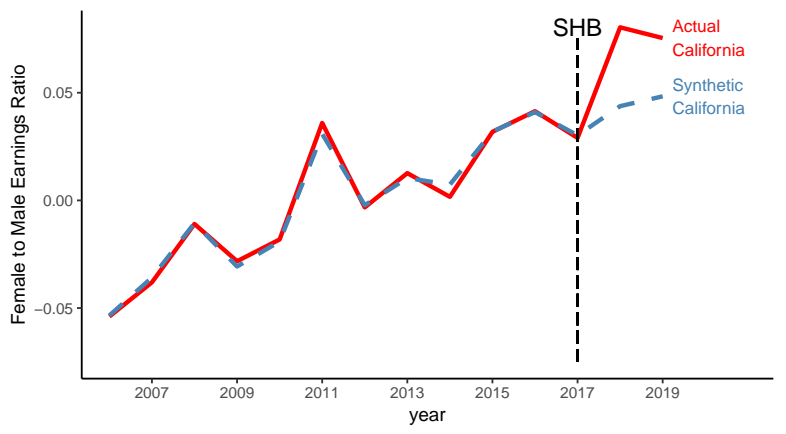

(c) Placebo Synthetic Controls

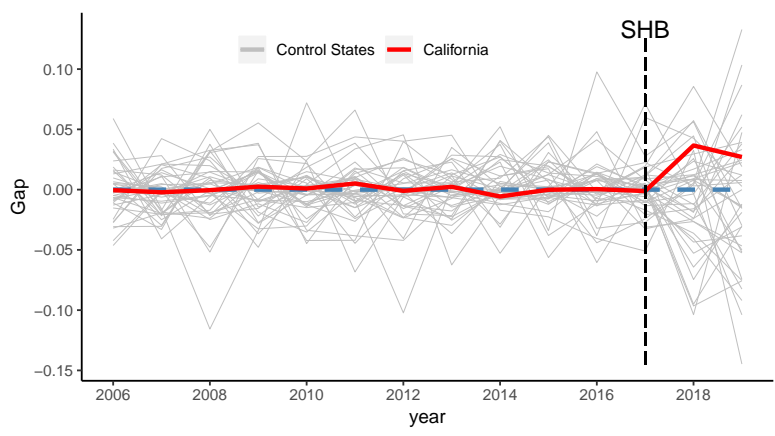

(e) Cross Validation

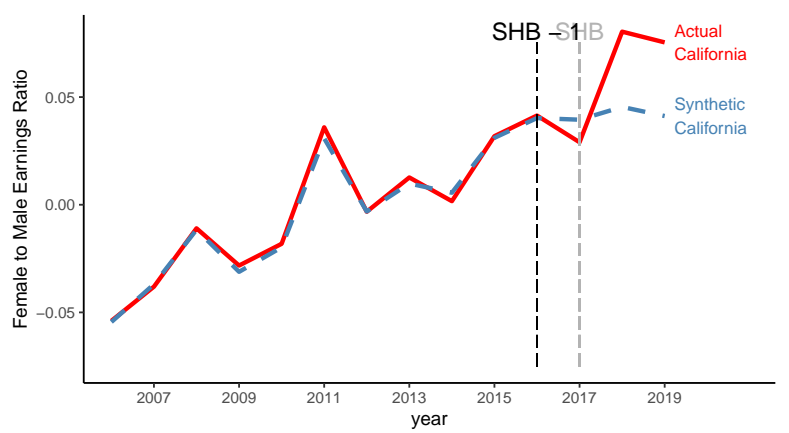

(b) Contributors to Synthetic Control

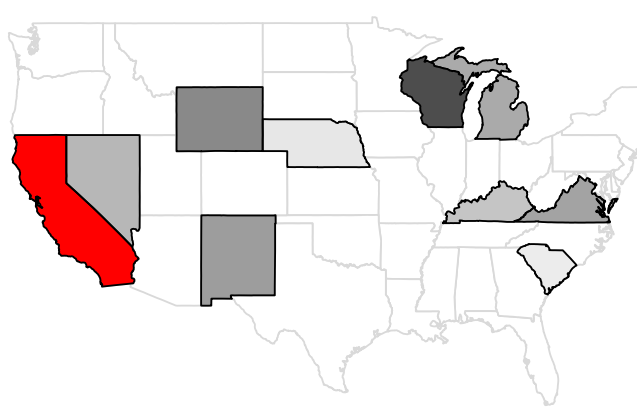

(d) MSPE Ratio Distribution

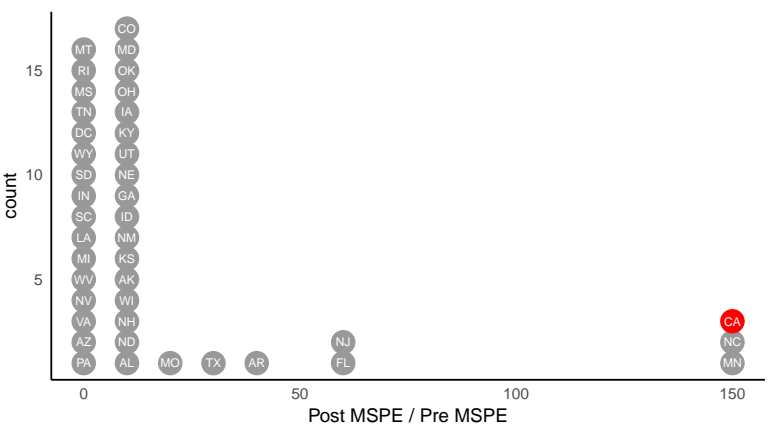

(f) Cross Validation

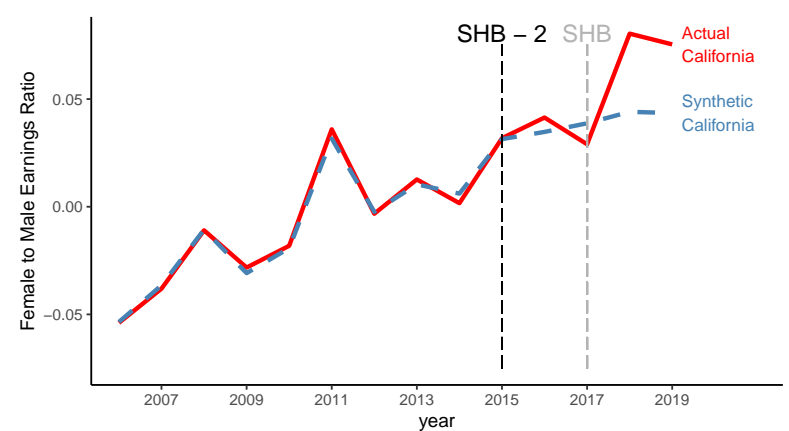




\section{Figure B.16}

California Synthetic Control for Female to Male Earnings Ratio Among Individuals Above Age 35, Demeaned

(a) Synthetic versus Actual

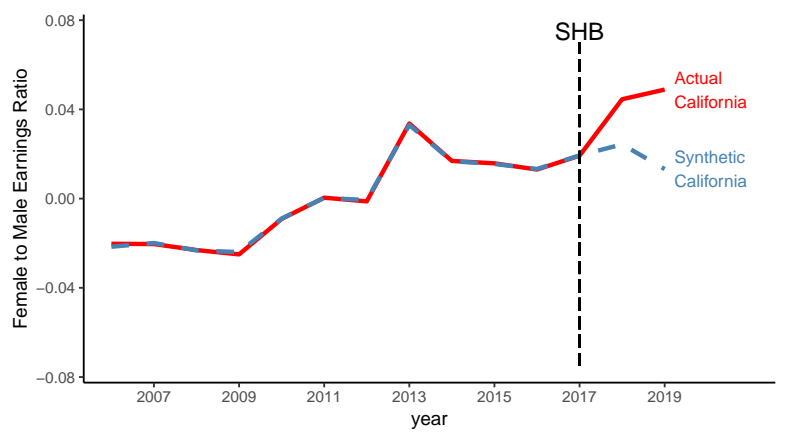

(c) Placebo Synthetic Controls

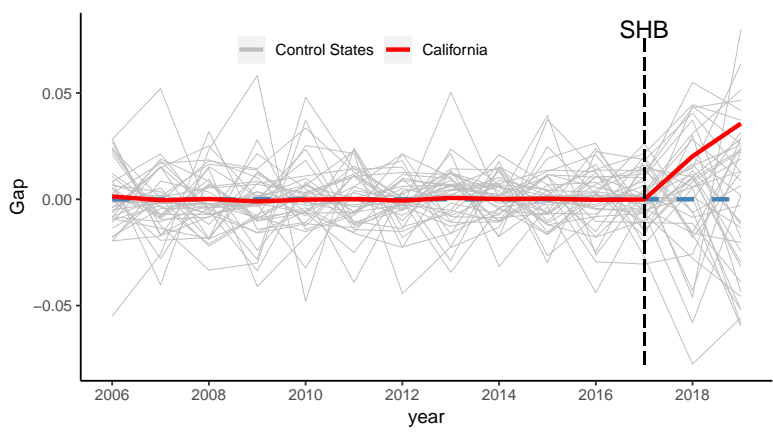

(e) Cross Validation

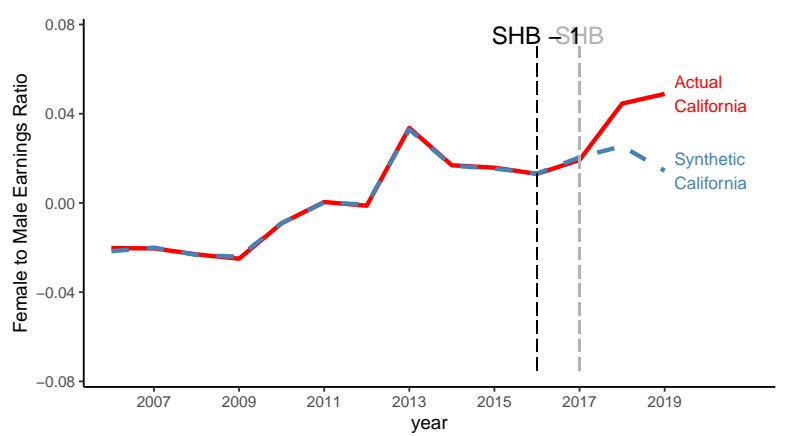

(b) Contributors to Synthetic Control

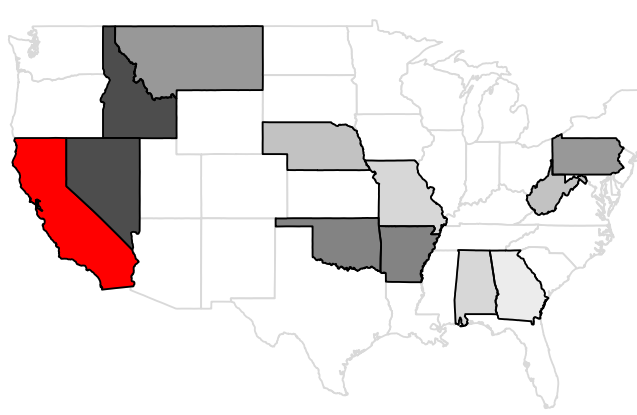

(d) MSPE Ratio Distribution

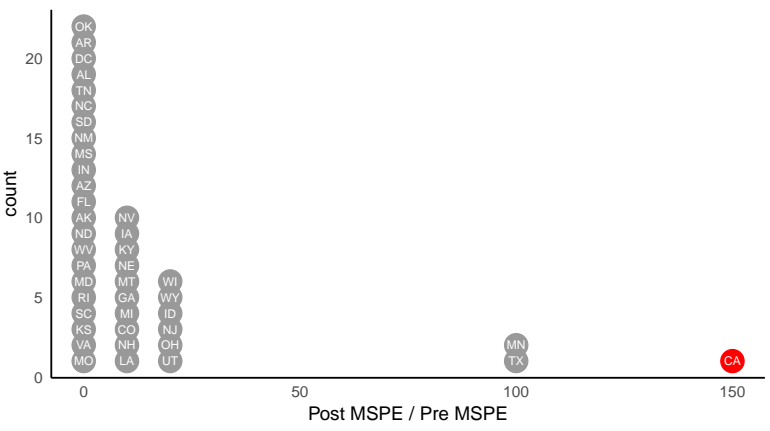

(f) Cross Validation

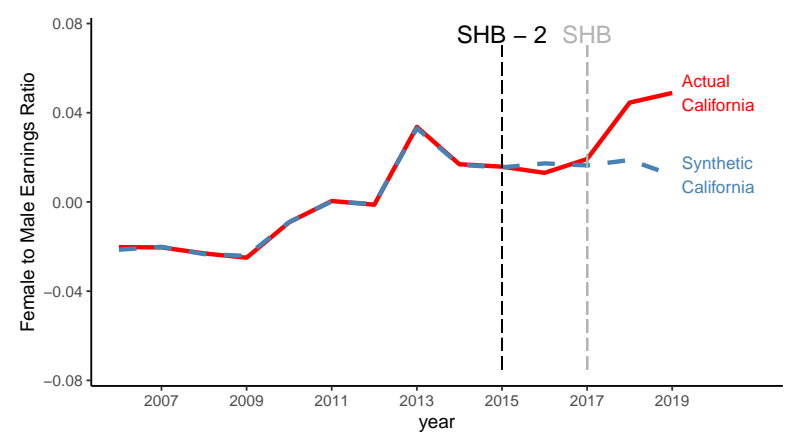




\section{Figure B.17}

California Synthetic Control for Female to Male Earnings Ratio Among Individuals Below Age 35, Demeaned

(a) Synthetic versus Actual

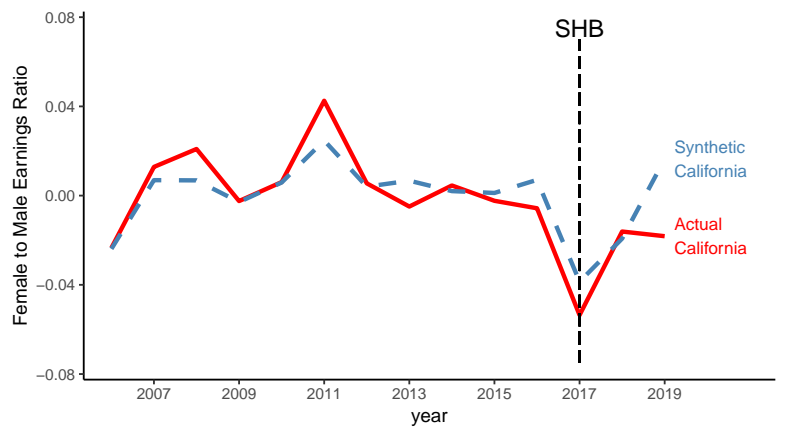

(c) Placebo Synthetic Controls

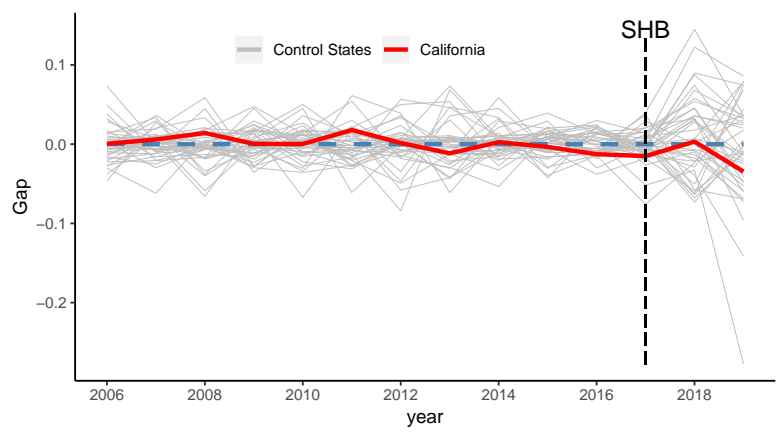

(e) Cross Validation

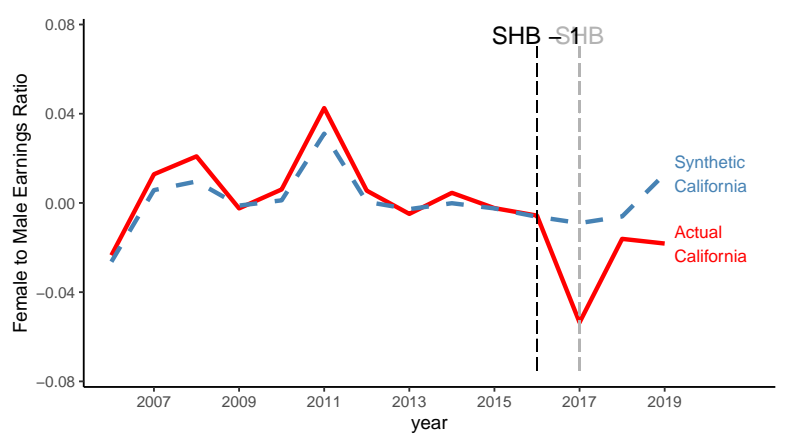

(b) Contributors to Synthetic Control

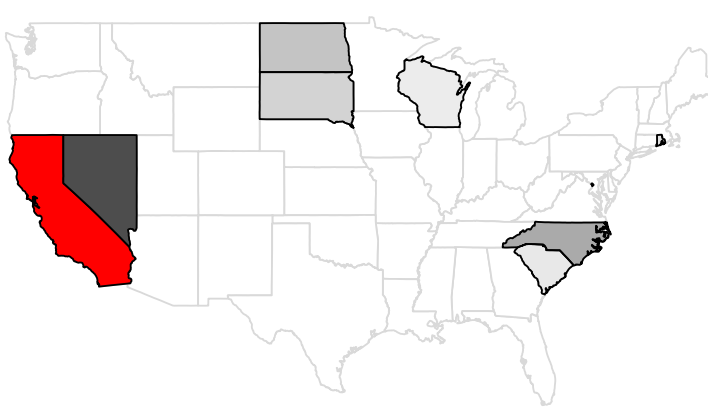

(d) MSPE Ratio Distribution

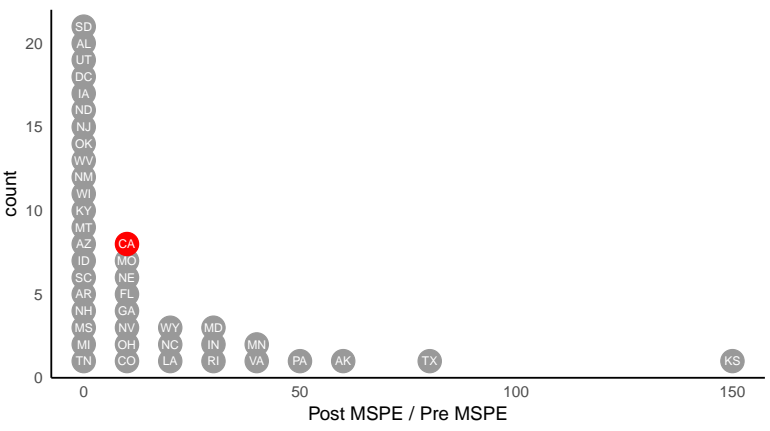

(f) Cross Validation

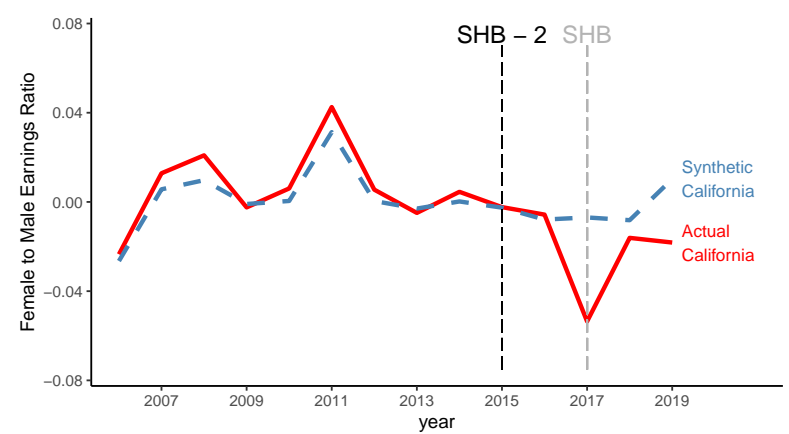




\section{Figure B.18}

California Synthetic Control for Female to Male Earnings Ratio Among Individuals With a New Job, Demeaned

(a) Synthetic versus Actual

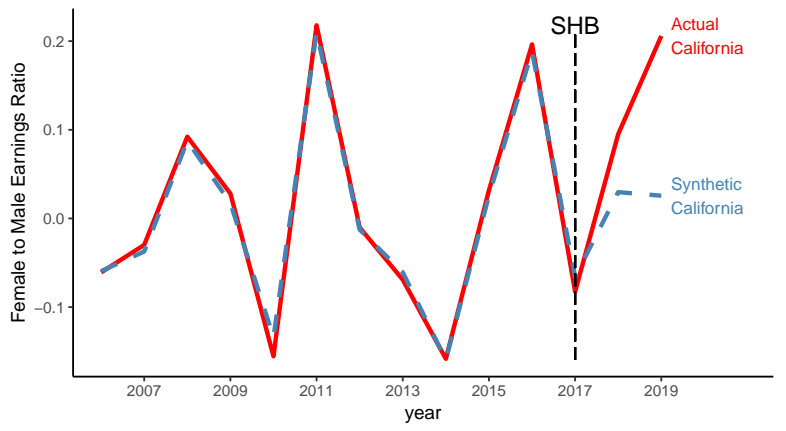

(c) Placebo Synthetic Controls

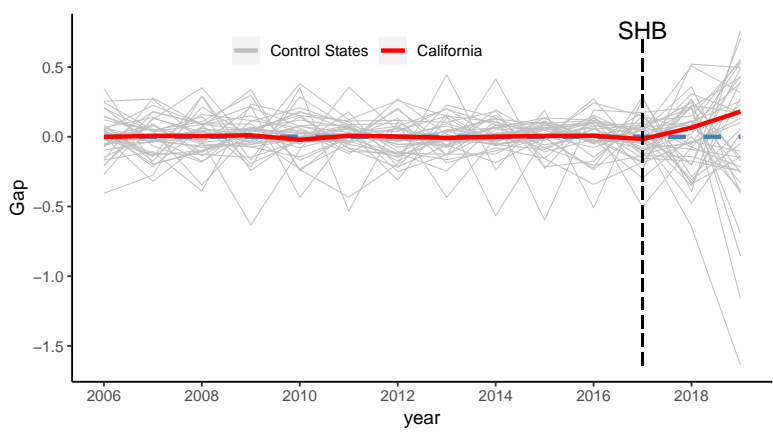

(e) Cross Validation

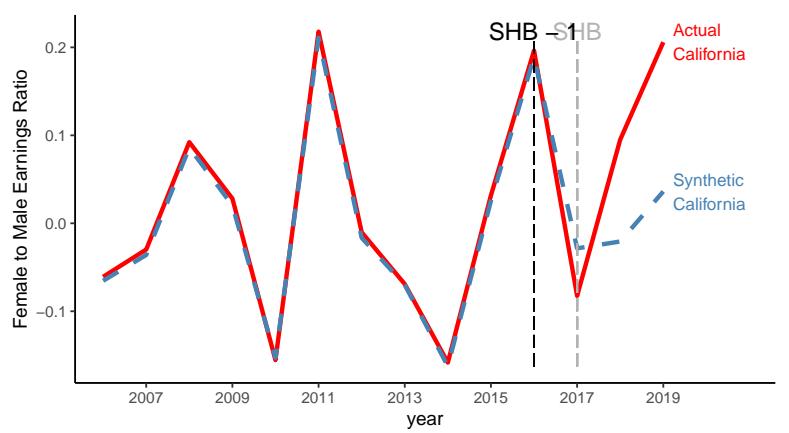

(b) Contributors to Synthetic Control

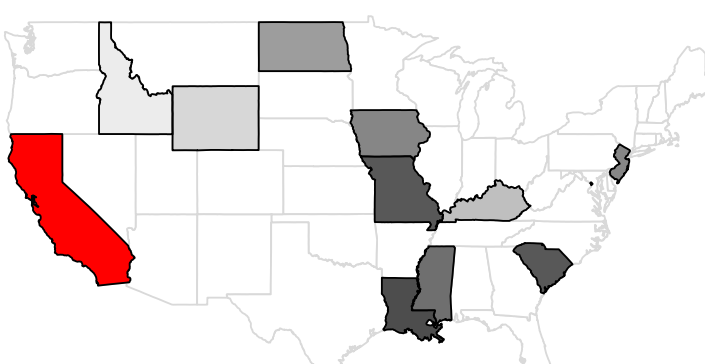

(d) MSPE Ratio Distribution

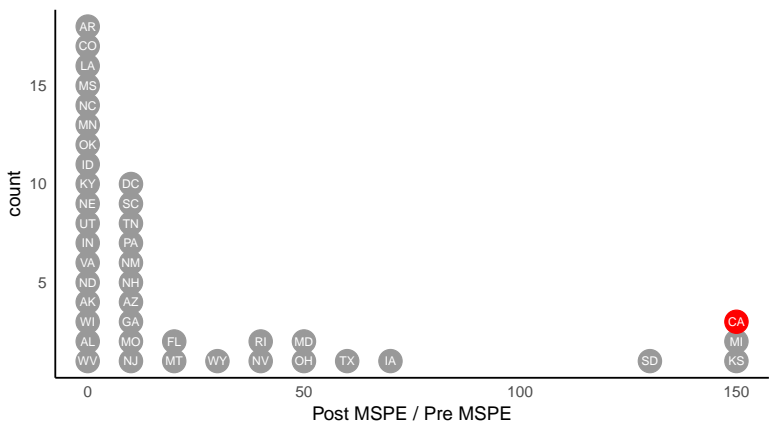

(f) Cross Validation

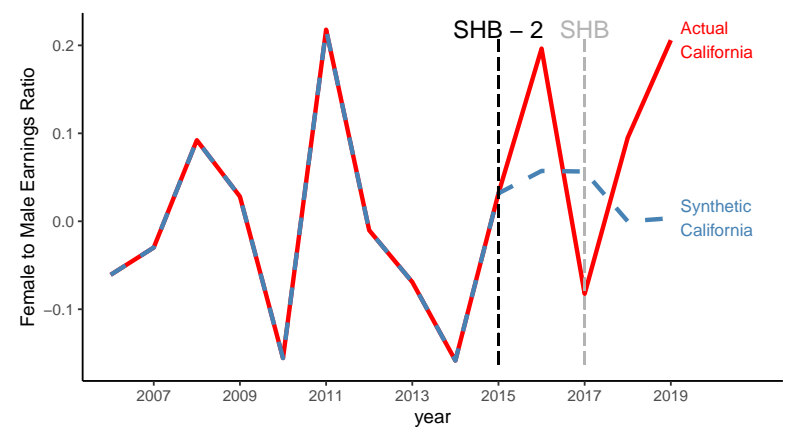




\section{Figure B.19}

California Synthetic Control for Female to Male Earnings Ratio Among Individuals With the Same Job, Demeaned

(a) Synthetic versus Actual

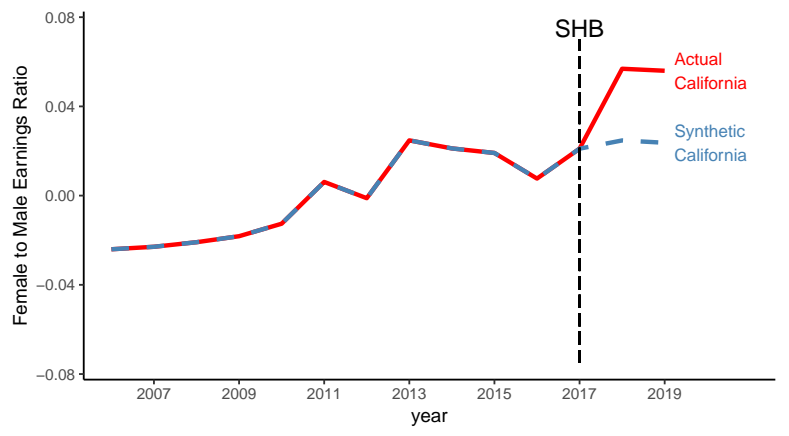

(c) Placebo Synthetic Controls

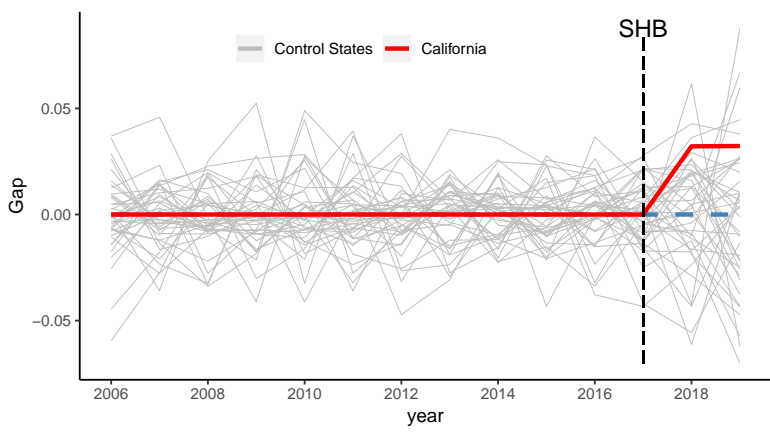

(e) Cross Validation

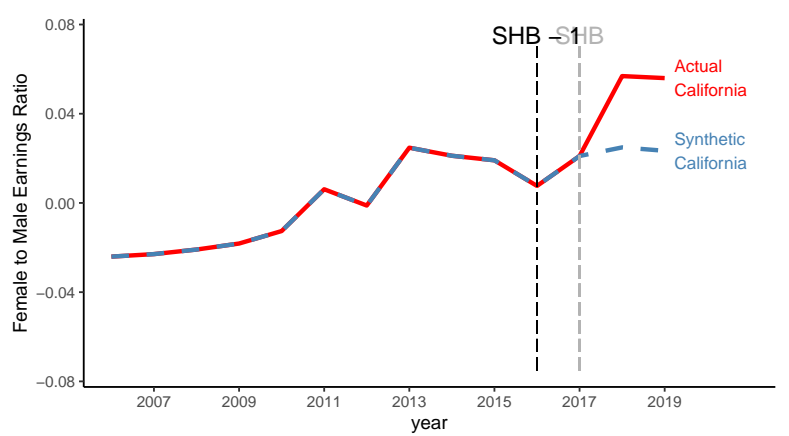

(b) Contributors to Synthetic Control

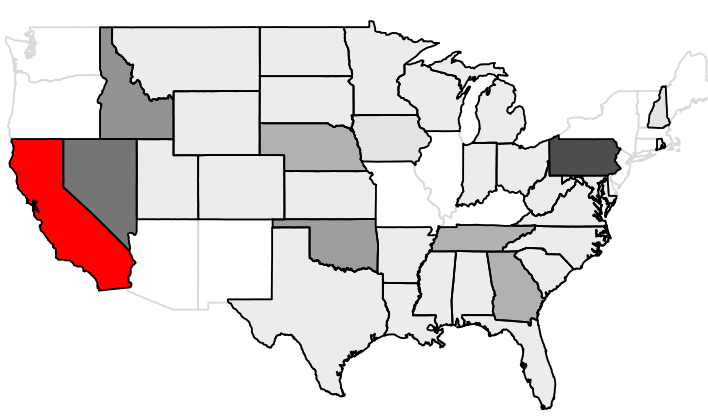

(d) MSPE Ratio Distribution

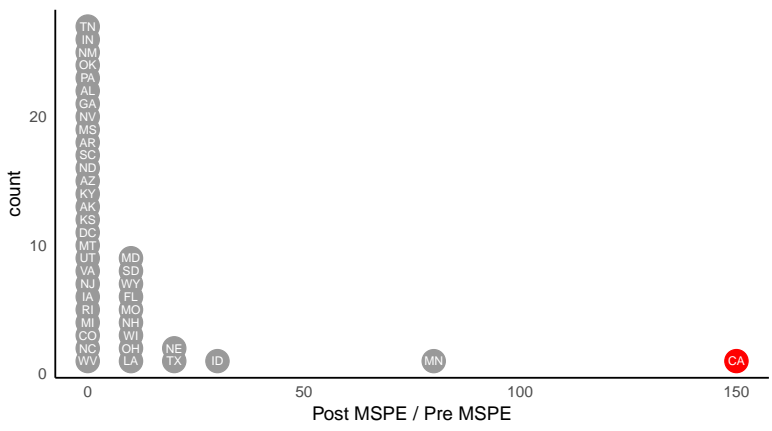

(f) Cross Validation

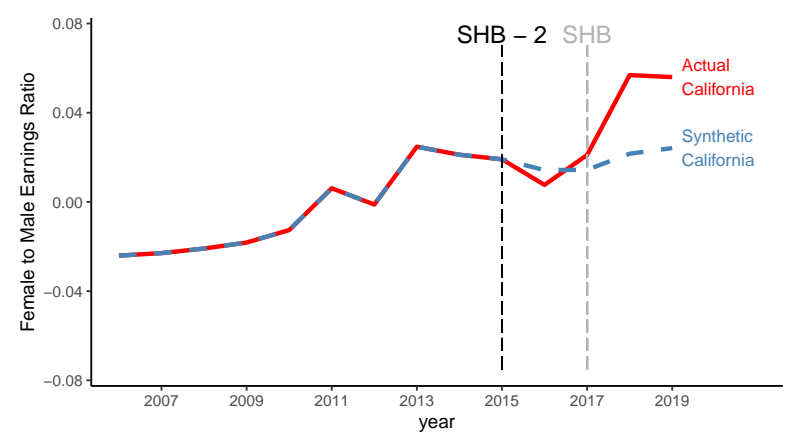




\section{B.3 All Treated States: Level Data}

Figure B.20

All Treated Synthetic Control for Female to Male Earnings Ratio

(a) Synthetic versus Actual

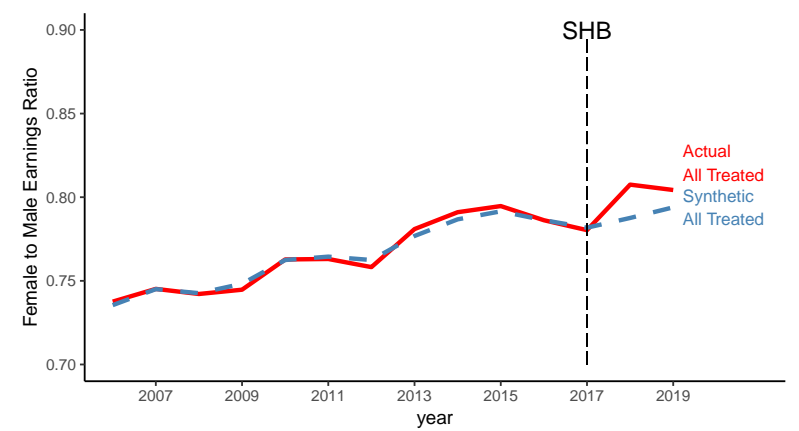

(c) Placebo Synthetic Controls

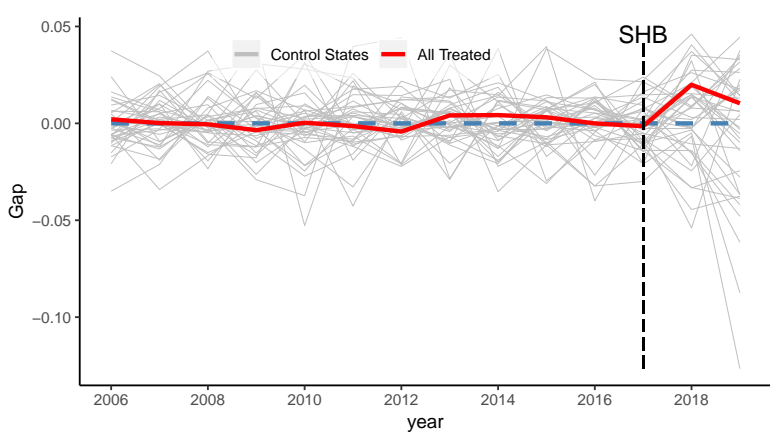

(e) Cross Validation

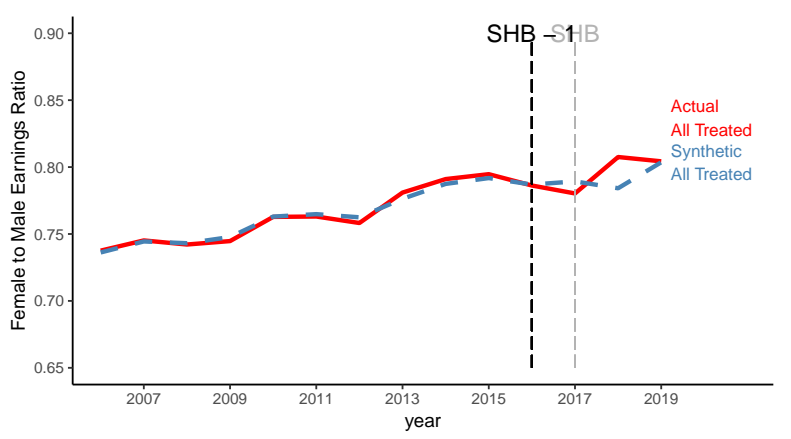

(b) Contributors to Synthetic Control

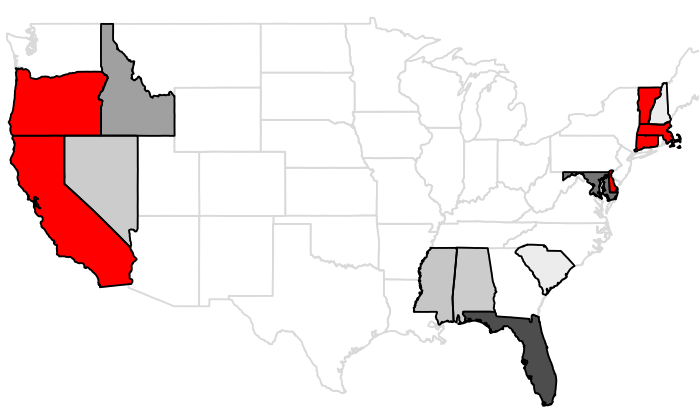

(d) MSPE Ratio Distribution

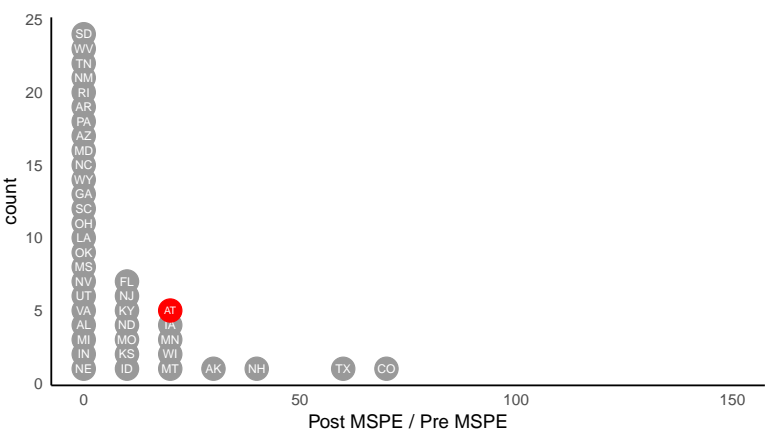

(f) Cross Validation

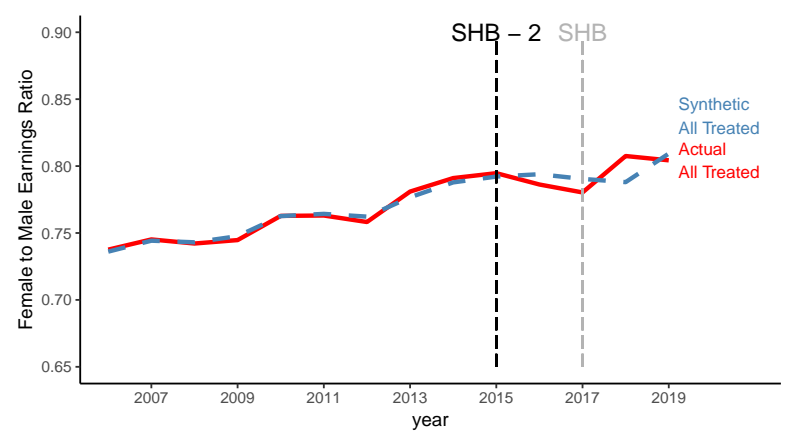




\section{Figure B.21}

All Treated Synthetic Control for Female to Male Earnings Ratio Among Female Dominated Industries

(a) Synthetic versus Actual

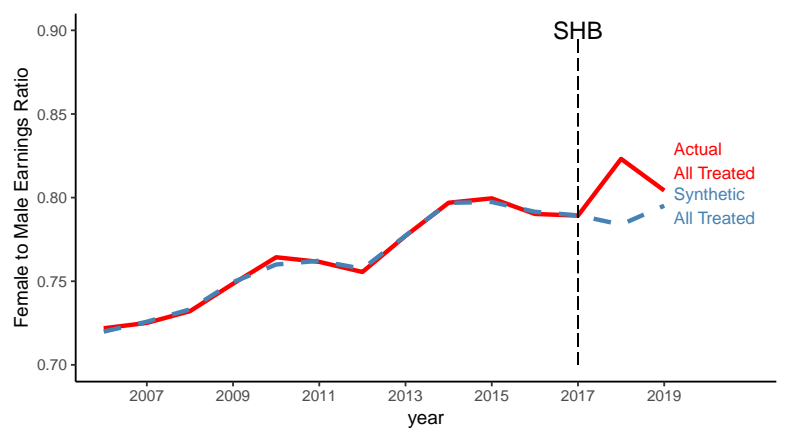

(c) Placebo Synthetic Controls

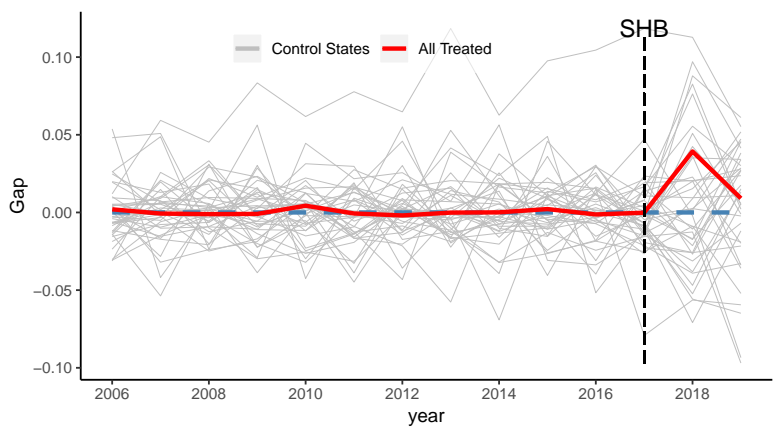

(e) Cross Validation

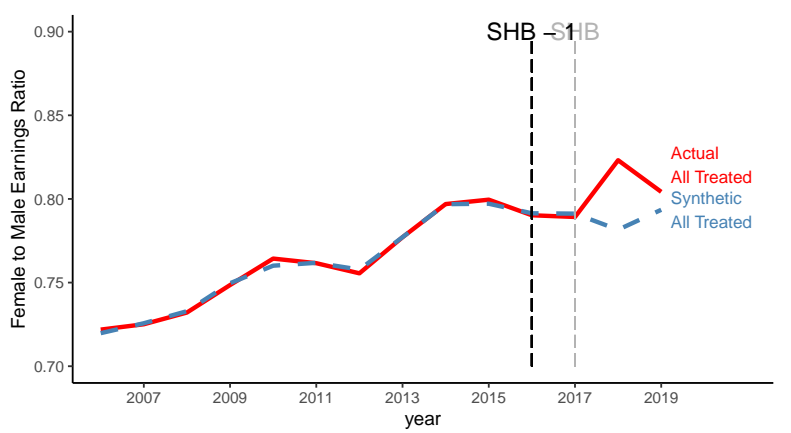

(b) Contributors to Synthetic Control

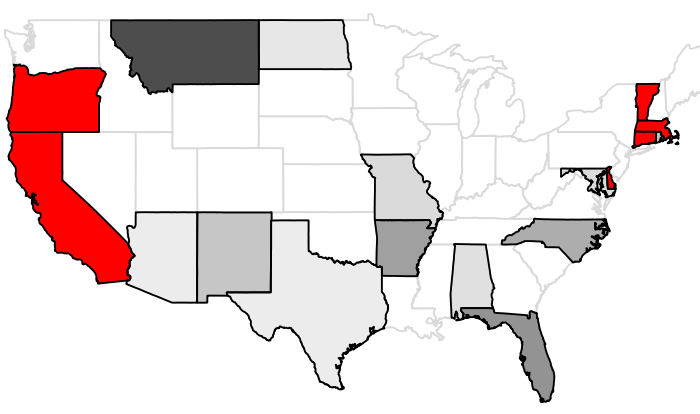

(d) MSPE Ratio Distribution

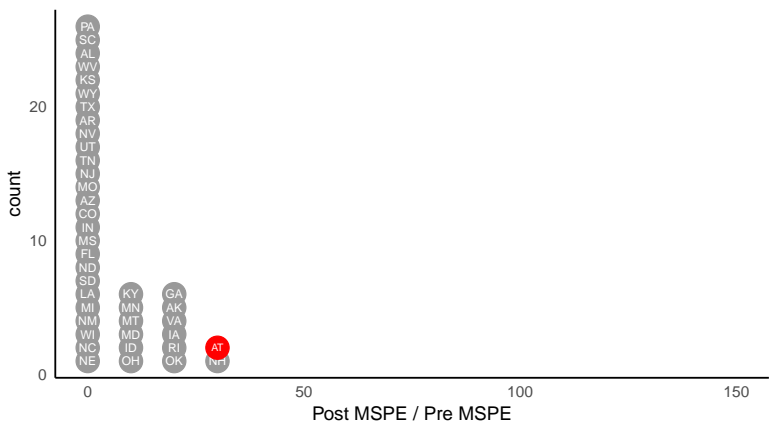

(f) Cross Validation

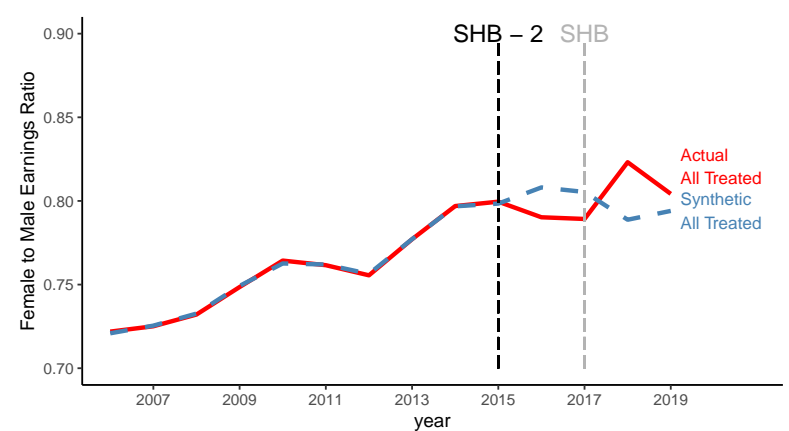




\section{Figure B.22}

All Treated Synthetic Control for Female to Male Earnings Ratio Among Male Dominated Industries

(a) Synthetic versus Actual

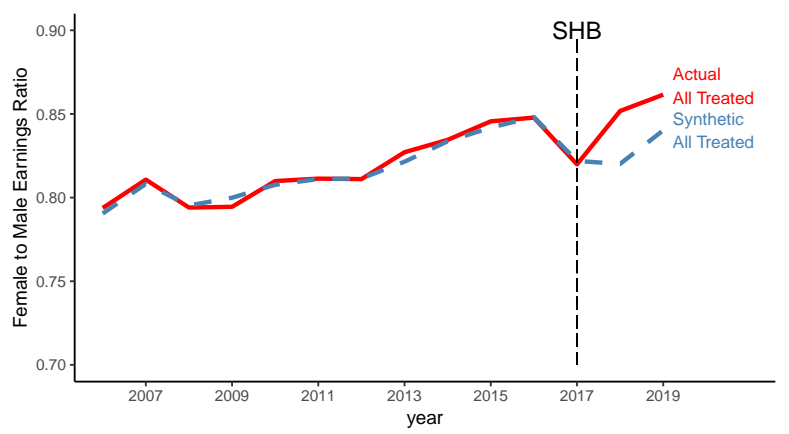

(c) Placebo Synthetic Controls

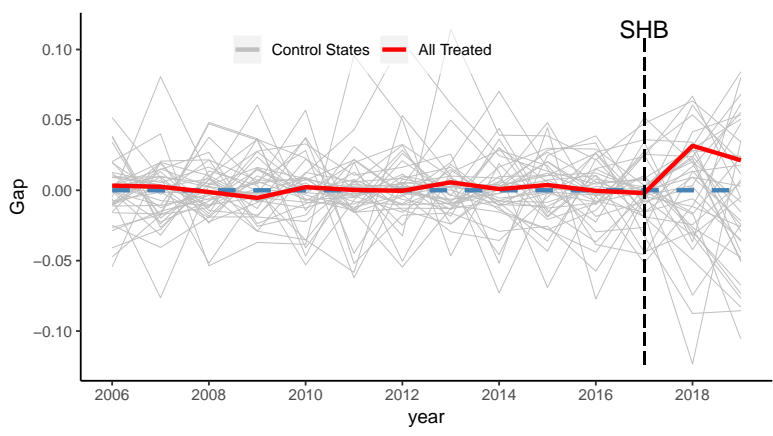

(e) Cross Validation

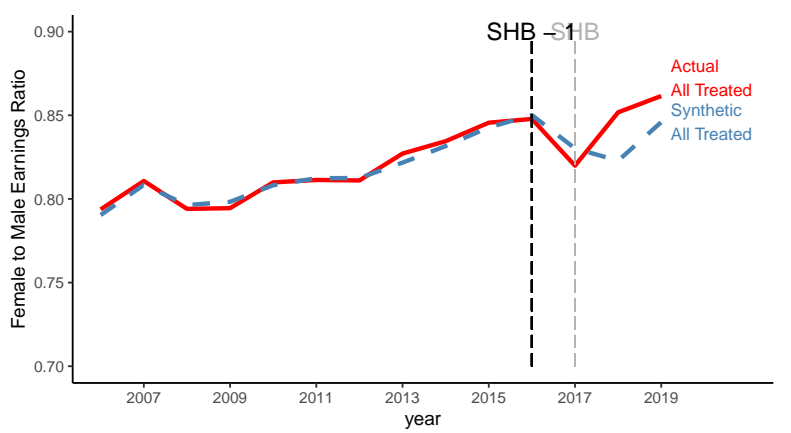

(b) Contributors to Synthetic Control

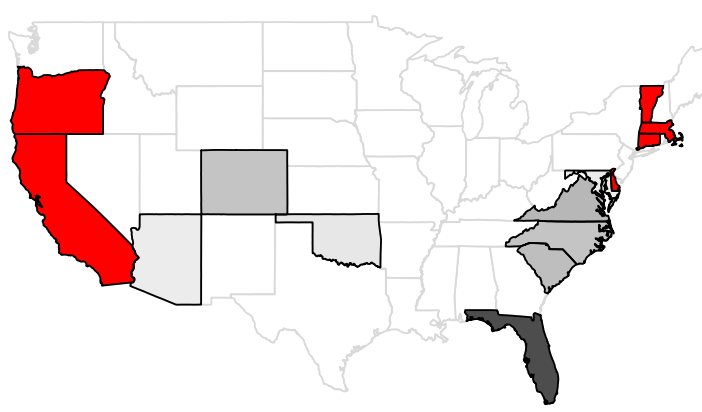

(d) MSPE Ratio Distribution

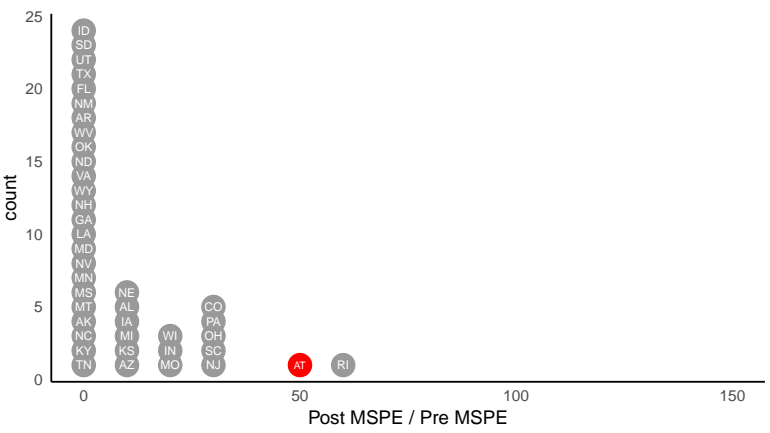

(f) Cross Validation

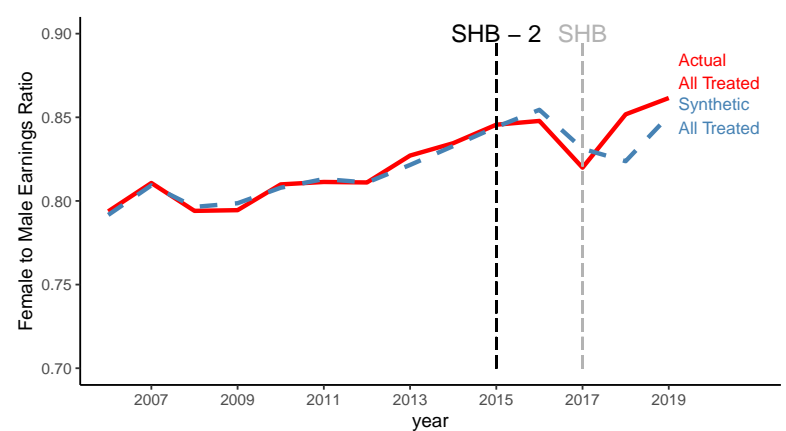




\section{Figure B.23}

All Treated Synthetic Control for Female to Male Earnings Ratio Among Individuals with Children less than 5 Years Old

(a) Synthetic versus Actual

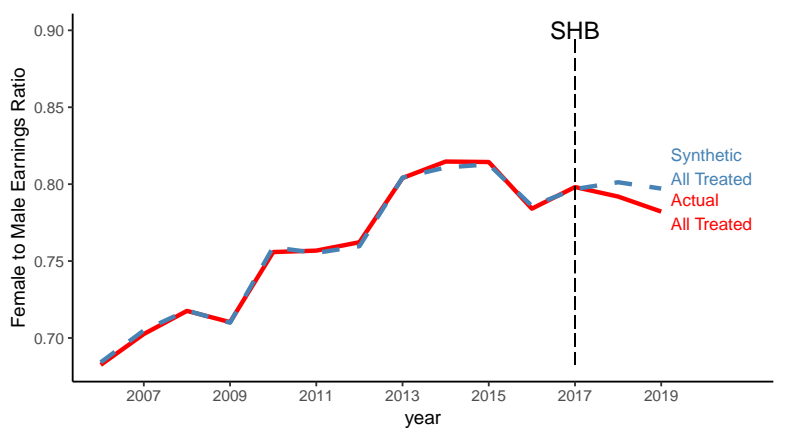

(c) Placebo Synthetic Controls

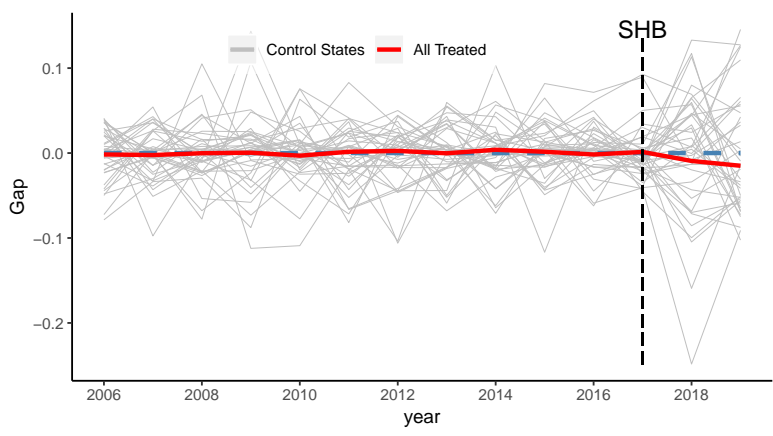

(e) Cross Validation

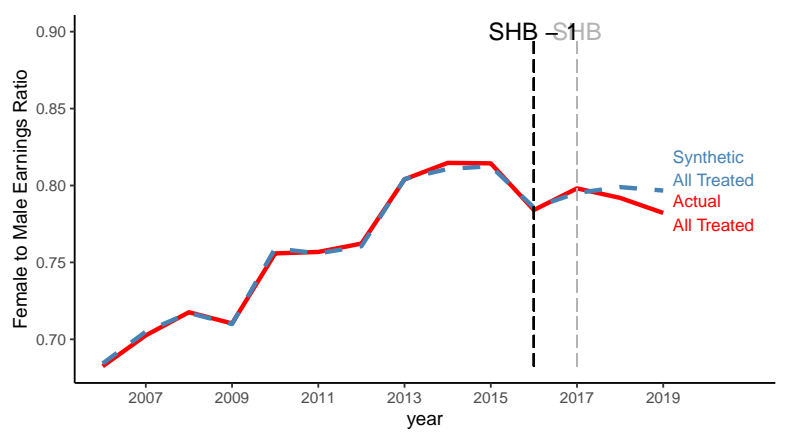

(b) Contributors to Synthetic Control

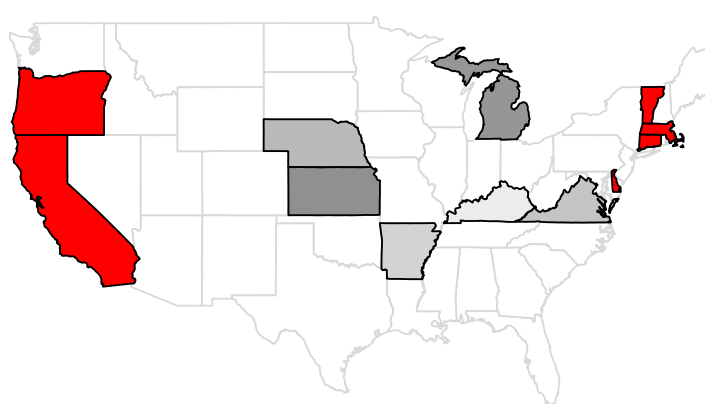

(d) MSPE Ratio Distribution

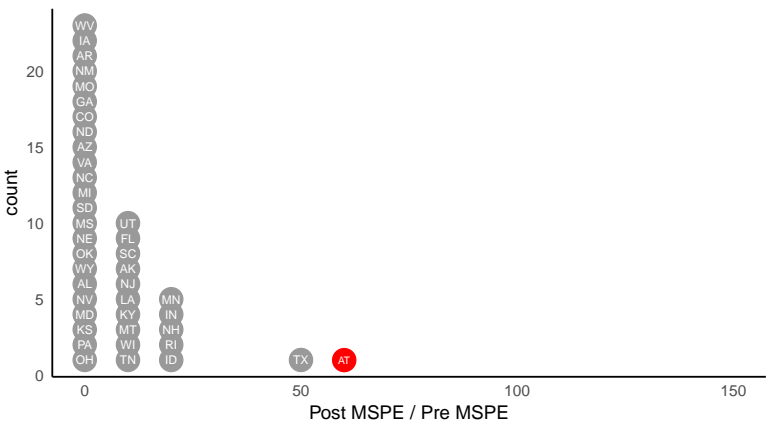

(f) Cross Validation

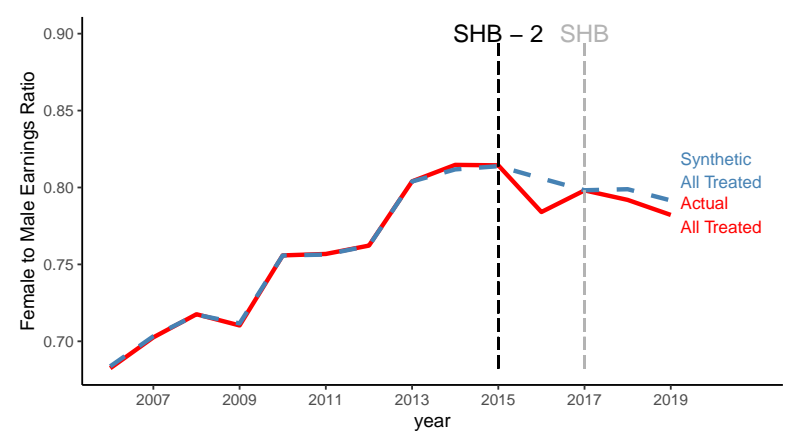




\section{Figure B.24}

All Treated Synthetic Control for Female to Male Earnings Ratio Among Individuals with Children above 5 Years Old

(a) Synthetic versus Actual

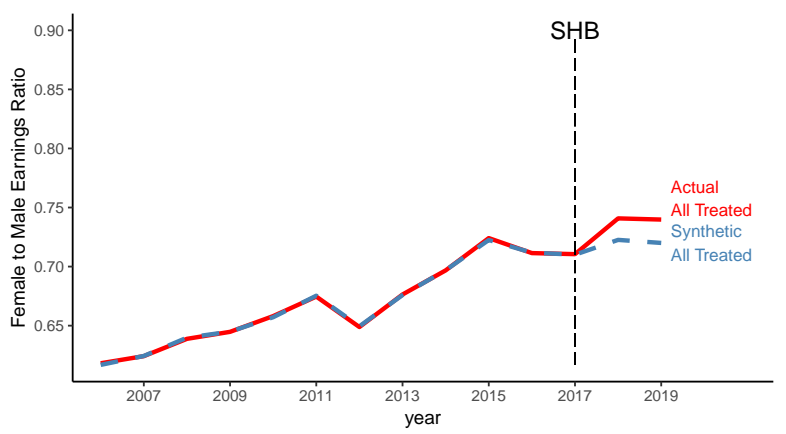

(c) Placebo Synthetic Controls

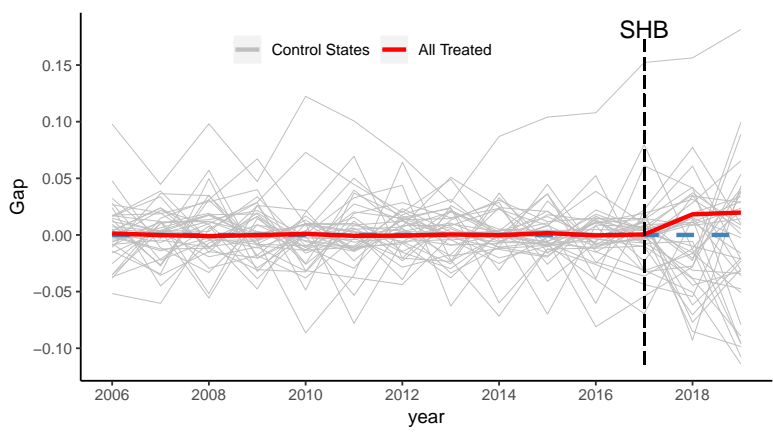

(e) Cross Validation

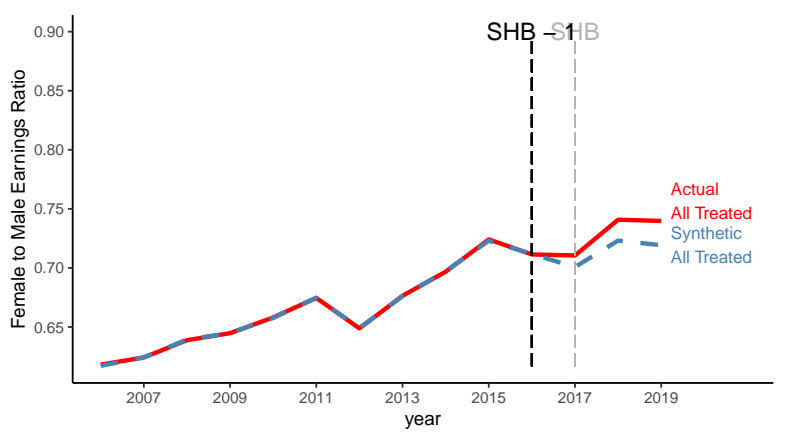

(b) Contributors to Synthetic Control

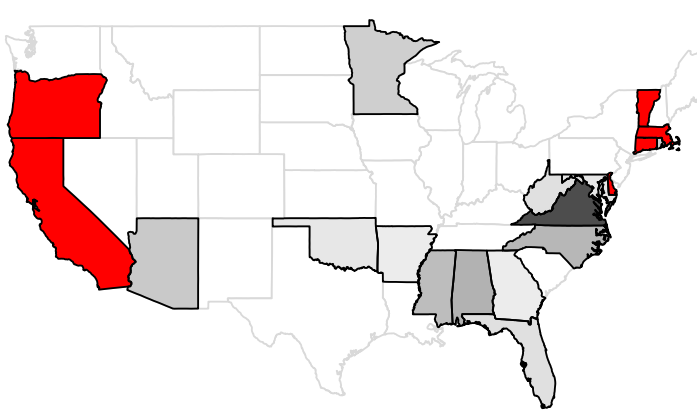

(d) MSPE Ratio Distribution

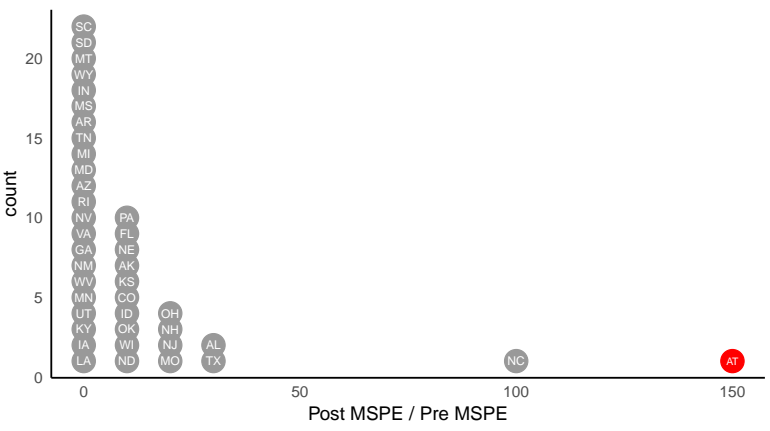

(f) Cross Validation

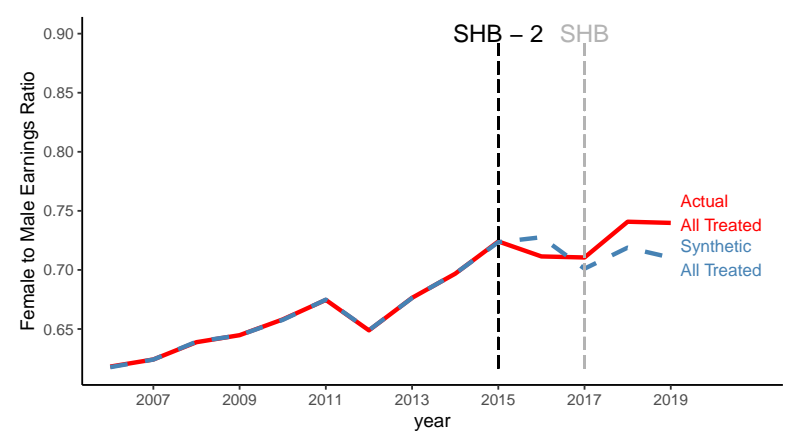




\section{Figure B.25}

All Treated Synthetic Control for Female to Male Earnings Ratio Among Individuals Above Age 35

(a) Synthetic versus Actual

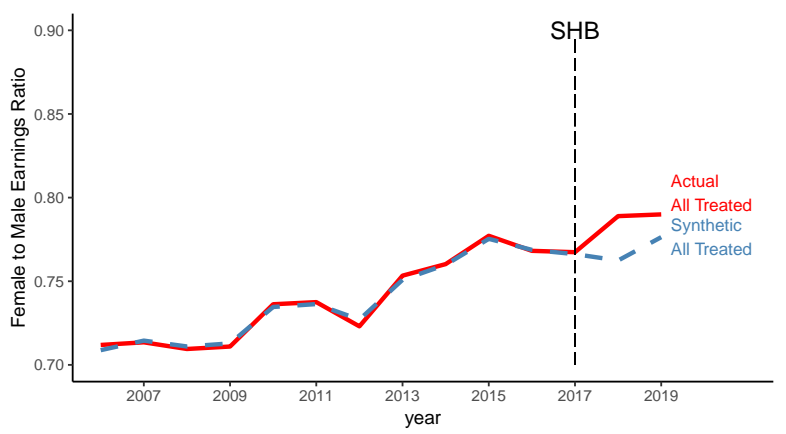

(c) Placebo Synthetic Controls

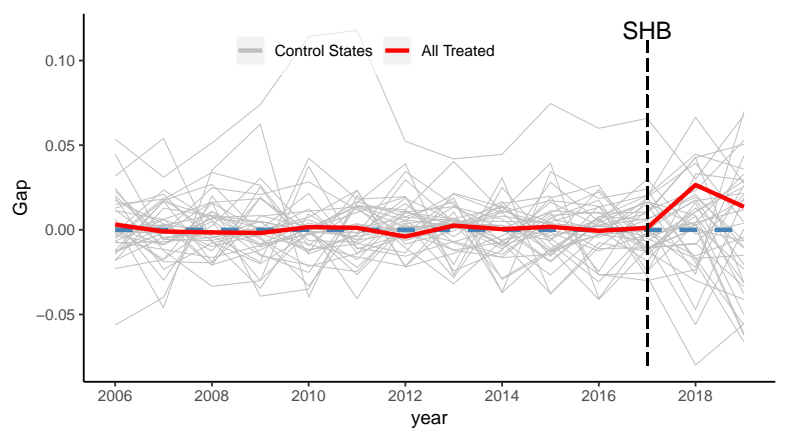

(e) Cross Validation

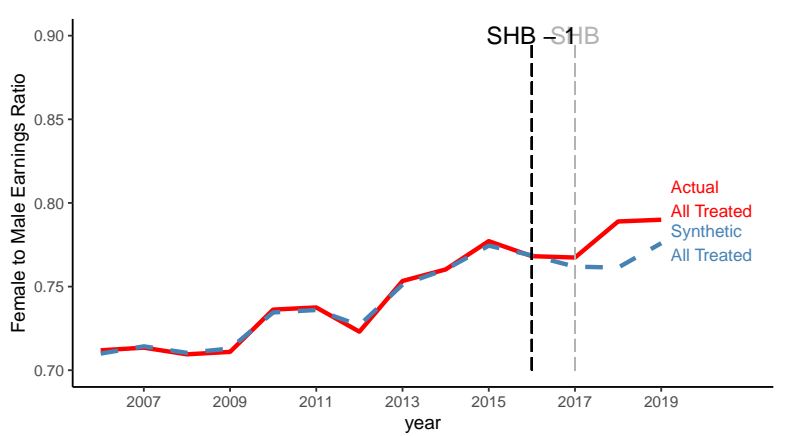

(b) Contributors to Synthetic Control

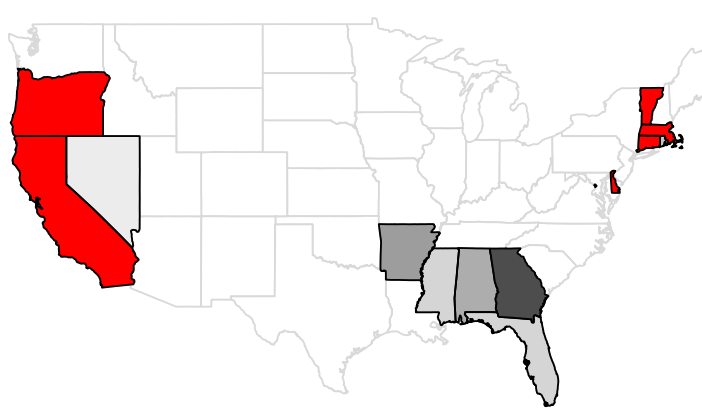

(d) MSPE Ratio Distribution

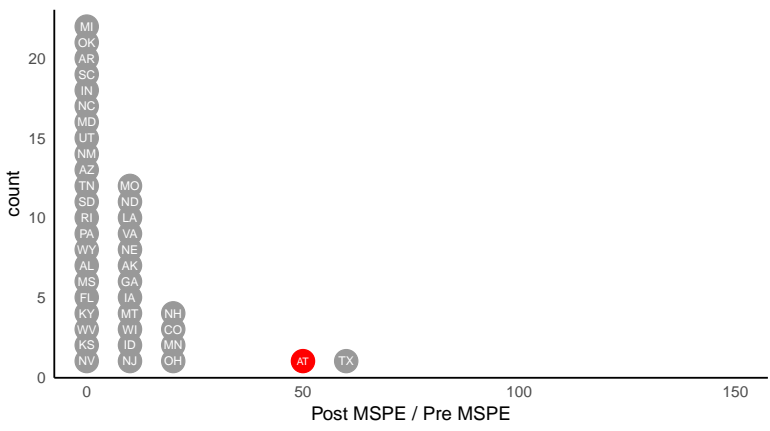

(f) Cross Validation

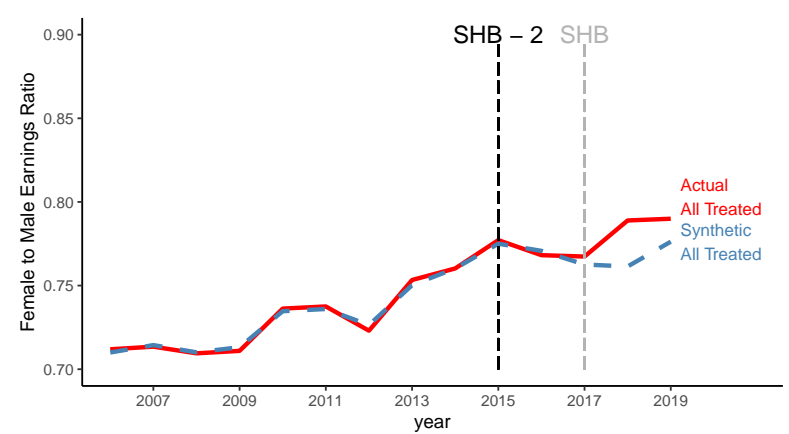




\section{Figure B.26}

All Treated Synthetic Control for Female to Male Earnings Ratio Among Individuals Below Age 35

(a) Synthetic versus Actual

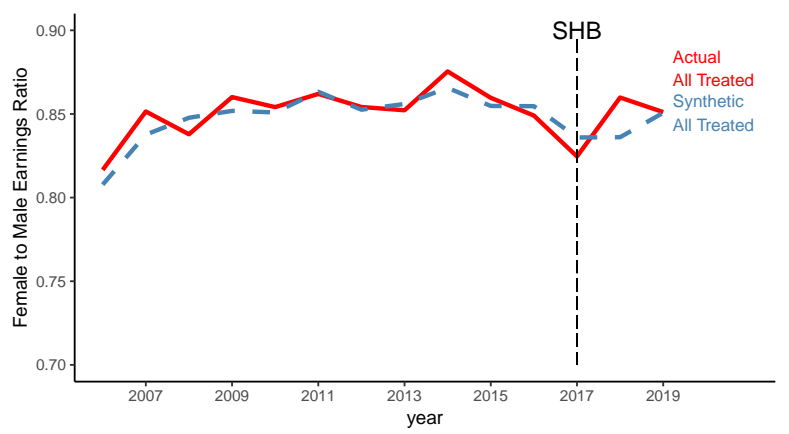

(c) Placebo Synthetic Controls

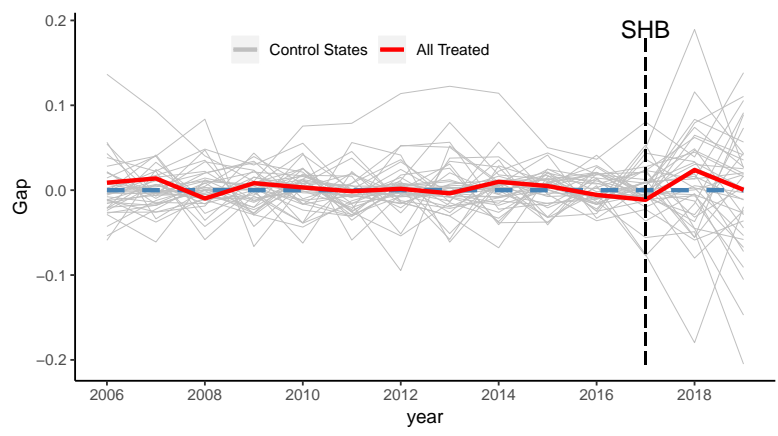

(e) Cross Validation

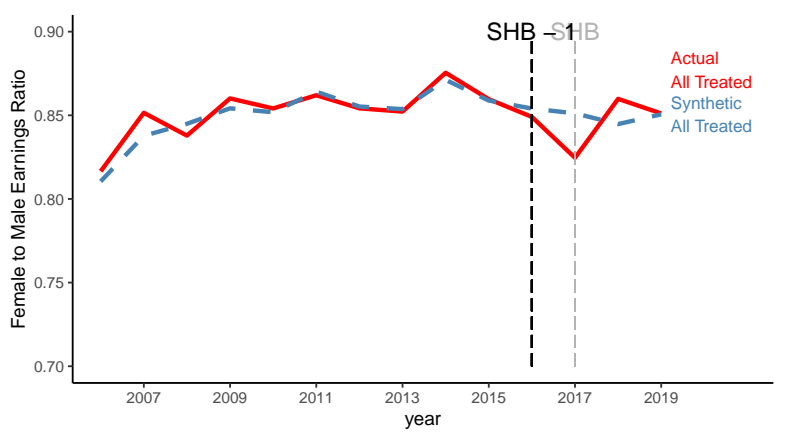

(b) Contributors to Synthetic Control

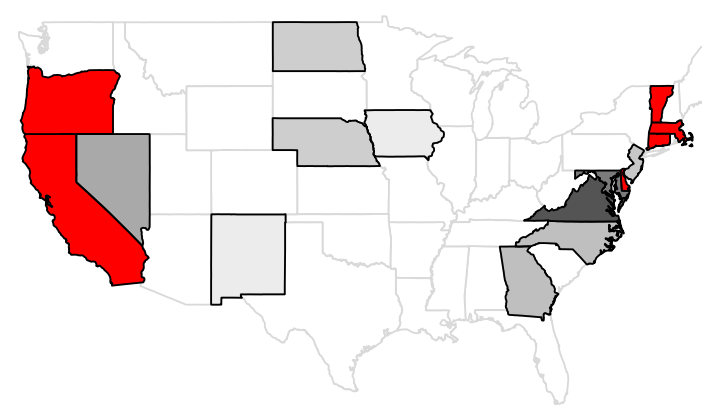

(d) MSPE Ratio Distribution

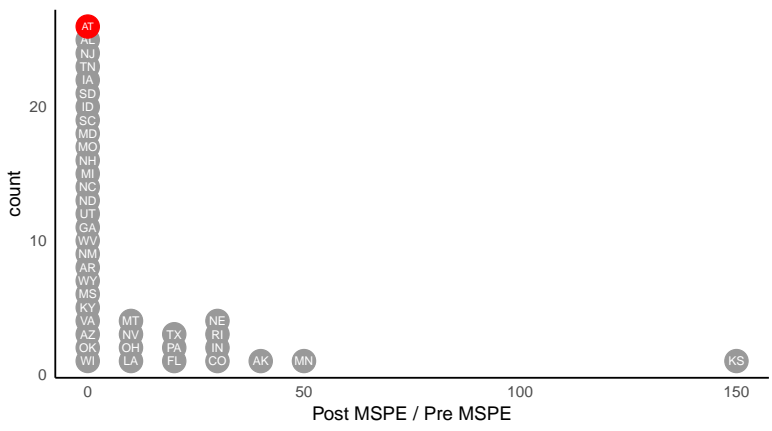

(f) Cross Validation

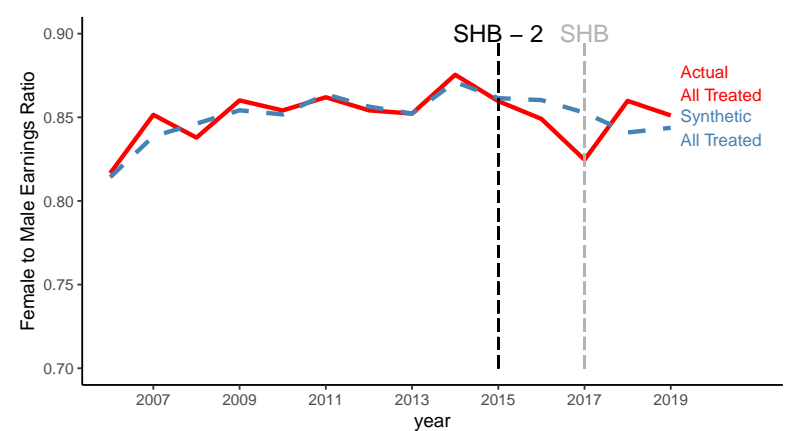




\section{Figure B.27}

All Treated Synthetic Control for Female to Male Earnings Ratio Among Individuals With a New Job

(a) Synthetic versus Actual

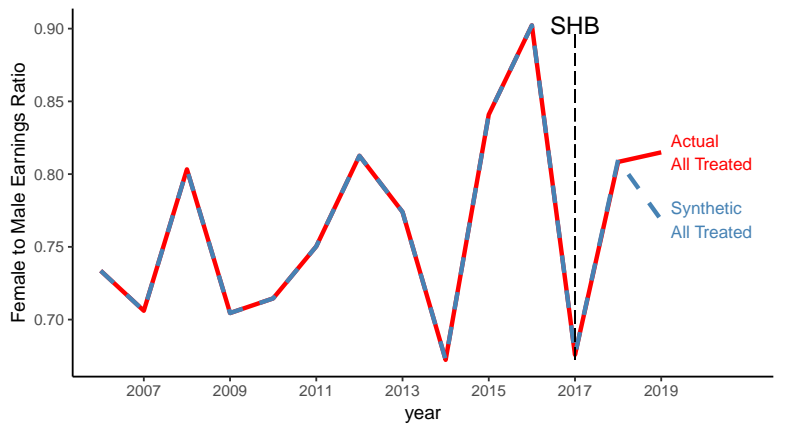

(c) Placebo Synthetic Controls

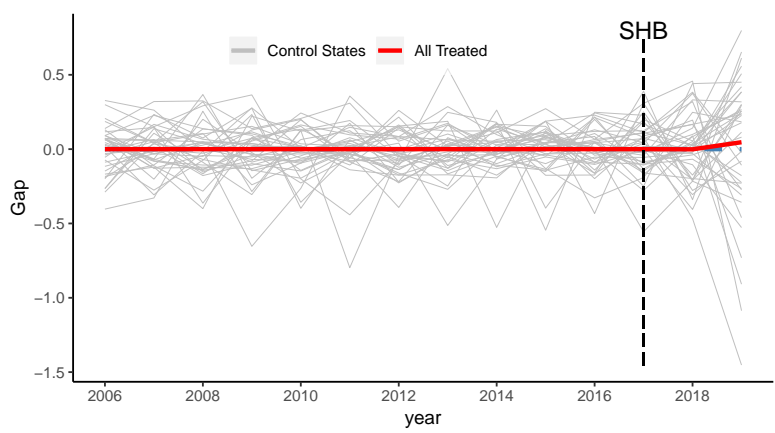

(e) Cross Validation

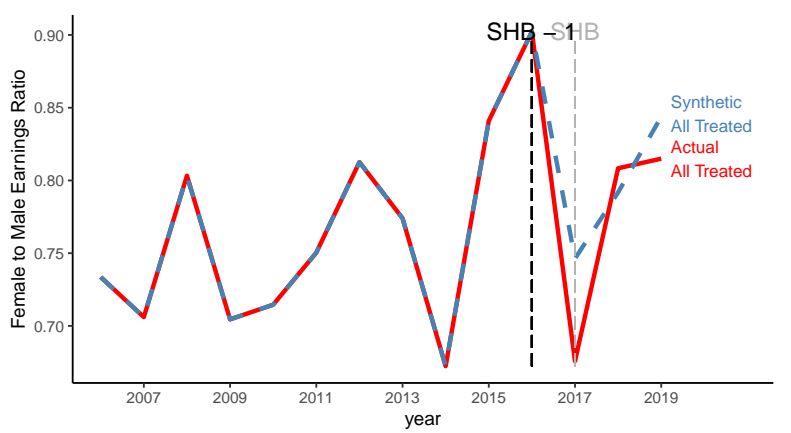

(b) Contributors to Synthetic Control

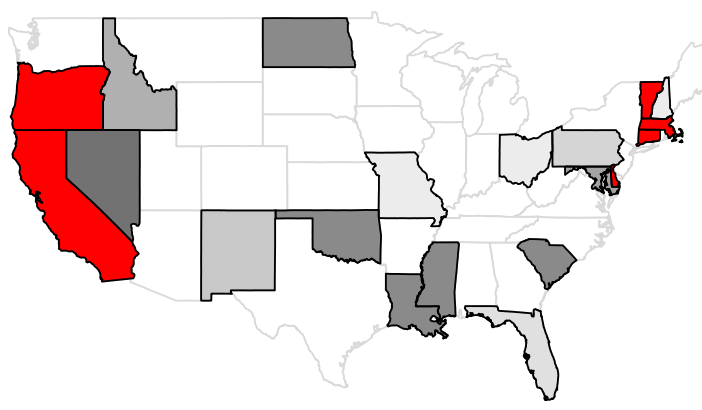

(d) MSPE Ratio Distribution

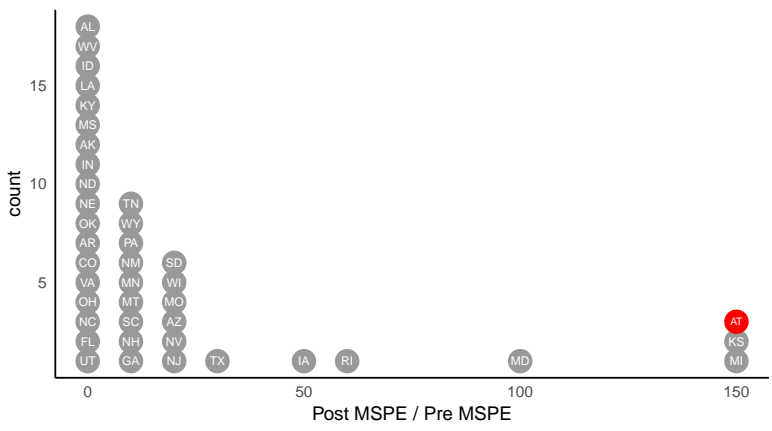

(f) Cross Validation

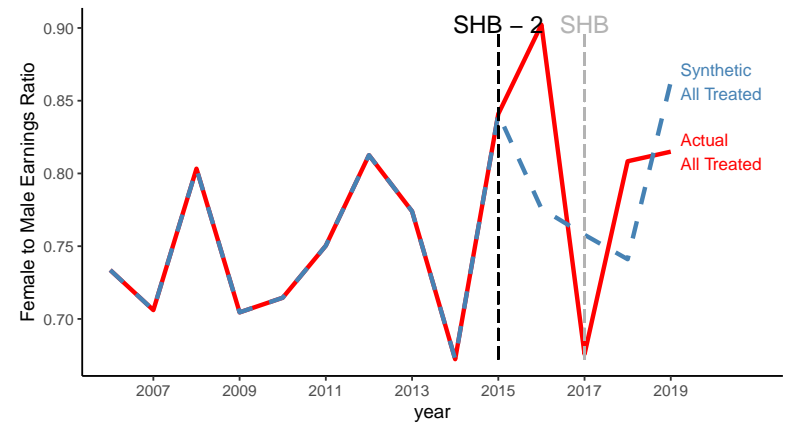




\section{Figure B.28}

All Treated Synthetic Control for Female to Male Earnings Ratio Among Individuals With the Same Job

(a) Synthetic versus Actual

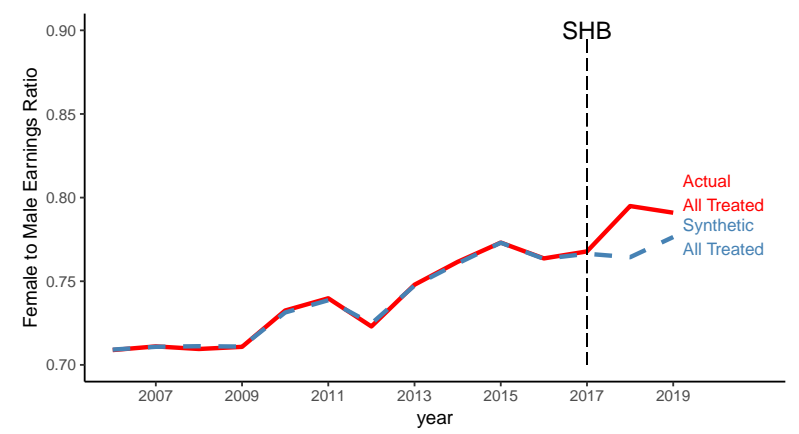

(c) Placebo Synthetic Controls

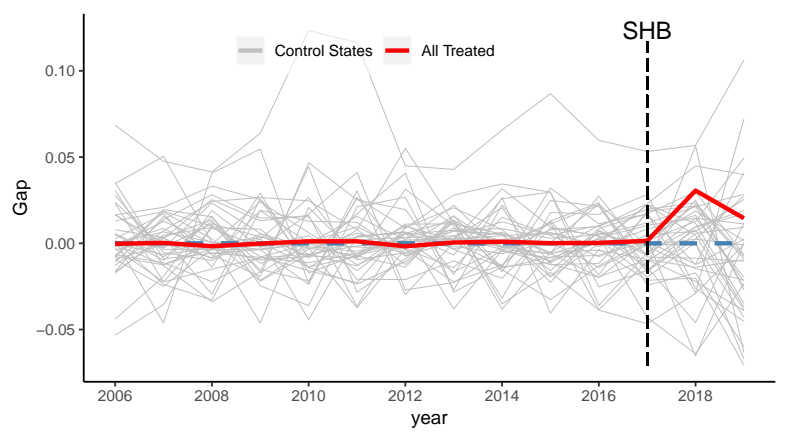

(e) Cross Validation

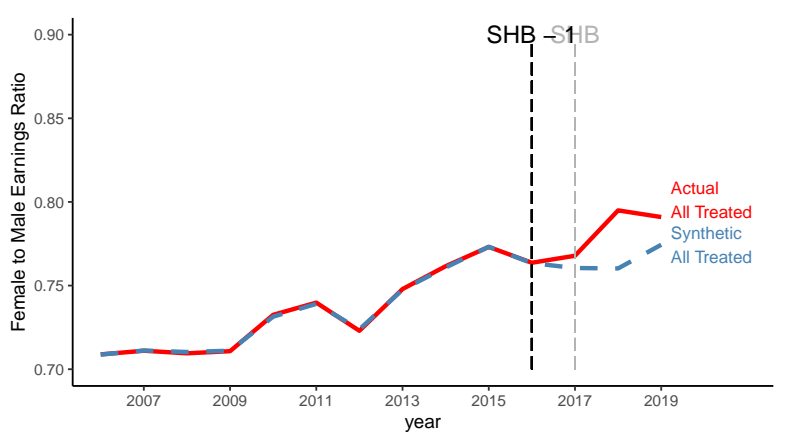

(b) Contributors to Synthetic Control

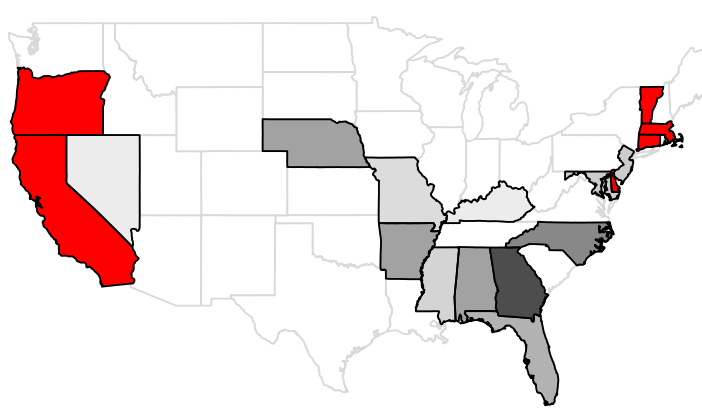

(d) MSPE Ratio Distribution

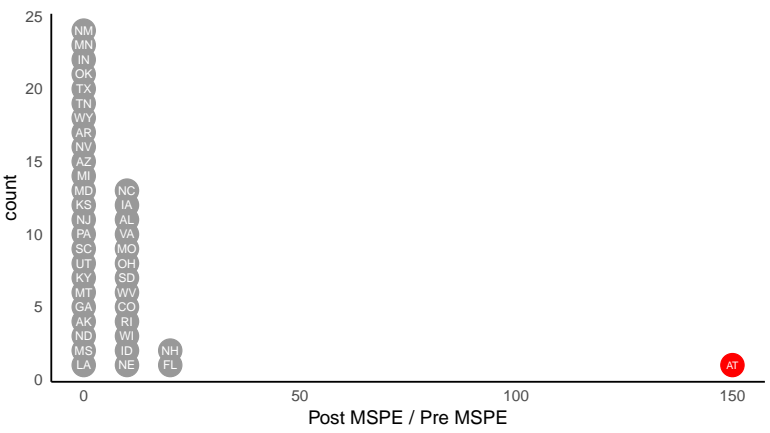

(f) Cross Validation

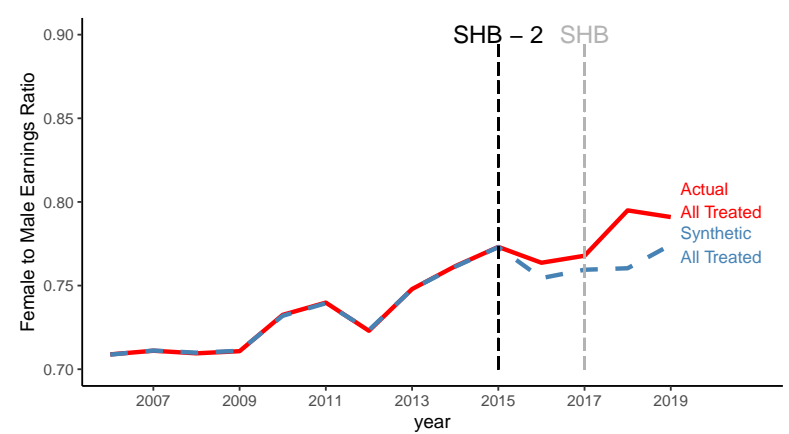




\section{B.4 All Treated States: Demeaned Data}

Figure B.29

All Treated Synthetic Control for Female to Male Earnings Ratio, Demeaned

(a) Synthetic versus Actual

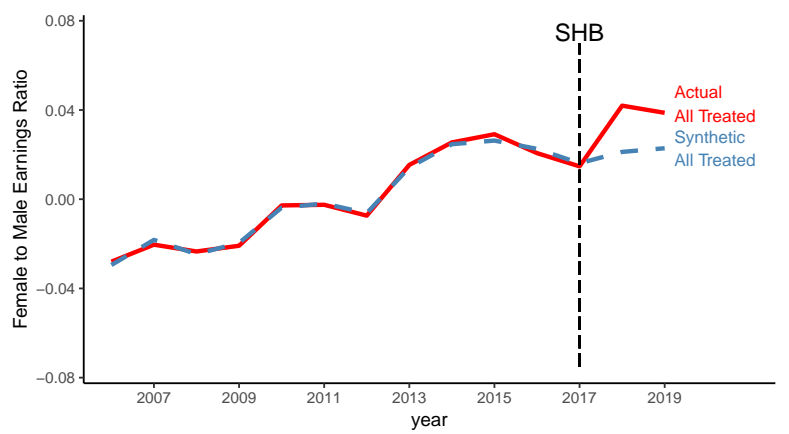

(c) Placebo Synthetic Controls

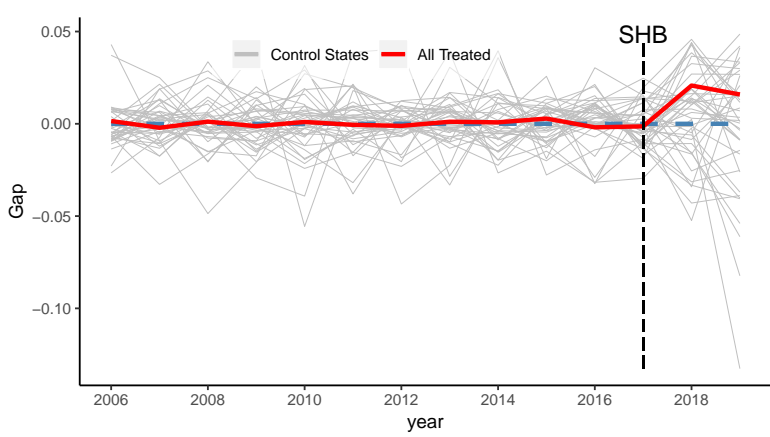

(e) Cross Validation

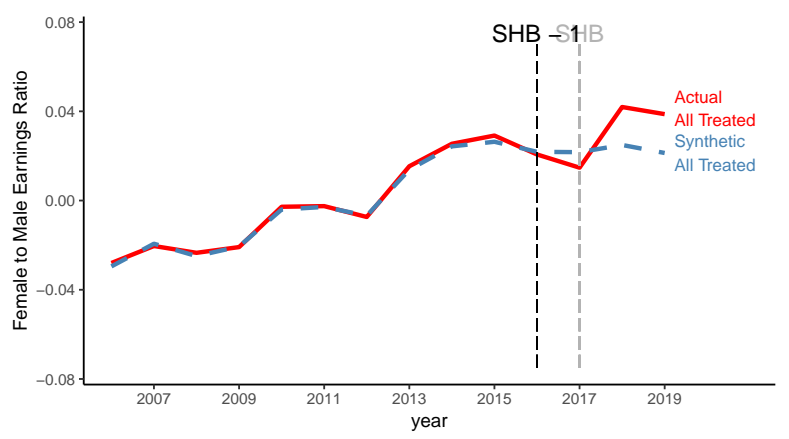

(b) Contributors to Synthetic Control

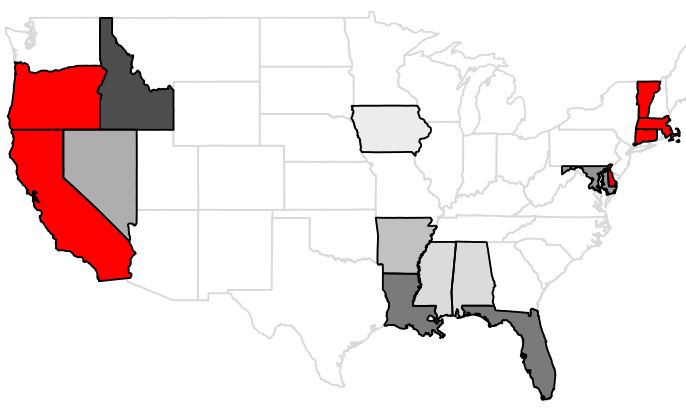

(d) MSPE Ratio Distribution

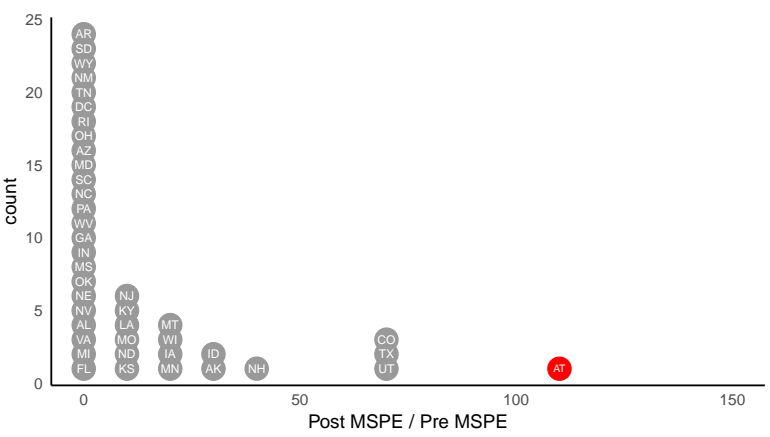

(f) Cross Validation

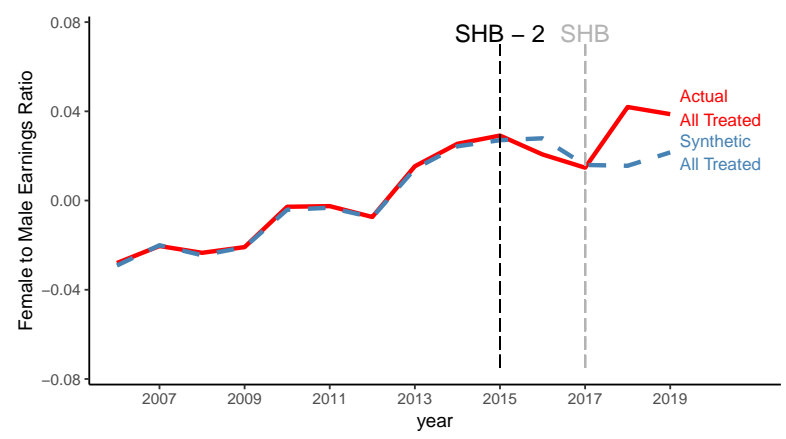




\section{Figure B.30}

All Treated Synthetic Control for Female to Male Earnings Ratio Among Female Dominated Industries, Demeaned

(a) Synthetic versus Actual

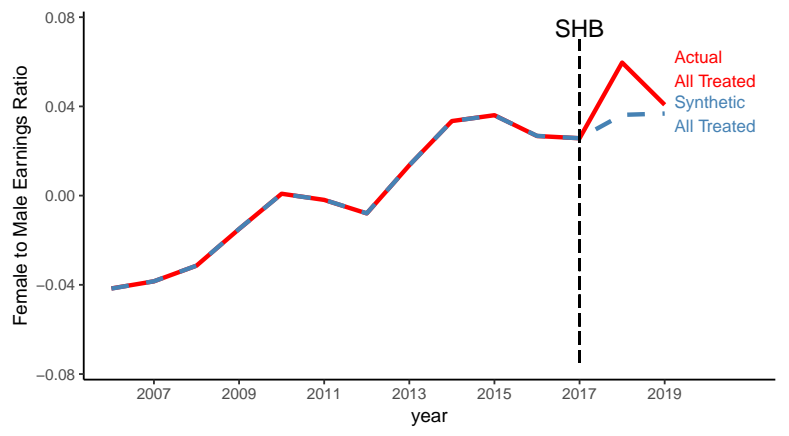

(c) Placebo Synthetic Controls

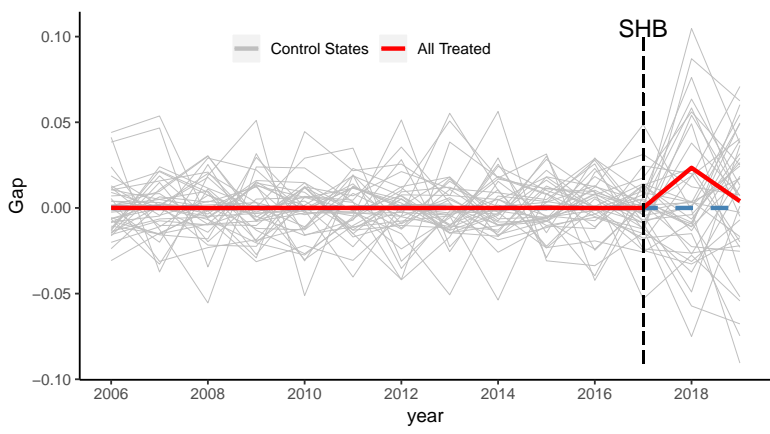

(e) Cross Validation

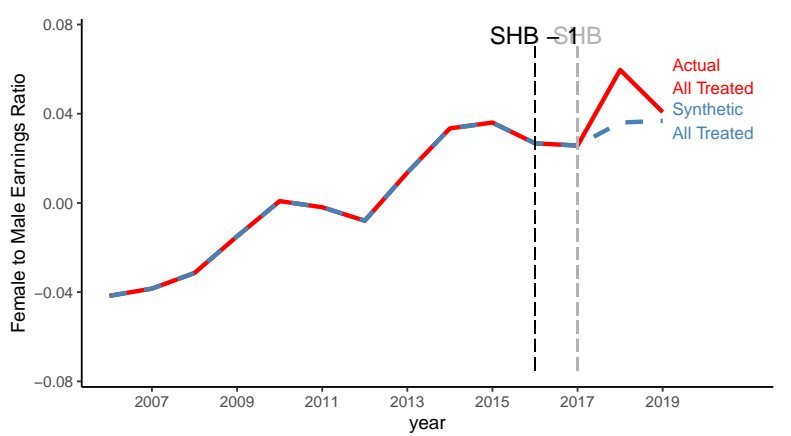

(b) Contributors to Synthetic Control

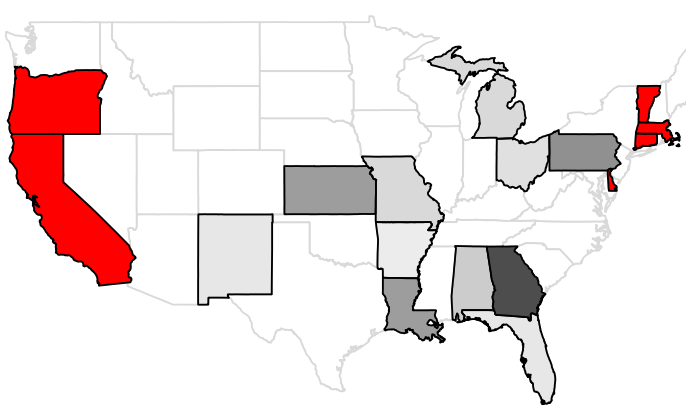

(d) MSPE Ratio Distribution

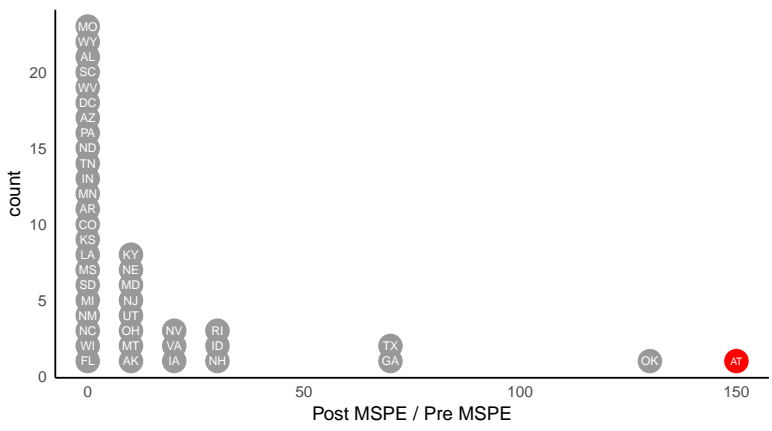

(f) Cross Validation

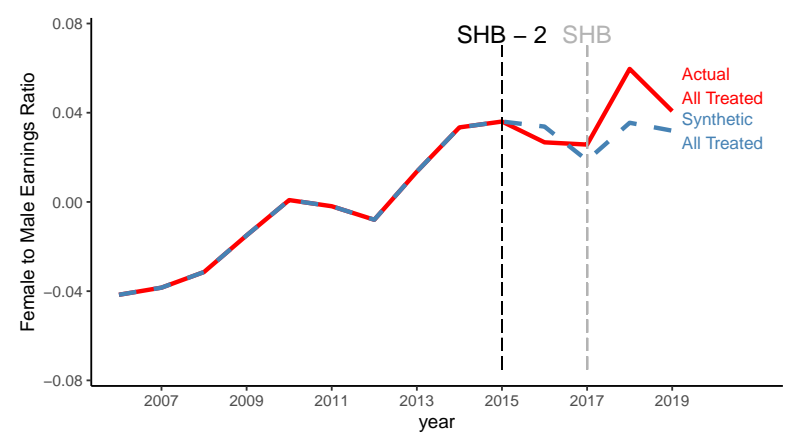




\section{Figure B.31}

All Treated Synthetic Control for Female to Male Earnings Ratio Among Male Dominated Industries, Demeaned

(a) Synthetic versus Actual

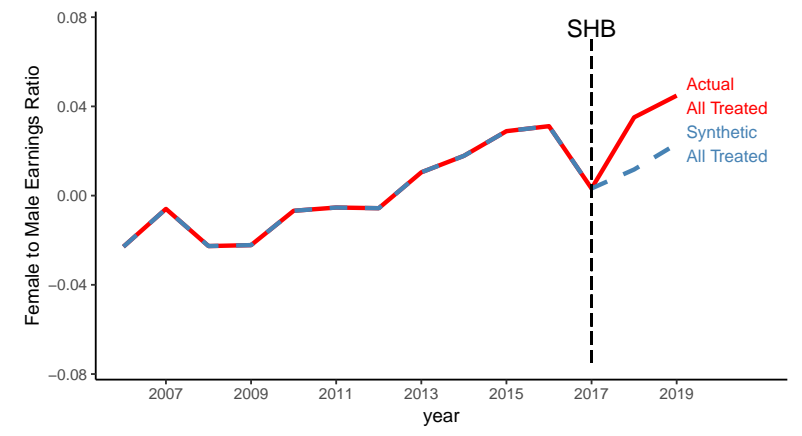

(c) Placebo Synthetic Controls

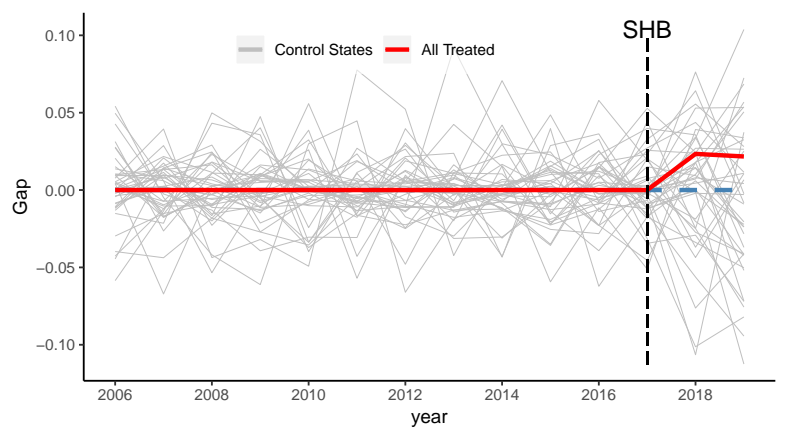

(e) Cross Validation

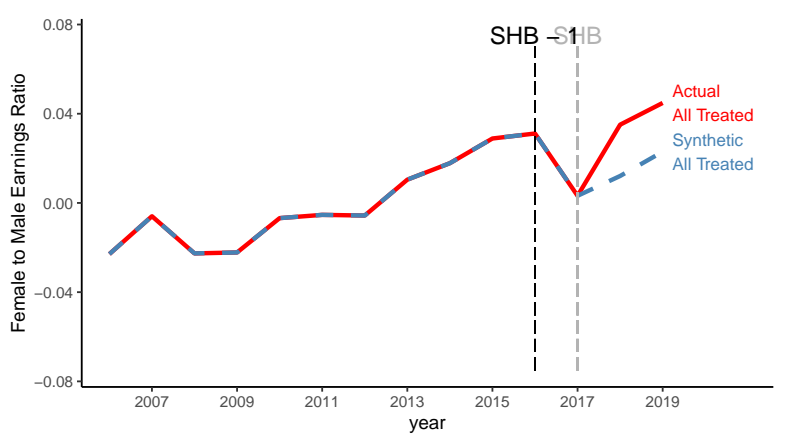

(b) Contributors to Synthetic Control

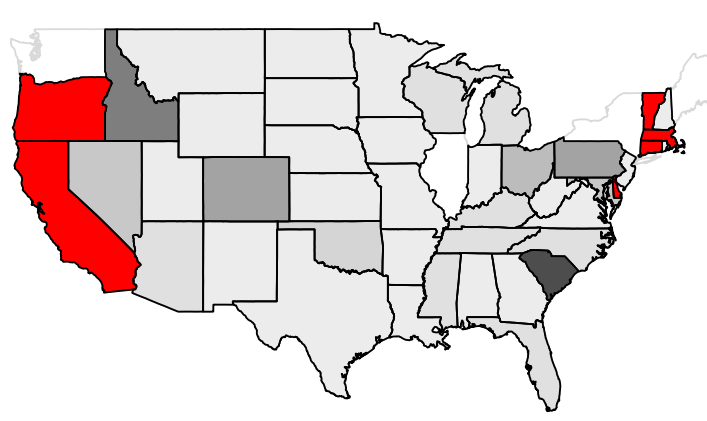

(d) MSPE Ratio Distribution

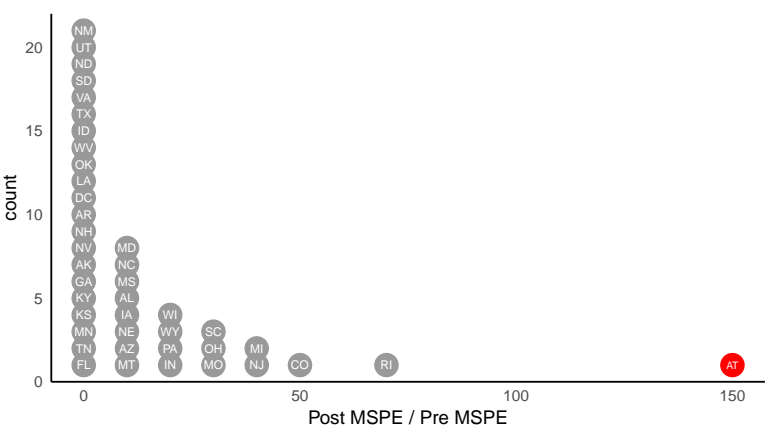

(f) Cross Validation

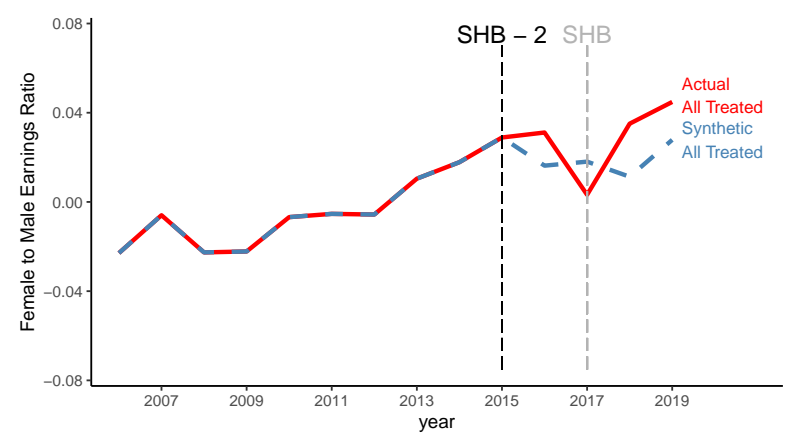




\section{Figure B.32}

All Treated Synthetic Control for Female to Male Earnings Ratio Among Individuals with Children less than 5 Years Old, Demeaned

(a) Synthetic versus Actual

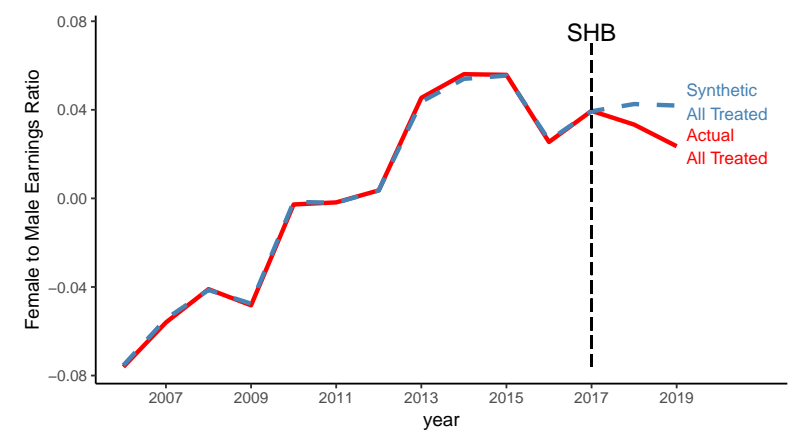

(c) Placebo Synthetic Controls

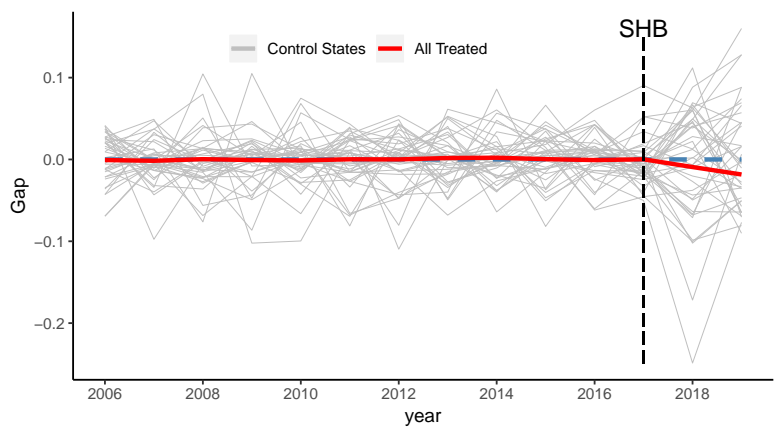

(e) Cross Validation

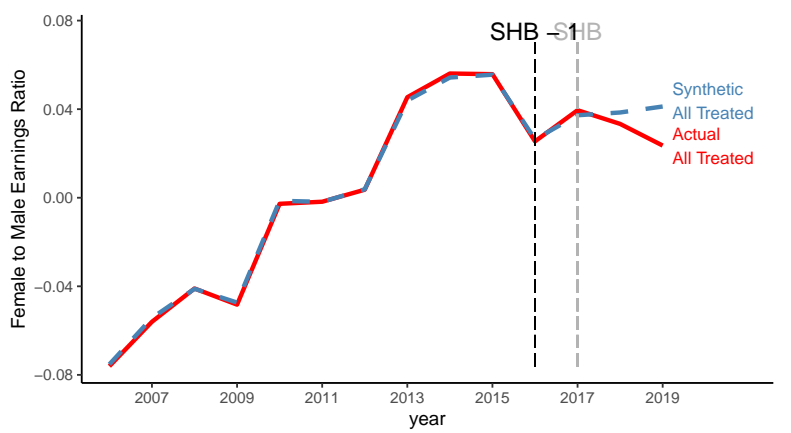

(b) Contributors to Synthetic Control

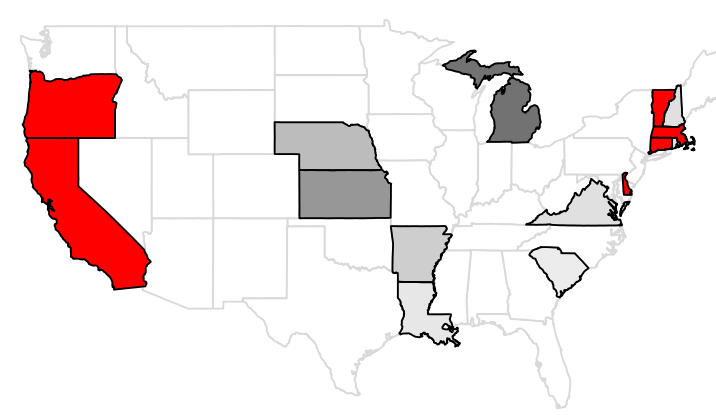

(d) MSPE Ratio Distribution

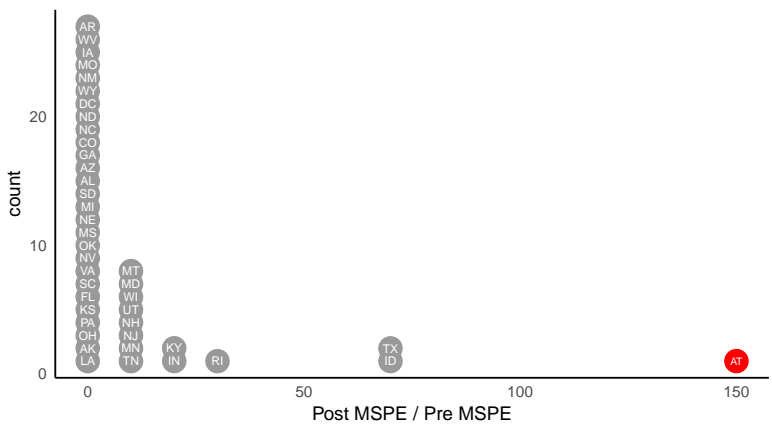

(f) Cross Validation

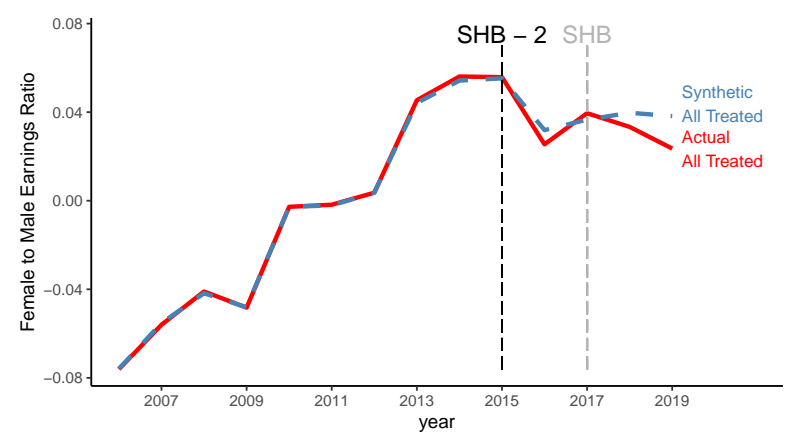




\section{Figure B.33}

All Treated Synthetic Control for Female to Male Earnings Ratio Among Individuals with Children above 5 Years Old, Demeaned

(a) Synthetic versus Actual

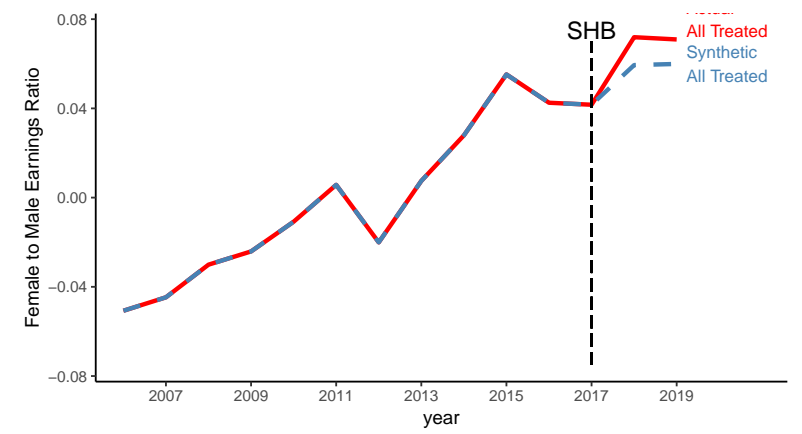

(c) Placebo Synthetic Controls

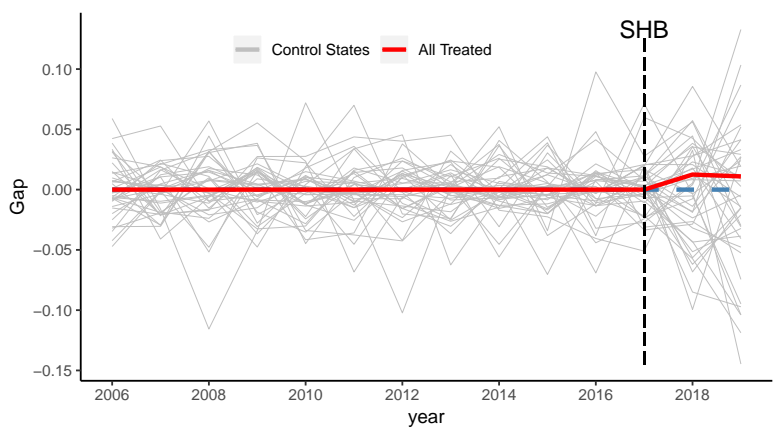

(e) Cross Validation

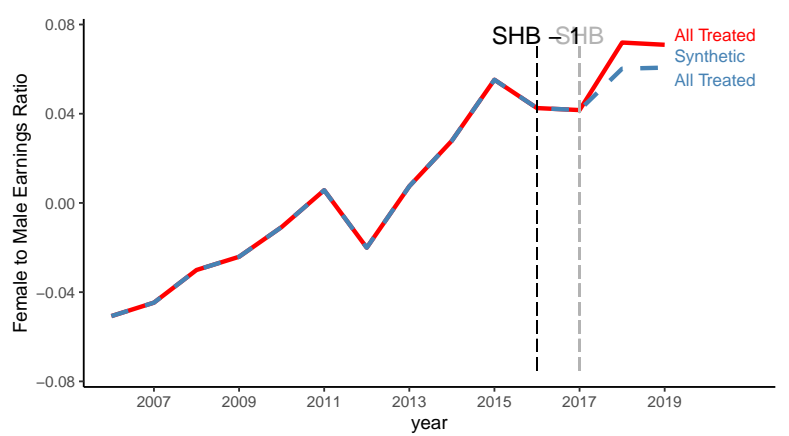

(b) Contributors to Synthetic Control

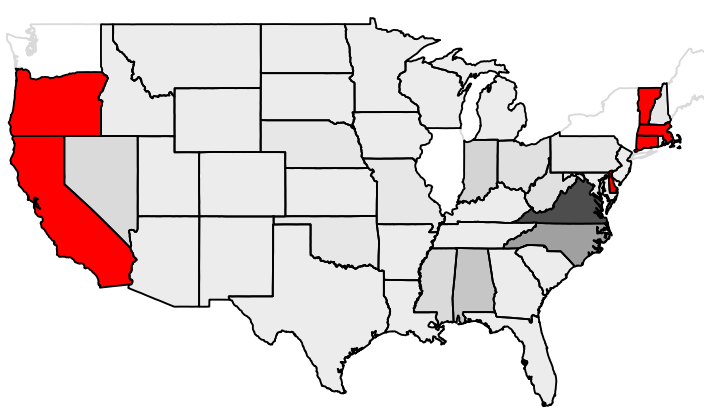

(d) MSPE Ratio Distribution

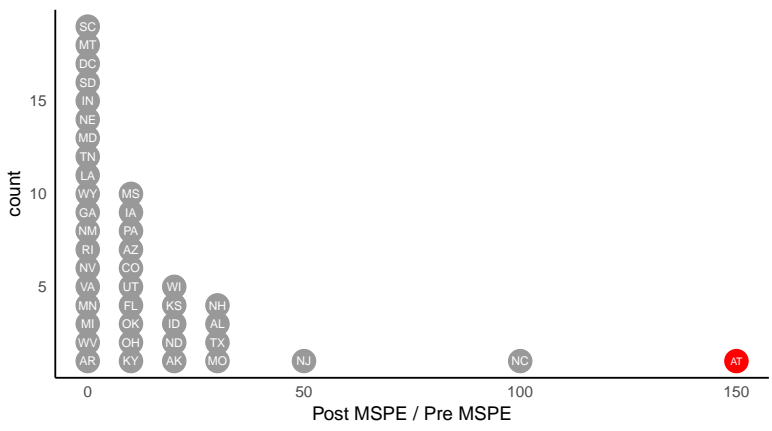

(f) Cross Validation

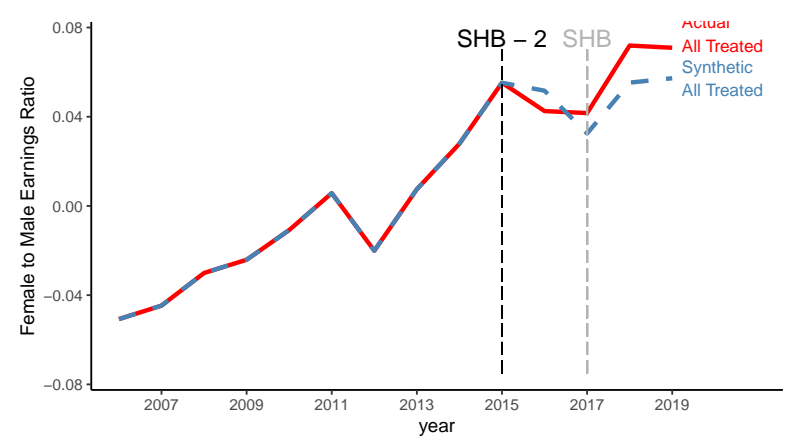




\section{Figure B.34}

All Treated Synthetic Control for Female to Male Earnings Ratio Among Individuals Above Age 35, Demeaned

(a) Synthetic versus Actual

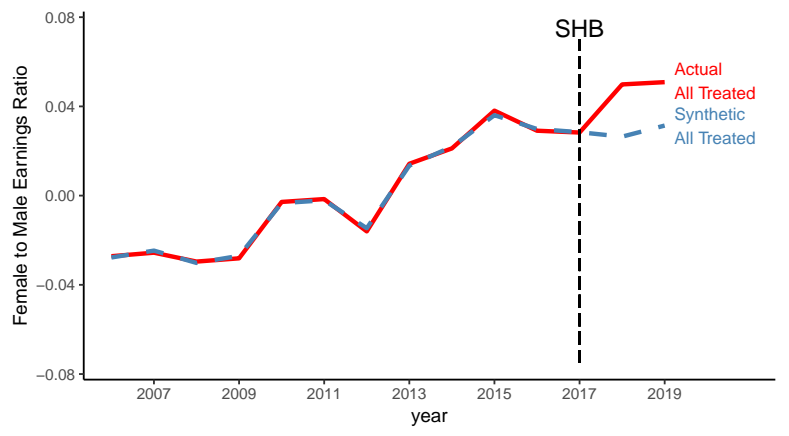

(c) Placebo Synthetic Controls

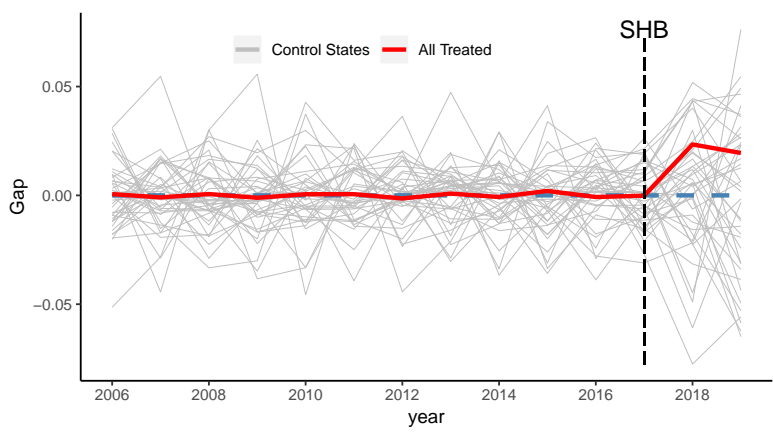

(e) Cross Validation

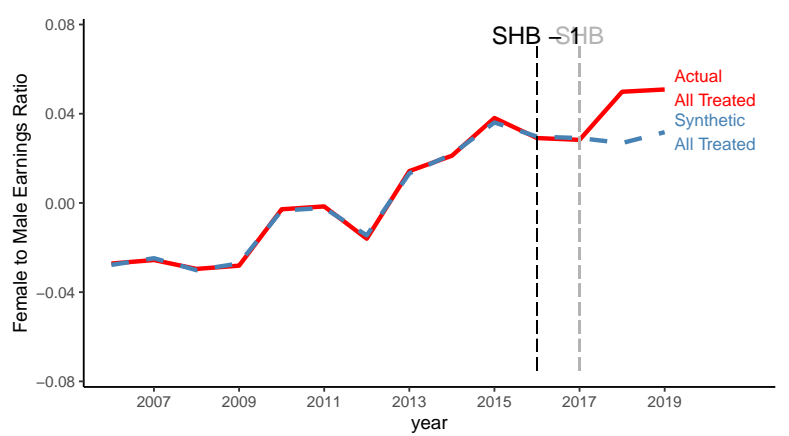

(b) Contributors to Synthetic Control

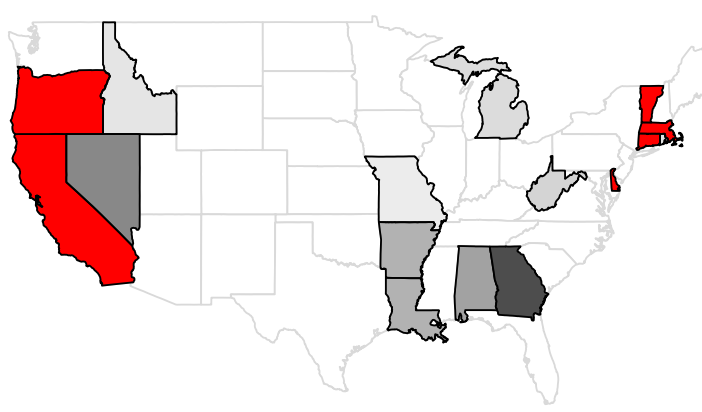

(d) MSPE Ratio Distribution

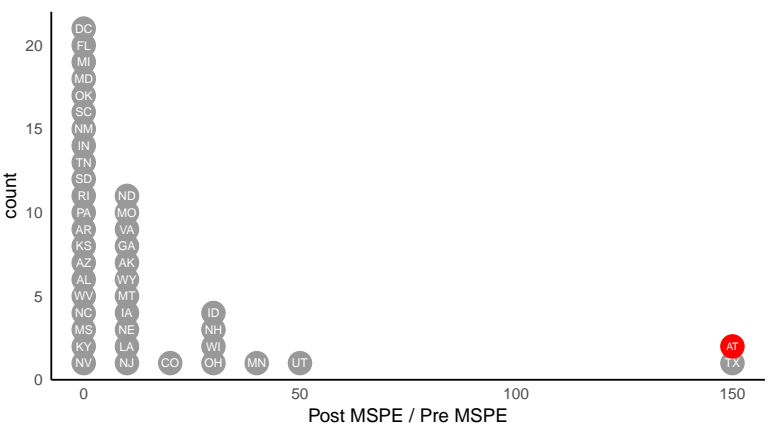

(f) Cross Validation

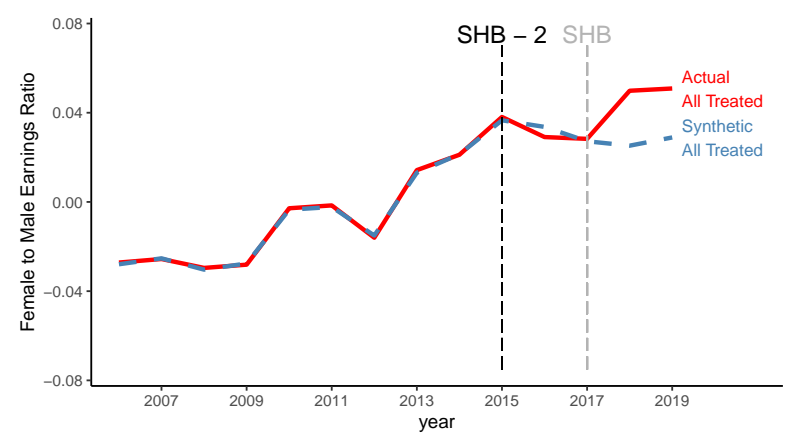




\section{Figure B.35}

All Treated Synthetic Control for Female to Male Earnings Ratio Among Individuals Below Age 35, Demeaned

(a) Synthetic versus Actual

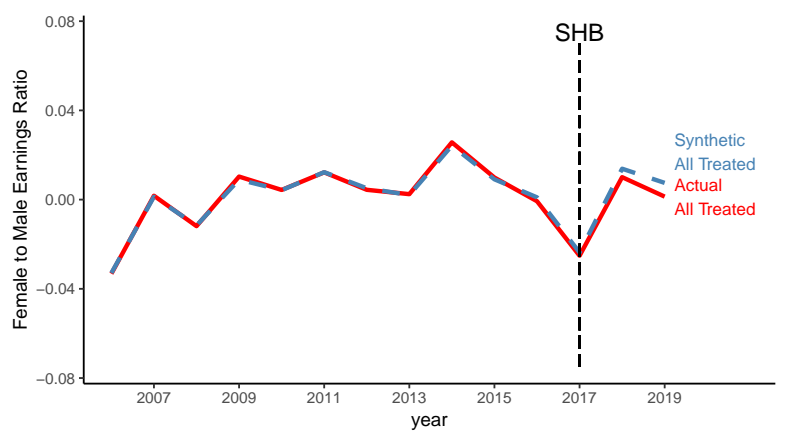

(c) Placebo Synthetic Controls

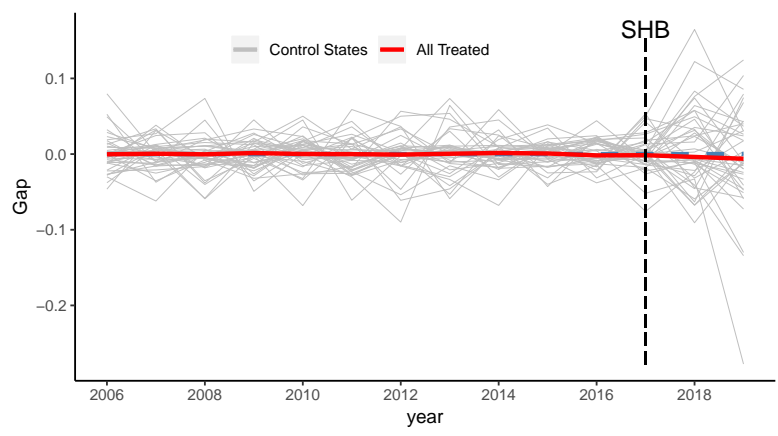

(e) Cross Validation

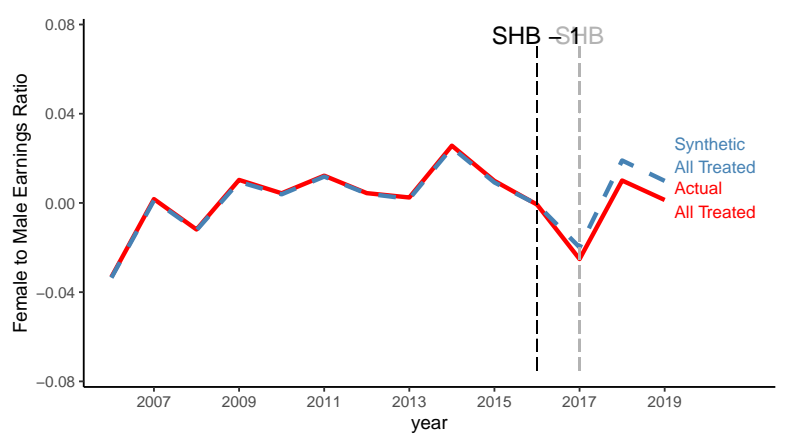

(b) Contributors to Synthetic Control

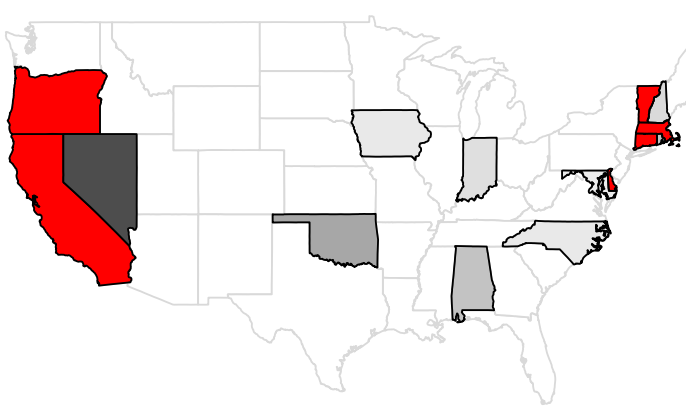

(d) MSPE Ratio Distribution

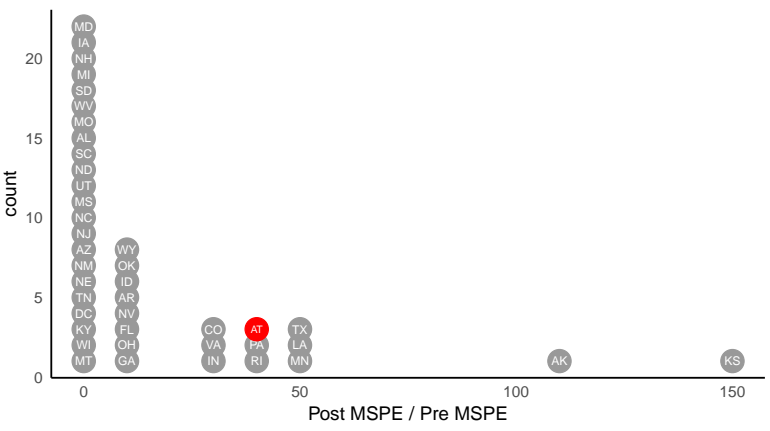

(f) Cross Validation

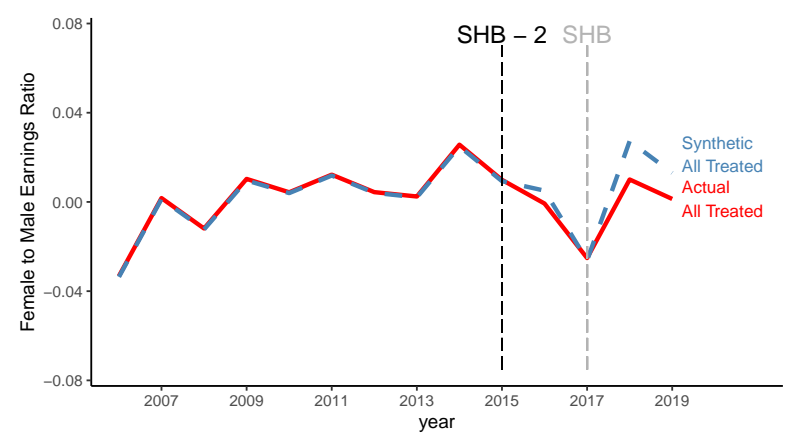




\section{Figure B.36}

All Treated Synthetic Control for Female to Male Earnings Ratio Among Individuals With a New Job, Demeaned

(a) Synthetic versus Actual

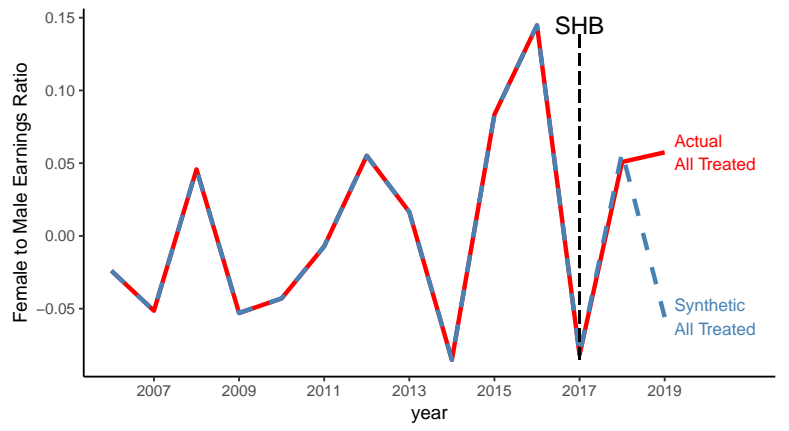

(c) Placebo Synthetic Controls

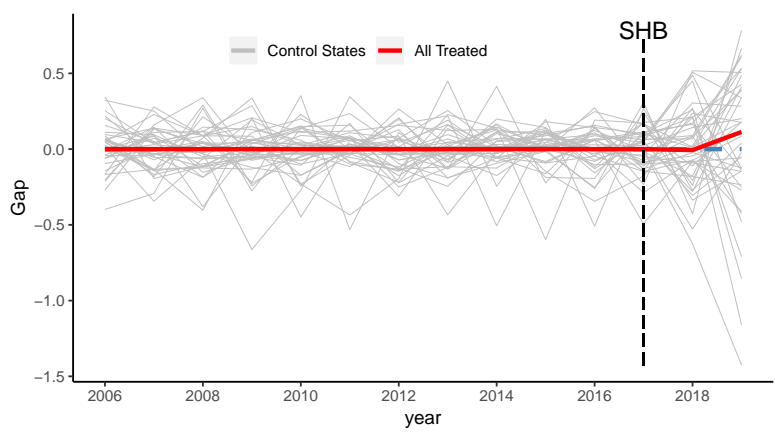

(e) Cross Validation

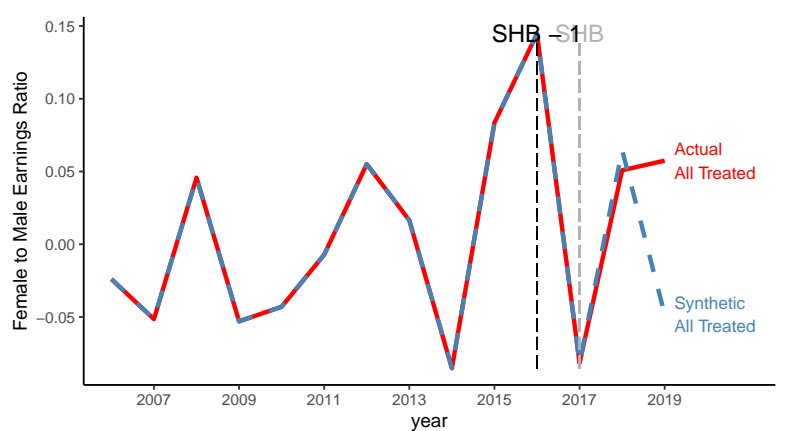

(b) Contributors to Synthetic Control

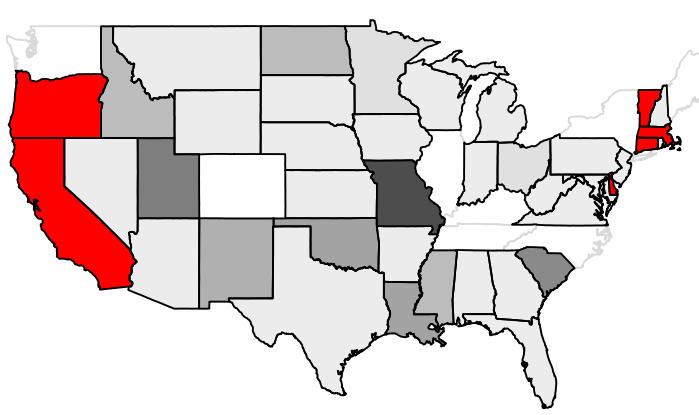

(d) MSPE Ratio Distribution

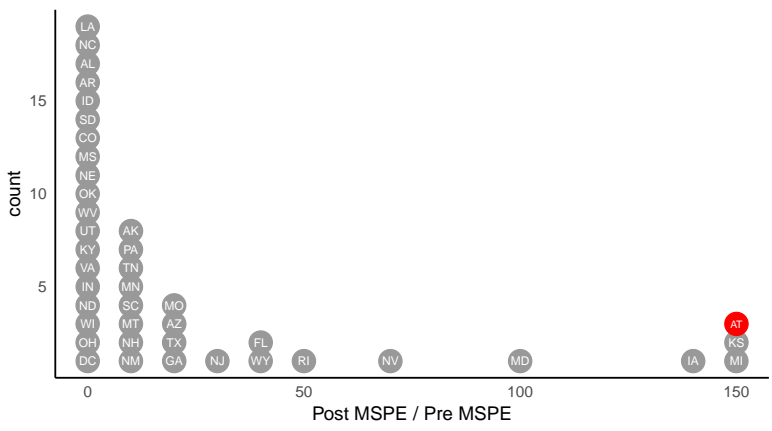

(f) Cross Validation

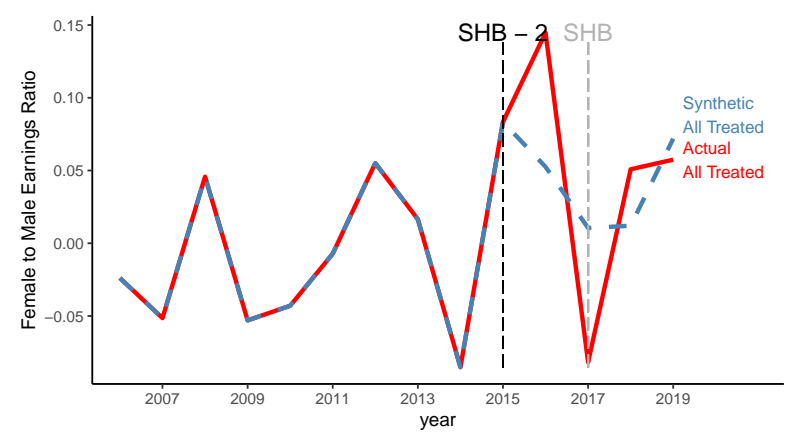




\section{Figure B.37}

All Treated Synthetic Control for Female to Male Earnings Ratio Among Individuals With the Same Job, Demeaned

(a) Synthetic versus Actual

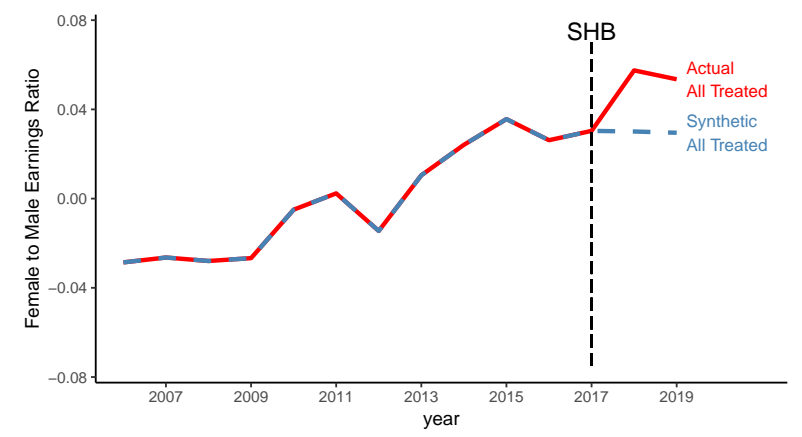

(c) Placebo Synthetic Controls

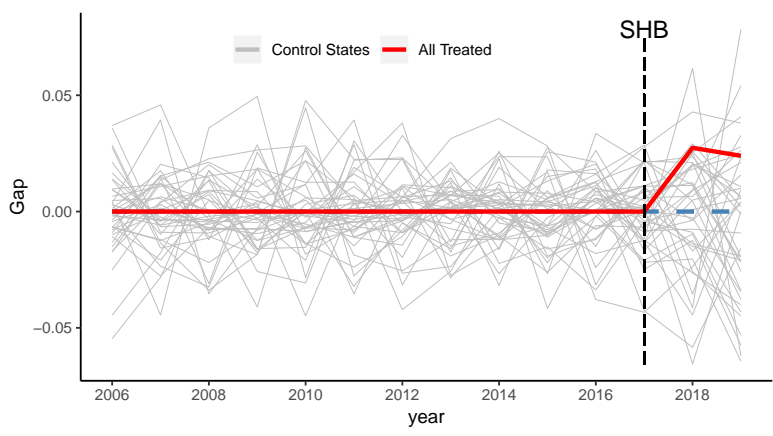

(e) Cross Validation

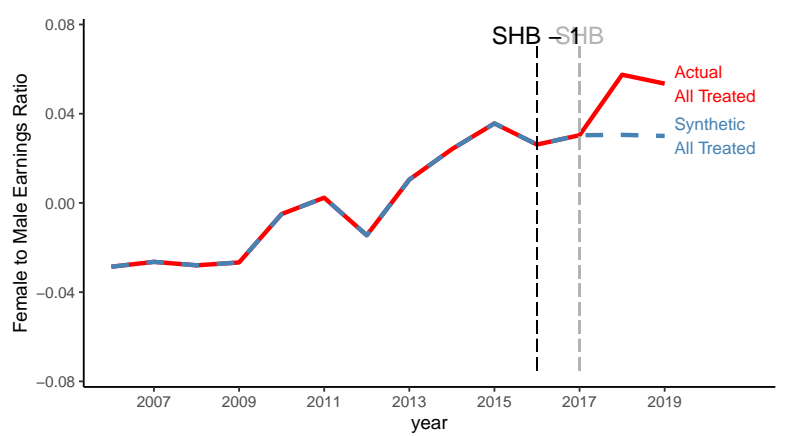

(b) Contributors to Synthetic Control

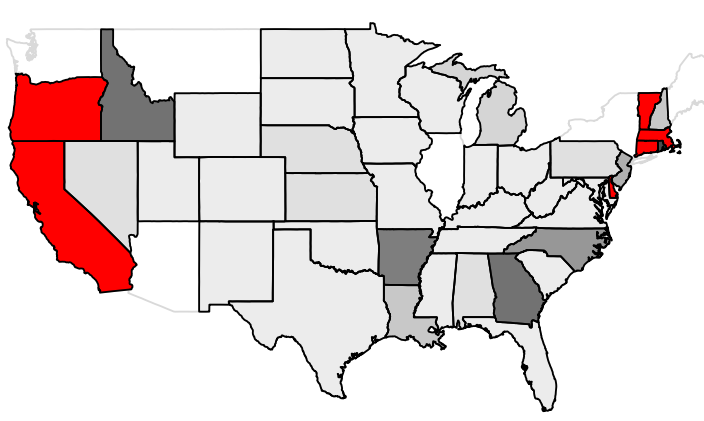

(d) MSPE Ratio Distribution

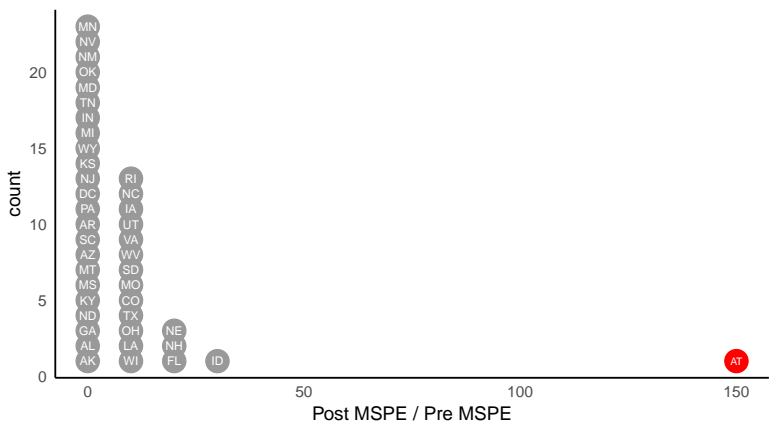

(f) Cross Validation

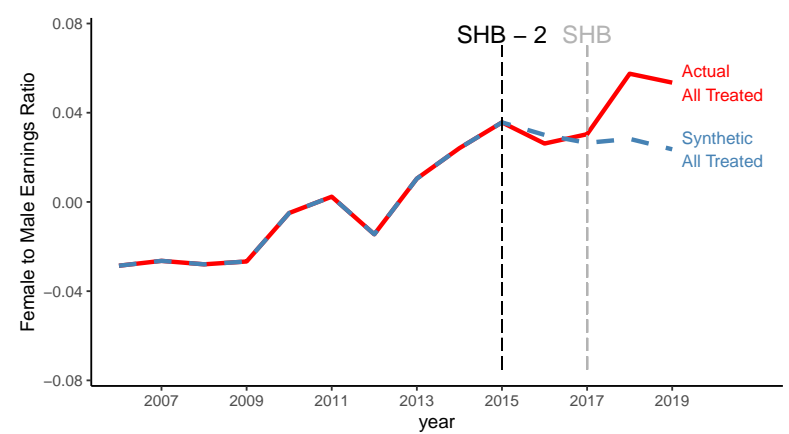

